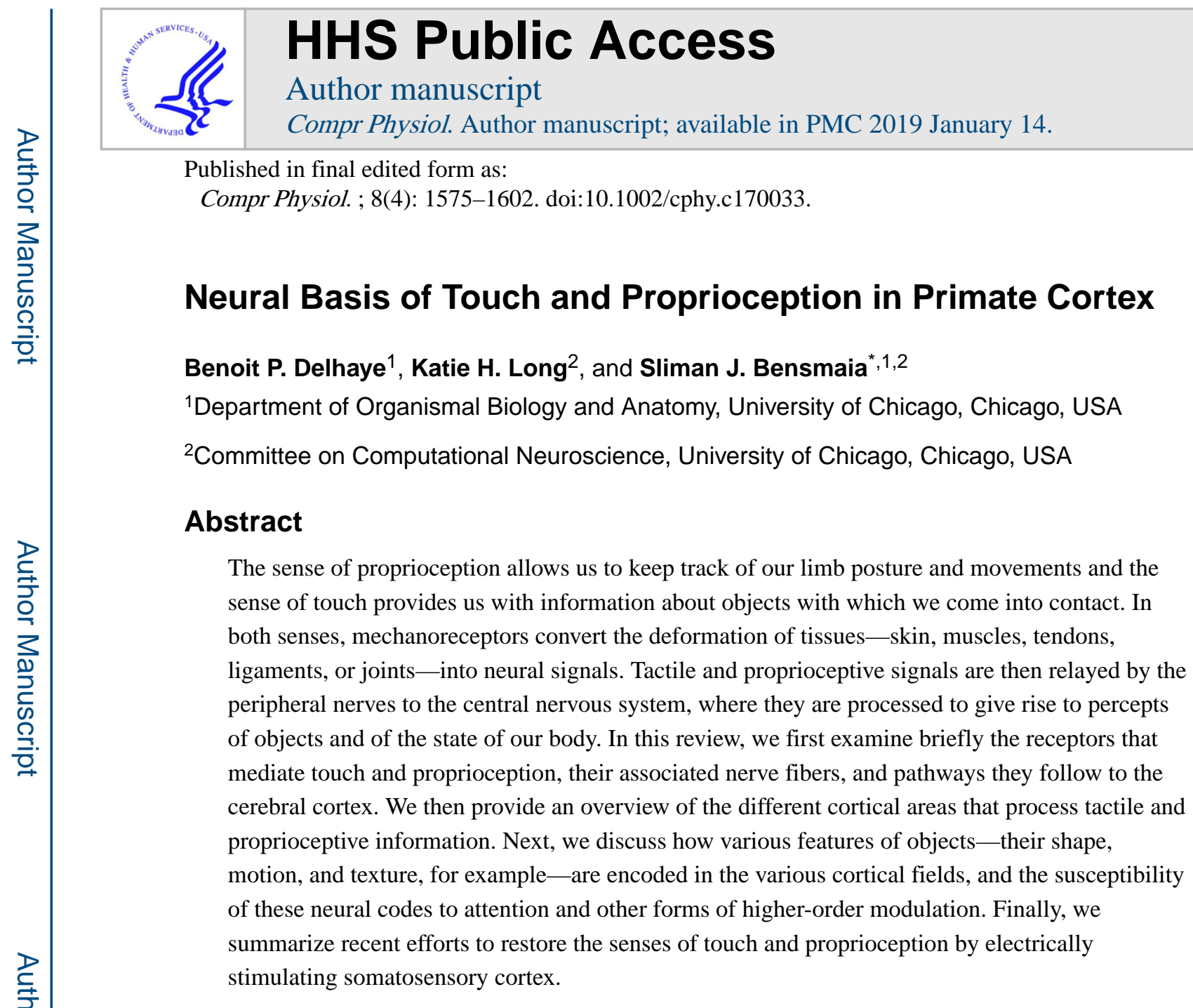

\title{
Introduction
}

How do we distinguish our body from the rest of the world? How do we keep track of its posture and movements? How do we sense objects or other organisms that we come into contact with? These abilities rely on somatosensation, a collection of senses that convey information about the state of the body and its physical interactions with the environment. Here, we examine in detail two of these senses: proprioception-the sense of the posture and movements of our body in space — and touch — the sense originating from our skin when we make contact with objects, with a specific focus on the hands. Proprioception and touch are critical for our ability to plan and execute movements and manipulate objects. Indeed, the elimination of proprioception results in severe movement deficits (324), and the elimination of touch severely impairs our ability to grasp and manipulate objects $(8,184,385)$. The sense of touch is also critical to our sense of embodiment: in fact, an extracorporeal device, like a robotic arm, can be made to feel like part of our body if it is endowed with a sense of touch (236). Moreover, touch plays a key role in emotional communication (153): we touch the people we love, and the absence of normal affective touch in childhood has devastating consequences on emotional development $(147,148,378)$. Touch is also essential to sexual

*Correspondence to sliman@uchicago.edu. 
function, as evidenced by the severe sexual dysfunction that follows sensory loss in erogenous zones $(121,262,317)$.

Touch and proprioception rely on a variety of different mechanoreceptors embedded in the skin, muscles, tendons, joints, and ligaments. These receptors are activated any time the skin is deformed or the limb moves. Primary afferents carry signals from these receptors to the spinal cord, brain stem, and ultimately to the neocortex, where information about contacted objects and about the state of the limb is elaborated. Here, we first provide a brief overview of the receptors that mediate touch and proprioception and of the nerve fibers that innervate these receptors. We then summarize the various pathways that carry somatosensory information to the central nervous system. Finally, we discuss the processing of tactile and proprioceptive information in the somatosensory cortex of primates, focusing on work conducted over the last 30 years (intended to complement ref. (249), which covers earlier findings in greater detail).

\section{The Somatosensory Periphery}

The senses of touch and proprioception involve mechanotransduction, the conversion of mechanical deformations of tissues (skin, muscles, tendons, and ligaments) into neural signals. Cutaneous (from cutis, latin for skin) mechanoreceptors, located in the skin, signal contact with objects. Proprioceptors (from proprius, latin for one's own)-located in the muscles, tendons, and ligaments (but also in the skin) — convey information about the position and movement of the limbs and about the forces they exert. The different types of receptors are innervated by nerve fibers or afferents that carry tactile and proprioceptive signals to the brain. Most tactile and proprioceptive fibers are large and myelinated, and thus exhibit high conduction velocities $(60-100 \mathrm{~m} / \mathrm{s}$ for Group I proprioceptive fibers and 30-80 $\mathrm{m} / \mathrm{s}$ for $A \beta$ tactile fibers and Group II proprioceptive fibers) with one exception, C-tactile fibers (see affective touch section below). Different types of cutaneous mechanoreceptors and proprioceptors respond in different ways to mechanical deformations, and therefore convey complementary information about the state of the limbs or about contacted objects. Signals from these different receptors are integrated to yield a rich neural image of the state of our bodies and of our immediate surroundings.

The following section briefly describes the neural basis of touch and proprioception at the somatosensory periphery to help frame the subsequent sections on central processing. For more detailed and complete reviews of the structure, physiology, and function of mechanoreceptors and their associated neurites, see refs $(73,184,189,369)$.

\section{Cutaneous innervation of the hand}

Cutaneous mechanoreceptors, which convert skin deformations into electrical signals, are located in the skin throughout the body, but their density differs across body regions. In primates, the hands and lips contain the highest densities of mechanoreceptors, the legs and back the lowest. Approximately 17,000 cutaneous afferents innervate the human hand, with densities peaking around 240 units $/ \mathrm{cm}^{2}$ at the fingertips (187). 
Glabrous skin-The cutaneous afferents of the glabrous skin are categorized into four classes, each exhibiting different response proper- ties (Fig. 1). These four classes can be split into two categories according to their responses to skin indentations: slowly adapting afferents produce a sustained response to a static indentation of the skin, one that declines (adapts) slowly over time, whereas rapidly adapting afferents respond only at the onset and offset of the indentation. These classes can also be distinguished based on the size of their receptive fields (RFs): mechanoreceptors innervated by type I afferents lie close to the surface of the skin and have small and clearly defined RFs, whereas mechanoreceptors innervated by type II afferents are deeper in the skin and have large RFs with ill-defined boundaries. The four different classes of afferents innervate different types of mechanoreceptors.

While all afferents respond to most contact events, different afferent fibers exhibit different response properties, conferred to them by the mechanoreceptors they innervate. Single afferents, and even single classes of afferents, convey ambiguous information, and signals from the different afferent populations are integrated to give rise to tactile percepts of objects $(321,379)$.

Slowly adapting type I (SA1) afferents.: SA1 fibers, which constitute about $25 \%$ of all tactile fibers that innervate the hand, split into multiple branches near the skin surface to impinge upon multiple clusters of Merkel receptors (257), distributed over different fingerprint ridges; this branching results in RFs with multiple "hot spots," each corresponding to an individual cluster, spanning an average of $10 \mathrm{~mm}^{2}(47,182,188,292)$. Most Merkel cell clusters are found at the base of dermal papillae close to sweat ducts (Fig. 1A). In response to a skin indentation, SA1 fibers produce a sustained response which slowly decreases over time, a property to which they owe their appellation (Fig. 1B) (211). SA1 fibers are most sensitive to static indentations (373) and to slow skin deformations $(112,252)$, responding to a combination of absolute skin displacement and rate of displacement (211). SA1 fibers respond preferentially to local spatial discontinuities of a stimulus $(185,281)$ and convey, as a population, a neural image of spatially patterned skin indentations (281), with a peak spatial resolution (at the fingertips) of about $1 \mathrm{~mm}$.

Rapidly adapting type I (RA) afferents.: RA fibers account for around $40 \%$ of all tactile fibers innervating the hand. Each RA fiber innervates multiple Meissner corpuscles (and Meissner corpuscles are typically innervated by more than one fiber) $(46,48,264)$, which results in complex RFs whose size is similar to that of SA1 fibers. Meissner corpuscles are regularly distributed at the apex of dermal papillae (Fig. 1A). RA afferents respond best to dynamic skin deformation at intermediate frequencies $(5-50 \mathrm{~Hz})(112,186,252)$, are silent when the skin is not moving (210), and produce a characteristic off response when a skin indentation is removed (Fig. 1B). Similarly to their SA1 counterparts, RA fibers convey a spatial image of indented patterns, but this image tends to be more poorly defined (280).

Slowly adapting type II (SA2) afferents.: SA2 fibers, which account for about $20 \%$ of the tactile fibers from the hand, are thought to each innervate an individual Ruffini corpuscle but have large RFs (with a mean of $50 \mathrm{~mm}^{2}$ ), presumably due to the depth of the mechanoreceptor in the skin. SA2 fibers primarily respond to tension and stretch in skin and 
subcutaneous tissues (211). SA2 units densely innervate the skin around the nails, an arrangement that is well suited to convey information about forces applied on and by the fingertips (20).

Rapidly adapting type II (PC or RA2) afferents.: PC fibers, which account for about 15\% of tactile fibers from the hand, each innervate a single Pacinian corpuscle, hence their name, and have large RFs due to the depth of the corpuscle in the skin and its high sensitivity to mechanical deformations propagating across the skin. The characteristic onion-like structure of the corpuscle confers to the fiber an exquisite sensitivity to rapid transients (9) and submicron-scale vibrations at high frequencies $(40-400 \mathrm{~Hz})(112,186,252)$. PC fibers respond strongly to textured surfaces scanned across the skin (379) and to vibrations transmitted through objects held in the hand (27).

Hairy skin-The four afferent types described above are also found in the hairy skin (at lower densities). However, afferents having RA-I type response, called "field units", have larger receptive fields and have not been associated with Meissner corpuscles (371). Other types of hair follicle afferents signal deformations of hairs with rapidly adapting responses, often with large receptive fields that include at least twenty hairs (371). Also present are Ctactile fibers (370), which are thought to play a role in affective touch (see affective touch section below) (1,229). Cutaneous afferents that innervate the hairy skin, particularly those with RFs over or near joints (for instance those on the dorsal surface of the hand), are sensitive to skin stretch $(92,94)$ and may also contribute to proprioception $(93)$.

\section{Sensory innervation of muscles and joints}

Proprioceptive afferents—-sometimes referred to as "deep" afferents—respond to deep palpation of the muscles and to joint movements, but not to light touch, and can be divided into three groups: muscle spindle afferents, Golgi tendon organs (GTOs), and joint receptors. These afferents can further be divided according to the size of their axons into type I and type II fibers: type I fibers are larger and therefore conduct signals faster than type II fibers.

Primary and secondary spindle afferents.-Primary and secondary spindle afferents (also known as type Ia and type II fibers, respectively) innervate the muscle spindles, which consist of a bundle of intrafusal muscle fibers contained within a spindle-shaped capsule and are innervated by one type Ia afferent and a few type II afferents (160). Afferents branch when entering the spindle and each innervate several fibers. Each afferent innervates a combination of intrafusal fibers in the spindles (nuclear bag 1 and 2, nuclear chain fiber), and the different combinations lead to different response proper- ties. The responses of spindle fibers to passive movements depend on both the length of the muscle and the rate at which length changes. Primary spindle fibers are more sensitive to the dynamic components (rate of length change) than are secondary spindle fibers $(58,95)$ (Fig. 2A). Importantly, muscle spindles are also innervated by gamma motor fibers that can contract intrafusal fibers thereby tuning the sensitivity of spindle afferents. The response properties of spindle afferents during active movements are therefore more complex (com- pared to the passive case) and poorly understood $(83,84)$. 
Golgi tendon organ afferents.-GTOs (also known as type Ib fibers) innervate thin capsules that envelop collagenous fascicles at the muscle-tendon junctions. GTO afferents are exquisitely sensitive to tension on the tendon and respond vigorously during isometric contractions (Fig. 2B). They also show some sensitivity to muscle stretch, most likely because muscle stretch results in small level of tension in the tendons $(95,96,238)$.

Joint receptor afferents._-As their name indicates, these fibers innervate receptors located in the joint capsules, but also nearby ligaments. Joint receptor afferents are not sensitive to cutaneous or muscle stimulation, but respond to moderate pressure applied directly over the joint, to joint movements, and to contraction of muscles inserting into the capsule (145). Three types of receptors are found in the joints: Ruffini-like corpuscles, Pacinian-like corpuscles, and Golgi organs located in the ligaments (395). Most joint afferents exhibit slowly adapting responses when the joint is near one of its extremahyperflexion and hyperextension $(30,145)$ — suggesting that these fibers play a limited role in proprioception under most circumstances and are involved primarily in signaling the potential for joint damage (Fig. 2C).

\section{Somatosensory Pathways}

Afferents that innervate nearby receptors bundle into fascicles that successively join other fascicles to ultimately unite into nerves, together with efferent (motor) fibers (Fig. 3). Three nerves innervate the hands: the median and ulnar nerves innervate the palmar side of the hand and arm, and the radial nerve innervates the dorsal side of the hand and arm. As it approaches the vertebral column, the nerve segregates into dorsal and ventral roots, with the former carrying sensory fibers and the latter motor ones. The cell bodies of the sensory neurons are located in the dorsal root ganglia (DRG).

\section{Spinal cord: Dorsal column}

Axons of afferent fibers in the DRG terminate in several different locations. First, they can project directly onto alpha motor neurons or interneurons at the same level of the spinal cord. Second, they can ascend or descend and project onto either interneurons or alpha motor neurons at nearby levels of the spinal cord. Finally, they can ascend (forming the dorsal column tract) and synapse onto neurons in the dorsal column nuclei (DCN) of the brainstem. Some second order neurons in the spinal cord follow the same tract to the DCN in the medulla while others follow the dorsolateral tracts (spinomedullothalamic and spinocervicothalamic tracts, see Fig. 3, spinal cord) to reach the same complex. Within the dorsal columns, fibers are grossly organized somatotopically (338); that is, afferents that innervate adjacent parts of the body tend to be near one another, thereby forming a structured map of the body, with the lower body located medially and the upper body located laterally. However, recent findings in multiple mammalian species, including monkeys and humans, suggest that the main organizing principle in the dorsal column is modality: cutaneous fibers tend to cluster medially while deep neurons are found mostly laterally (263). Somatotopy is there- fore a secondary organization principle, within modality. The dorsal columns contain all of the inputs that ultimately activate primary somatosensory 
cortex (S1) as evidenced by the abolition of S1 activation following complete lesions of the dorsal columns $(177,234)$.

\section{Medulla: Dorsal column nuclei (DCN)}

The dorsal column nuclei (DCN) comprise three nuclei, which mainly receive input from first order neurons. Signals from the upper body project to the cuneate and external cuneate nuclei and signals from the lower body to the gracile nucleus (Fig. 3, medulla). Note that the mechanoreceptive fibers from the head and face are supplied by the trigeminal nerve to the principal division of the trigeminal nucleus. The cuneate nucleus receives input primarily from cutaneous afferents while the external cuneate nucleus receives primarily proprioceptive or deep input $(91,122,161)$. The DCN are somatotopically organized proceeding from the lower limb to the head along the mediolateral axis $(387,388)$. Response properties of neurons in the DCN seem to be very similar to those of their afferent inputs, but most studies have been carried out in cats and careful characterization in primate is lacking. The DCN also receive descending input from sensorimotor cortices $(17,54)$ which may modulate sensory signals before they are relayed to higher processing structures. The projection neurons of the DCN send axons contralaterally to the ventroposterior complex of the thalamus (297), forming the medial lemniscal pathway. The external cuneate also projects to the cerebellum (306). The DCN have long been thought to be relay stations for somatosensory signals, simply transmitting sensory information without processing it. However, recent work reveals that individual neurons in cuneate are dominated by the input of a few afferents (4-8) and may carry out some degree of feature extraction $(10,150,196)$, but most of this work has been carried out in cats. Not much is known about the response properties of DCN neurons in primates except that they relay sensory information with high temporal fidelity (384). Recent advances in chronic implants will likely lead to insights about neural coding in the DCN $(304,350)$.

\section{Thalamus: Ventroposterior complex}

The somatosensory thalamus receives inputs from the contralateral dorsal column nuclei via the medial lemniscal pathway (and the trigeminal lemniscus). The ventroposterior complex has been subdivided into three major regions, the ventroposterior nucleus (VP, also known as the ventrocaudalis region, or $\mathrm{Vc}$, in humans, see Fig. 3, Thalamus), the ventroposterior superior nucleus (VPS), and the ventroposterior inferior nucleus (VPI) (217). VP is further subdivided into a lateral compartment (VPL) and a medial compartment (VPM). Different parts of the ventroposterior complex receive different sensory inputs: VPL receives cutaneous inputs from the DCN and VPM from the trigeminal nucleus; VPS receives input from proprioceptive fibers; VPI receives major input from the spinothalamic tract and is associated with thermoreception and nociception $(6,67,204,225)$. Each of three main divisions of the ventroposterior complex (VP, VPS, and VPI) is somatotopically organized and contains a complete map of the contralateral body (269). This organization is also reflected in the cytoarchitecture of these structures: single digit representations are separated by cell-poor septa (293). The response properties of somatosensory neurons in the thalamus have been described as similar to those of primary afferent fibers, suggesting that there is little processing of sensory information before cortex, but this assertion is based on scant evidence. Finally, neurons in the thalamus do not seem to be modulated by attention or 
cognitive tasks in contrast to their counterparts in the somatosensory cortices $(40,41,51$, 372).

Thalamic projections to cortex are highly divergent and convergent $(71,193,269)$ : while the bulk of VP neurons project to areas $3 \mathrm{~b}$ and 1, they also sparsely project to areas $3 \mathrm{a}, 2$, and 5 $(115,192,195,269)$. Thalamic projections have different layer targets in different areas: projections in areas $3 \mathrm{a}$ and $3 \mathrm{~b}$ reach layer 4 and deep part of layer 3 while projection to areas 1 and 2 reach layer 3 (192). The most anterior part of VPL, VLp (also termed VPLo previously), relays deep inputs to area 3a (269). The bulk of VPS neurons project densely to areas 2 and 5 and less so to areas $3 \mathrm{a}, 3 \mathrm{~b}$, and 1 . Individual thalamic neurons can sometimes branch over distributed regions of the anterior parietal cortex (APC), sometimes spanning multiple cortical fields $(133,269)$.

\section{Cortex}

The principal cortical recipient of tactile and proprioceptive signals from the periphery is the APC - often referred to as primary somatosensory cortex - located along the anterior border of the parietal lobe (Fig. 4A). APC comprises four cytoarchitectonically defined areasBrodmann's areas 3a, 3b, 1, and 2-only one of which can be considered primary somatosensory cortex proper based on the prominence and laminar targeting of its thalamocortical input, namely area $3 b(197,212)$. Areas 1 and 2 are generally considered to be higher cortical areas as evidenced by larger RFs and more complex response properties $(104,169,218,268)$. APC, in turn, sends projections along two parallel streams (Fig. 5), which have drawn analogies to the ventral and dorsal streams described for the visual system $(123,246)$. The ventral stream, in the lateral parietal cortex (LPC), includes the secondary somatosensory cortex (S2) and the parietal ventral area (PV), where neurons have even larger RFs and more complex response properties than do their counterparts in APC. This somatosensory pathway is linked to higher level feature extraction (106) and to cognitive functions such as attention and decision-making $(181,218,245,311)$. The dorsal stream in the posterior parietal cortex (PPC) includes areas 5 and 7 , where neurons have large and often bilateral RFs $(223,325,332)$, and is more tightly linked to motor behavior, such as reach and grasp $(5,109,123,138,180,253)$.

The hierarchical organization of somatosensory cortex draws strong parallels with that observed in other sensory modalities and is supported by several lines of evidence. First, lesions in early somatosensory areas abolish or nearly abolish activation of higher areas, but the reverse is not true $(130,284)$. Second, responses begin later (36) and last longer (255) as one ascends the somatosensory neuraxis. Third, as further described below, the size of RFs increases and response properties become increasingly complex and selective. That is, neurons in the early stages of processing respond to most stimuli impinging upon their RFs whereas neurons down- stream respond only when a preferred feature is present in their RFs. Finally, while the APC and LPC of mammals receive parallel projections from the VP nucleus of the thalamus $(90,131,316)$, LPC receive only very sparse input from VP in monkeys and other higher primates (VPL or VPM, not VPI) $(116,216)$. These four lines of evidence all point to a hierarchical structure in somatosensory cortex with APC as an earlier stage of processing than LPC.

Compr Physiol. Author manuscript; available in PMC 2019 January 14. 
In the next section, we describe the overall organization and structure of the somatosensory areas, beginning with APC. Then, we describe higher cortical areas, first the ventral stream (lateral parietal cortex) then the dorsal one (posterior parietal cortex). Next, we present in more detail the neural computations performed in APC and LPC along several stim- ulus continua that have been extensively studied. Most of the referenced studies involve singleunit or multi-unit recordings in macaque monkeys, but recent imaging studies carried out in humans confirm many findings from the animal work and are highlighted when helpful.

\section{Anterior Parietal Cortex}

The APC consists of four distinct cortical fields that form parallel bands along the central sulcus: areas 3a, 3b, 1, and 2 (199). A major feature of APC is its somatotopic organization: nearby APC neurons respond to stimulation of nearby and partially overlapping patches of skin on the body or to nearby combinations of joints (Fig. 4B). As a result, APC comprises four complete maps of the contralateral side of the body-one in each area-with the foot representations near the midline and the face and tongue representations at the lateral end. Body regions that are more densely innervated (such as the fingers and the lips) occupy more cortical area than do less innervated regions (such as the proximal arms or the back), a phenomenon referred to as cortical magnification (347). At the same time, RF size is inversely proportional to neural magnification: for example, neurons with RFs on fingers have much smaller RFs than do neurons with RFs on the back (347).

The body maps in each area of APC are organized systematically with respect to one another (see Fig. 4B). That is, the representation of each body part in each area is approximately aligned along the central sulcus and the organization along the axis perpendicular to the sulcus is also predictable and systematic. For instance, proceeding caudally along the axis orthogonal to the central sulcus, RFs in area $3 \mathrm{~b}$ shift from the digit tips, down the digits, to the palm, and there the transition with area 1 occurs. In turn, RFs in area 1 shift back toward the fingertips as one continues to proceed caudally to area 2. The RFs of area 2 then shift back from the fingertips down the finger as one maintains course (283). The somatotopy in area 2 is cruder than that in areas $3 \mathrm{~b}$ and $1(170)$.

The four APC areas are also histologically distinct, differing in laminar morphology and overall cell density (197). Within each area, subregions representing different parts of the body are also histologically distinguishable: subdivisions of area $3 \mathrm{~b}$ related to different body parts form myelin-dense ovals separated by myelin-light septa (178). The representations of individual digits, and even of individual fingerpads, are isolated from each other by cell-poor septa (294). These histologically observed boundaries appear to be immutable even after deafferentation (179). While the general organization of APC is consistent across individuals, the precise locations of the boundaries between areas along the rostral-caudal axis are not $(159,330)$. Recent studies in humans corroborate findings in primates $(23,135$, 136).

The following sections describe the major patterns of connections between areas (summarized in Fig. 5). Note, how- ever, that other relatively sparse connections exist. 
Area 3b.

Area $3 b$ is homologous to primary somatosensory cortex described in other mammals (197). The vast majority of neurons in area $3 \mathrm{~b}$ respond to cutaneous stimulation $(165,176,332$, 356) and are organized in cortical columns: neurons in a given column exhibit similar RF properties (including almost complete spatial overlap) and are thought to be involved in a common sensory computation $(56,118,348,349,365)$. Most neurons in area $3 \mathrm{~b}$ exhibit responses that imply input from multiple tactile submodalities (SA1, RA, and PC) (see below) (274). RFs on the hand are small $\left(10-60 \mathrm{~mm}^{2},(82)\right)$, typically limited to a single digit or even a single finger pad, and tend to be smallest for neurons in layer 4, intermediate for neurons in the subgranular layers, and largest for neurons in the supragranular ones, a size progression that is also observed in area 1 (346). Lesions in area $3 \mathrm{~b}$ result in a nearly complete abolition of tactile abilities, including texture and shape discrimination and haptic object recognition. Neurons in area $3 \mathrm{~b}$ are strongly interconnected and reciprocally connected to neurons in areas 3a, 1, and 2, and in lateral parietal cortex $(33,194,216)$.

\section{Area 1.}

Similarly to their counterparts in area $3 \mathrm{~b}$, nearly all neurons in area 1 respond to cutaneous stimulation (90\% or more) $(165,172,174,176,332,356)$. A small proportion of neurons in area 1 have Pacinian-like response properties (5\%), which are even rarer in area $3 \mathrm{~b}$. Neurons in area 1 tend to have larger RFs than their counterparts in area $3 b$, sometimes spanning multiple digits $(7,172)$. Lesions of area 1 selectively impair the tactile discrimination of texture while preserving shape discrimination $(44,296)$. Ablation of area $3 \mathrm{~b}$ abolishes cutaneous responsivity in area 1 , consistent with the afore- mentioned hierarchical relationship between these two areas. Area 1 has reciprocal connections with areas 3a, 3b, and 2, primary motor cortex (M1), lateral parietal cortex, and posterior parietal area 5 (33, $194,216,286,345)$ and also receives thalamic input from anterior pulvinar area (Pla) (269).

\section{Area 3a.}

Located in or near the fundus of the central sulcus, neurons in area 3a exhibit primarily proprioceptive responses, that is, respond to joint manipulations and muscle stretch (173, $174,176,215,356)$, and perhaps also heat- induced pain $(362,363)$. RFs in the hand representation of area 3a sometimes include a single digit, sometimes multiple digits, and sometimes the entire hand (215). Whether RFs spanning multiple digits result from convergent input from multiple afferents or from single afferents innervating multi- joint muscles remains unknown. Area $3 \mathrm{a}$ has dense intrinsic connections and makes reciprocal connections with area 2, M1, and supplementary motor area (SMA) and also receives input from area $1(70,158,159,194,345)$. Interestingly, area 3 a also contains $15 \%$ of the corticomotoneuronal $(\mathrm{CM})$ cells that monosynaptically drive motoneurons of the hand in the spinal cord (299).

\section{Area 2.}

Neurons in area 2 exhibit both cutaneous and proprioceptive responses (55\% deep, 45\% cutaneous in the hand representation) $(165,176,332,356)$, and the submodality composition follows a gradient across its extent: neurons near the boundary with area 1 tend to be more 
cutaneous, neurons near the caudal boundary tend to be more proprioceptive $(176,283)$. The hand representation is especially rich in cutaneous input but also includes neurons that exhibit both proprioceptive and cutaneous responses $(165,171,172,206)$, which may constitute an initial step toward stereognosis, that is, three-dimensional haptic representations of objects (see stereognosis section). Neurons in area 2 typically have large RFs, comprising multiple fingers, and may even occasionally have bilateral receptive fields, at least on the hind limb (356). Large RFs lead to a more blurred somatotopy than that observed in the three other anterior parietal fields (283). Lesions of area 2 impair the coordination of finger movements and the ability to discriminate the shape and size of grasped objects. Area 2 makes reciprocal connections with areas 3a, 3b, and 1 (286), with M1 (194, 286, 345), and with anterior pulvinar area in thalamus (269). Area 2 projects to lateral parietal cortex (S2 and PV) and to posterior parietal cortex (area 5) (286).

\section{Corticothalamic feedback from APC}

In cats, corticothalamic feedback projections are more numerous than thalamocortical feedforward projections (228), but little is known about the corticothalamic projections from area $3 \mathrm{~b}$ of primates. Convergent evidence in primates and other mammals suggests that area $3 \mathrm{~b}$ sends feedback projection to the somatosensory thalamus $(72,315)$ and that these feedback projections exert a powerful influence on the response properties of thalamic neurons. Indeed, suppression of neuronal activity in area $3 \mathrm{~b}$ results in a striking enlargement of thalamic RFs (99).

\section{Response properties of cutaneous neurons in APC}

\section{Submodality convergence}

As briefly summarized above, touch in the glabrous skin is mediated by four classes of nerve fibers which each respond to different aspects of skin deformation. These different sensory channels were initially thought to serve different sensory functions (shape perception, motion perception, etc.) and remain relatively segregated along the somatosensory neuraxis $(189,348)$. However, recent studies suggest that neurons in APC—including in area $3 \mathrm{~b}$, the first cortical target for tac- tile input—exhibit response properties that imply convergent input from multiple afferent classes. For example, a large pro- portion of APC neurons (51\% in area $3 \mathrm{~b}$ and $40 \%$ in area 1) produce a sustained response during the static phase of a skin indentation - which implies input from SA1 fibers-but also an off response during the offset of the indentation - which implies input from RA and/or PC fibers (274) (Fig. 6). Indeed, RA and PC fibers do not respond during the static phase of a skin indentation, and SA1 fibers do not pro- duce a phasic response at its offset. The presence of both features in the majority of APC neurons strongly suggests that convergent input is the rule rather than the exception. Furthermore, the time varying firing rates of APC neurons to simple and complex vibrations are better predicted from the combined responses of multiple afferent classes than from those of a single class (322). These observations indicate that touch does not comprise distinct sensory channels, each serving a different function, but rather relies on the integration of sensory signals across tactile submodalities to extract behaviorally relevant information during manual interactions with objects (321). 


\section{Spatial structure of receptive fields}

The receptive fields of many neurons in area $3 \mathrm{~b}$ comprise excitatory subfields flanked by inhibitory ones and can often be well approximated by linear spatial filters (Gabor functions, see Fig. 7). That is, stimulation of excitatory patches of skin sum to create an excitatory drive to the neuron; stimulation of the inhibitory patches sum to create an inhibitory drive, and the overall activity of the neuron is well approximated by the linear combination of these excitatory and inhibitory drives. The inhibitory surround is distinct from the surround suppression observed in the receptive fields of tactile fibers, which reflects skin mechanical effects (343). In addition to inhibitory components flanking the excitatory one, RFs tend to also comprise an inhibitory component co-localized with the excitatory field but delayed by 20 to $30 \mathrm{~ms}(81,125)$. This RF structure results in an initial excitatory drive that is followed by an inhibitory one, rendering the neuron less excitable for a period of time. As mentioned above, excitatory and inhibitory inputs are combined in an approximately linear fashion (11, 81) and their interplay yields RFs whose spatial structure is relatively consistent across scanning speeds (80) (Fig. 7). Importantly, neurons in area $3 \mathrm{~b}$ tend to have elongated RFs (with a mean aspect ratio of 1.7), which confers orientation tuning to these neurons (see shape section below) $(11,82)$. The RF structure of neurons in area $3 \mathrm{~b}$ thus draws a strong analogy to that of simple cells in primary visual cortex.

In contrast to their counterparts in area $3 b$, neurons in areas 1 and 2 tend to have larger, more complex RFs, that are poorly approximated using linear spatial filters $(11,166,171,172$, 175). That is, RFs often do not comprise distinct excitatory and inhibitory fields, and to the extent that they do, these fields are poor predictors of the neurons' response properties.

Rather, neurons in these higher processing areas within somatosensory cortex tend to exhibit more complex feature selectivity, such as a selectivity for curvature or a shape-invariant selectivity for direction of motion, neither of which are reflected in the spatial structure of their RFs.

\section{Receptive field interactions}

Touch involves the integration of information stemming from hundreds or thousands of tactile fibers, each innervating a small patch of skin, and this integration occurs gradually as signals ascend the neuraxis through subcortex and cortex. Interestingly, while S1 neurons (area $3 b$ ) are characterized by relatively small RFs, seemingly reflecting only weak integration from periphery to the cortex, thalamocortical projections have been shown in anatomical studies to branch extensively over wide spatial areas (133), as have corticocortical connections (33). While widespread branching and lateral connectivity is obscured when RFs are mapped using sequential application of well-controlled indentations, these connections manifest themselves as modulatory influences on APC responses when stimuli are simultaneously applied to a neuron's RF and outside of it. Indeed, a stimulus applied outside a neuron's classical RF results in a decrease in sensitivity for a period of about $100 \mathrm{~ms}(302,303)$. In fact, this suppression is sometimes observed when the conditioning stimulus is applied to the contralateral hand (301), an observation also made using optimal intrinsic signal (OIS) imaging (361). Paired stimulation of multiple digits also produces a reduced spatial pattern of activation compared to what would be expected based on the stimulation of each digit individually, suggesting lateral inhibition (119). Such spatial 
interactions can also account for the tactile funneling illusion, referring to the phenomenon in which the simultaneous presentation of brief tactile stimuli at two skin locations evokes a sensation localized between the two sites where no stimulus is present. Indeed, simultaneous stimulation of two adjacent digits produces a single patch of activation in cortex located between the activation sites of the individual digits (57). Some of these second order properties can be described mathematically using models in which the primary receptive field is captured by a linear filter (as described above, see Fig. 7) and the interdigit interactions are captured by nonlinear components (359). Another manifestation of longdistance spatial interactions is the increased synchronous firing over the entire hand representation when a fingertip is touched (300). Taken together, these results suggest that, even at the earliest stage of cortical processing (area 3b), tactile signals from large swaths of skin are integrated in complex ways.

\section{Temporal response properties}

As summarized above, the different classes of tactile fibers differ in their frequency sensitivity profiles. SA1 fibers are most sensitive to low-frequency vibrations, below about $10 \mathrm{~Hz}$, while PC fibers peak in sensitivity at around $250 \mathrm{~Hz}$, and RA fibers exhibit intermediate frequency sensitivity. APC neurons also differ in their frequency-sensitivity pro- files $(251,329)$ but these tend to be much more idiosyncratic, in part because individual neurons receive input from multiple classes of afferents. Indeed, the frequency-sensitivity profile of the afferent input will shape the frequency profile of its target and so APC neurons will differ in their spectral sensitivity because they differ in the relative strength of the input from each of the tactile modalities. Moreover, the frequency profile of APC neurons is shaped by how this input is processed. Indeed, APC responses to vibrations-particularly those of neurons in area $3 \mathrm{~b}$ - can be well approximated as a linear function of the afferent input passed through a temporal filter and these filters vary from neuron to neuron (322). Interestingly, filters tend to differ systematically depending on the input modality: RA input tends to be excitatory whereas PC input tends to be balanced or inhibitory. In other words, RA signals tend to be integrated over time whereas PC signals tend to be differentiated. As a result, the strength of APC responses to skin vibrations is determined largely by the RA (and probably SA1) input, whereas the precise timing of the responses is shaped primarily by the PC input (322). These finding are in line with those from OIS imaging studies which showed that $25-\mathrm{Hz}$ vibrations (which excite primarily SA1 and RA fibers) produce strong localized excitation, whereas $200-\mathrm{Hz}$ vibrations (which excite primarily PC fibers) produce a short excitatory transient followed by strong, spatially extended inhibition $(364,366)$. Thus, while input from the different tactile channels converges onto individual APC neurons, their impact is highly channel-dependent. Because vibratory sensitivity depends on the submodality composition of the input (which varies from neuron to neuron) and on the way that submodality specific input is integrated (which also varies from neuron to neuron), APC neurons exhibit a wide array of frequency response properties.

\section{Response properties of proprioceptive neurons in APC}

As mentioned earlier, proprioceptive signals from the periphery-signals originating from muscle, joint, ligament, and skin afferents that provide information about time varying muscle length and joint position - target primarily areas 3a and 2 in APC. Much less is 
known about the RFs and response properties of these so-called "deep" neurons com- pared to their cutaneous counterparts. As mentioned previously, a striking observation at the periphery is that afferent responses to passive and active movements elicit very different responses, because muscle spindle discharge is power- fully affected by fusimotor activity and because many muscle and joint receptors are sensitive to the level of tension or contraction in the muscle. Such differences between active and passive movement are also a hallmark of proprioceptive responses in cortex. Some neurons respond only to passive movements or only to active moments, while others respond to both $(231,341)$. During passive movements, responses have been classified as phasic, thus encoding movement, tonic, thus encoding posture, or a combination of both $(127,341)$. Phasic neurons typically respond to either flexion or extension, but not both (393). Individual neurons exhibit different combinations of tonic and phasic responses, forming a continuum from purely phasic to purely tonic (289). As shown during an active reaching task, proprioceptive neurons from the arm typically exhibit a unimodal and broad tuning for reach direction (289). The preferred direction is generally similar during the phasic and tonic components of the response, and consistent for active and passive movements $(231,289)$. Moreover, imposing a load on the arm affects responses, but less so in APC than in M1. A subset of proprioceptive neurons exhibit RFs that include multiple joints which are not necessarily adjacent to each other (66). The responses of some neurons with multi- joint RFs are a simple summation of their single-joint activations. Others neurons show complex interaction between joints, with their response peaking at a preferred combination of joint postures. Some neurons discharge before the onset of voluntary movement, an observation that has been attributed to efference copy $(231,260)$. Note that cutaneous units also discharge during arm movements, although more weakly than during direct touch (16), and some of these exhibit the same kind of direction tuning observed in deep neurons $(59,288)$. These neurons may thus also contribute to kinesthetic sensations. Interestingly, a subregion of area 3a, in the representation of the head, provide proprioceptive signals to encode eye position in the head (375). These neurons are tuned for the direction of gaze and their responses increase with increasing orbital eccentricity. Little is known about how hand movements and postures are encoded in somatosensory cortex.

\section{Lateral Parietal Cortex (LPC)}

The second somatosensory area (S2) and the parietal ventral area (PV) sit within the upper bank of the lateral sulcus, just lateral to the tongue representation of APC (Fig. 4B-C). The border between APC and LPC is medial to the lateral sulcus and splits the head representations of the two regions (32). S2 and PV contain mirrored body maps that meet at the digits, lips, and mouth $(32,87,214)$ and have been characterized in both macaques and humans $(87,88,97,98,214)$. In primates, S2 and PV have only been clearly identified and separated relatively recently $(213,214,216)$, so earlier reports often confuse or combine the two areas $(308,383)$.

Over the years, different groups have published seemingly conflicting reports of the properties of neurons in LPC. These discrepancies are likely due to several factors, including the precise locations of recording sites, the behavioral relevance and complexity of the stimuli, and the attentional state of the animal. When somatosensory properties were 
reported in the upper bank of the lateral sulcus in the 1940s, only one area was described (386). Later, when two mirror-reflected body maps were observed in this region and histological differences were characterized, the terminology expanded to two regions, S2 and PV, the latter located anterior to the former (214). Neurons in the central region that spans the boundary between PV and S2 exhibit primarily cutaneous responses, whereas neurons in the outer regions tend to exhibit proprioceptive responses $(105,214)$. In macaques, the hand representation within the central region spans $10 \mathrm{~mm}$ along the anterior posterior axis (105) and is relatively well defined and consistent across animals (32). The face region is rostral, medial, and superficial, while the tail and sacrum are caudal, lateral, and deep in the sulcus.

Receptive fields in LPC tend to be larger and more diffuse than those in earlier stages of processing. RFs encompass multiple finger pads, span multiple digits, and respond bilaterally to stimuli applied to either hand $(32,106,170,287,320,336)$ or to multiple regions of the body (355) or even the entire body. Indeed, while both areas primarily receive input from the contralateral side of the body, bilateral RFs have also been reported. For neurons with bilateral RFs, stimulation of the ipsilateral side typically exerts a modulatory effect on the response evoked by contralateral stimulation $(87,88)$. About half of LPC neurons respond to cutaneous stimulation and half to deep stimulation (355). Both S2 and PV receive projections from all four APC areas $(34,216,295)$ as evidenced by the fact that lesioning individual areas reduces the responsiveness of their downstream targets $(35,132$, 284): selective removal of proprioceptive input (areas 3a and 2) or cutaneous input (areas $3 \mathrm{~b}$ et 1) selectively reduces proprioceptive and cutaneous responses in LPC, respectively (285) (Fig. 5). LPC receives input from area 5 (286) and area 7b (86). LPC also receives direct inputs from the thalamus $(85,116)$ : PV from ventroposterior inferior nucleus (VPI) and Pla; S2 from VPI, ventroposterior superior nucleus (VPS), and Pla. Thus, LPC integrates proprioceptive, and thermoreceptive/nociceptive signals directly from thalamus (85). LPC in turn projects densely to ipsilateral APC, particularly areas $3 \mathrm{~b}$ and 1 , and area $7 \mathrm{~b}$ (117), with connections between $\mathrm{S} 2$ and PV, as well as contralaterally to LPC, area $7 \mathrm{~b}$, and area $3 \mathrm{~b}$ (86). LPC is also reciprocally connected with multiple insular areas (117), and sends corticothalamic feedback projections to the VPL and the anterior pulvinar $(31,374)$. PV projects to areas $3 \mathrm{~b}$ and $7 \mathrm{~b}$, premotor cortex, and other posterior parietal areas (86). Lesions of LPC severely impair the ability of monkeys to perform texture and shape discrimination tasks $(254,351)$.

\section{Response properties of neurons in LPC}

LPC neurons tend to exhibit more complex response properties; for example, some orientation-tuned neurons in LPC have the same preferred orientation over large swaths of skin on the hand, an extent of positional invariance not seen in APC (106). When RFs are mapped using passive presentation of behaviorally irrelevant stimuli, modality is difficult to identify and tends to vary over time (336), a property that can be attributed to the strong susceptibility of LPC responses to changes in attentional state $(39,52,157,244,329)$. Not only do the responses of LPC neurons depend on the attentional state of the animal, they also depend on the behavioral task and its demands. Indeed, while APC neurons faithfully encode the stimulus, irrespective of the task, LPC neurons exhibit a tendency to encode both 
the stimulus and the behavioral outcome in a task-dependent way (Fig. 8), a hallmark of higher cortical processing $(151,181,218,311,329)$. This task-dependent modulation and the correlation of neural activity with perceptual reports suggest a role of LPC in sensory decision making $(311,313)$.

Visually $(3,203)$ and acoustically $(103,307)$ evoked responses in LPC have long been reported in human imaging studies, but had not been observed in single-unit recordings from nonhuman primates until recently $(154,243)$, a discrepancy that may be attributable to particular stimuli used in early neurophysiological studies. Indeed, sounds and images that have no tactile correlate, like pure tones or speech, do not drive neurons in $\operatorname{LPC}(154,310)$, but the sound of hands rubbing together does. These multisensory responses may underlie a phenomenon documented in humans: modifying the sound that hands makes while rubbing against one another influences how moist or dry the skin feels (146,351). Additionally, about a third of neurons exhibiting somatosensory responses also respond to visual stimuli and sometimes to auditory stimuli (154), and these neurons, interspersed throughout LPC among a majority of unimodal somatosensory neurons, may play an important role in multisensory integration.

\section{Posterior Parietal Cortex (PPC)}

The posterior parietal cortex (PPC) is caudal to APC and straddles the intraparietal sulcus (IPS) (164). PPC comprises two major architectonical areas originally described by Brodmann: area 5, located on the rostral side of the IPS, and area 7, located between the IPS and the lateral sulcus (Fig. 4A). Both areas have been divided into multiple distinct cortical fields based on a variety of criteria including cytoarchitecture, patterns of connectivity with other areas, and neural response properties. The names and boundaries of these subregions are a matter of ongoing debate $(144,226,271,332)$, probably because different studies have used different criteria. Area 5 can be split into two major parts-a lateral region, presently referred to as $5 \mathrm{~L}$ (previously $5 \mathrm{a}, 5 \mathrm{v} / \mathrm{d}$ or PE) (332), and a medial region dubbed the parietal reaching region (PRR) (5). Area 7 is traditionally split into two major regions-a rostral, mostly somatosensory region $7 \mathrm{~b}$, and a caudal, mostly visual region $7 \mathrm{a}$. However, some histological and physiological evidence suggests that area 7 actually comprises three separate fields, PF, PFG, and PG $(271,319)$. Other cortical fields have also been identified within the IPS (namely AIP, LIP and VIP, see Fig. 4A), but are mostly visual or visuomotor areas, and will not be discussed here. The pattern of cortical connections suggests two major streams in PPC, both originating in area 2 and progressing rostral-to-caudal, one along the superior lobule (area 5) and the other along the inferior lobule (area 7) (271). Connections and the response properties of PPC neurons also suggest that area 5 precedes area 7 in the processing hierarchy (see below). PPC comprises strong interhemispheric connections as well as many connections with premotor areas $(49,50,170,356)$. The correspondence between macaque and human PPC, both in terms of location in cortex and functional properties, is not straightforward and remains poorly characterized (143).

Most PPC areas contain neurons that respond to cutaneous stimulation and joint movements, but PPC, unlike APC and LPC, is not a somatosensory region per se. First, neurons in PPC respond to other sensory modalities, mainly visual, but also auditory (60) and vestibular 
(340). Second, a large subset of neurons responds most strongly when the animal is awake and behaving, and many sites are unresponsive during anesthesia $(250,332)$. Third, cortical fields in PPC are known to be involved in motor functions such as planning reaching and grasping movements, as indicated by dense, reciprocal connections to prefrontal and motor areas $(42,279)$ and by the fact that neurons seem to encode not just limb position but also target locations and motor intent (202). Fourth, lesioning or ablating areas within the PPC does not strongly impact passive tactile discrimination but does affect animals' ability to reach and grasp objects or to recognize an object's shape through haptic exploration (stereognosis) (114). For all of these reasons, the PPC is thought to play a critical role in both multisensory integration and sensorimotor planning and guidance, especially for the upper limbs (339). In the following sections, we describe the properties of PPC areas that exhibit somatosensory responses.

\section{Area 5L.}

The lateral aspect of area 5, called 5L (332), borders the hand and arm representations of area 2 and is partially buried in the IPS. The somatosensory RFs of neurons in area 5L span only the shoulders, forelimbs, and hands with a somatotopic organization that roughly follows that in area 2 (under anesthesia, 333). RFs tend to be larger than those in APC, often containing multiple joints and digits, can be bilateral (357), and typically exhibit proprioceptive responses ( $\sim 90 \%)$. Only a small fraction of area $5 \mathrm{~L}$ neurons maintain activity during anesthesia and most respond best while animals make voluntary movements (250, 325). Area 5L receives the majority of its inputs from APC (137), especially area 2 $(273,286)$. Area 5L also receives direct input from the thalamus: Pla, lateral posterior (LP) nucleus (392), and VP (286). Area 5L projects ipsilaterally and bilaterally to other parts of area 5, area 7, LPC, motor cortices, and superior temporal gyrus (164). Neurons in area 5L have been shown to encode texture and object shape $(2,171)$ but lesions in this area have only modest effects on animals' ability to discriminate passively presented textures (254, 270), consistent with its putative role in the planning of grasping and other manual behaviors that require information about shape and texture $(124,128,129,298)$. During a grasp, neurons in area $5 \mathrm{~L}$ respond strongly during the approach, their response peaks during the grasp, and then drops during the lift, with a majority inhibited during hold (124). Neurons in area $5 \mathrm{~L}$ show evidence for synergies between reaching and grasping that may facilitate smooth, coordinated actions of the arm and hand (55). Ablation or lesions of area 5L interferes with the ability to orient the hand to grasp (270). Interestingly, area 5L neurons respond during reaching even if the animal is deafferented, showing again the tight interplay between area $5 \mathrm{~L}$ and motor areas (331).

\section{Parietal reach region.}

The parietal reach region (PRR) is found in the medial aspect of area 5 (Fig. 4A), located in part in the convexity of the superior parietal lobule (region also named PEc) and partially buried in the IPS (a region also named MIP). PRR probably contains multiple fields, the precise boundaries and locations of which remain vague. PRR receives major input from area $5 \mathrm{~L}$, as well as inputs from other parietal visual areas (areas 7a and V6A, just caudal to it). PRR projects to areas $7 \mathrm{a}$ and $7 \mathrm{~b}$ and is strongly reciprocally connected with the dorsal premotor cortex $(227,237,271)$. Neurons in PRR respond to passive somatosensory 
stimulation, in particular movements of the joints (26) with RFs located on the arm. PRR neurons also respond to visual stimuli (342) and most are multisensory (visual and somatosensory). In active reaching tasks, PRR cells are strongly activated before and during reaching movements and their responses are typically tuned for movement direction (200, 201). In light of these observations, PRR is thought to encode cognitive signals related to the direction of intended arm movement $(5,339)$ and movement-related sensory feedback.

Ablation of PRR only has only modest effects on tactile discrimination (254) and inactivation of PRR causes impairments in reaching (162).

\section{Area $7 b$.}

Area $7 \mathrm{~b}$ is located in the lateral aspect of area 7 (Fig. 4A), in part on the convexity of the inferior parietal lobule, caudal to area 2, and in part buried in the lateral sulcus (a region also denoted 7op), adjacent to LPC (214). Area $7 \mathrm{~b}$ is strongly and reciprocally connected with area 5 and LPC $(258,259)$. The rostral part of area $7 \mathrm{~b}(\mathrm{PF})$ is primarily connected with somatosensory areas while the caudal part (PFG) also receives inputs from multiple visual areas (MST, temporal visual areas and lateral intraparietal area) $(4,319)$. Area $7 \mathrm{~b}$ also receives input from thalamic pulvinar areas $(116,272,380)$ and projects to frontal and premotor areas as well as caudal PPC (144). While some neurons only respond during voluntary movements, the majority of neurons in area $7 \mathrm{~b}$ also respond to imposed movements of the joints and to tactile stimuli, some respond to visual stimuli, and some to both $(4,89,223,250,310)$. Furthermore, some neurons respond to both tactile and thermal or nociceptive stimuli, and a few to only nociceptive stimuli $(89,309)$. RFs in area $7 \mathrm{~b}$ are generally large but vary greatly in size (from single digit to whole hand or even whole arm). The RFs follow a crude somatotopic organization, with the head represented in the anterior portion of area 7b, aligned with the head representation of area 2, and the hand, arm, and trunk representations further posterior $(163,223,224)$. Little is known about the functional properties of neurons in area $7 \mathrm{~b}$, though some qualitative similarities have been reported in the response properties of areas $7 \mathrm{~b}$ and $5 \mathrm{~L}(124)$.

\section{Top-down modulation of APC}

As mentioned above, APC projections to thalamus exert a strong influence on the response properties of thalamic neurons. Such top-down modulation is also observed from PPC to APC. In fact, PPC sends corticocortical projections to APC (33) and corticothalamic projections to Pla of the thalamus $(43,380,392)$, which in turn projects back to APC (areas 1 and 2) $(68,217)$ and these feedback loops between PPC and APC exert a strong influence on the response properties of APC neurons. Indeed, reversible inactivation of area $5 \mathrm{~L}$ or $7 \mathrm{~b}$ results in an expansion of RFs in areas 1 and 2 (64) and can increase or decrease the cutaneous sensitivity of individual APC neurons (140). This powerful top-down effect from PPC to APC stands in contrast to that from LPC to APC: LPC lesions seem to have negligible effects on APC responses (284, 394). 


\section{Sensory Coding in Somatosensory Cortex}

\section{Vibration}

Frequency-Vibratory stimuli-mechanical sinusoids in particular-have been used extensively to probe tactile sensibility, inspired by the use of auditory pure tones to probe hearing. As summarized above, the different classes of tactile nerve fibers have different sensitivity profiles, with SA1 fibers tending to be more sensitive at the low frequencies ( $~ 5$ $\mathrm{Hz}$ ), PC fibers peaking in sensitivity at around $250 \mathrm{~Hz}$, and RA fibers preferring intermediate frequencies (354). A striking aspect of afferent responses to skin vibrations is that they exhibit phase locked responses to periodic vibratory stimuli-that is, they produce one spike or burst of spikes within a restricted portion of each stimulus cycle-as do their counterparts in the auditory nerve $(112,113,354)$ (Fig. 9A). This temporal patterning in afferent responses carries information about the frequency composition of vibratory stimuli applied to the skin $(21,233)$.

APC neurons also exhibit phase locking to low-frequency sinusoids (Fig. 9B), but the fidelity of the phase locking decreases rapidly as vibratory frequency increases: the vast majority of APC neurons entrain at $1 \mathrm{~Hz}$, but only a small proportion of them is capable of following a $300 \mathrm{~Hz}$ stimulus $(152,251)$. Surprisingly, a small fraction of neurons $(4 \%)$ can phase lock to vibrations with frequencies up to $800 \mathrm{~Hz}$ (149). For low-frequency stimuli, the spike rates of individual APC neurons increase or decrease monotonically with frequency and the interspike or interburst intervals decrease systematically, so frequency information is conveyed in the strength of the response (firing rate) as well as in its temporal patterning (phase locking) $(152,329)$ (Fig. 9B). At high frequencies, on the other hand, firing rates become frequency independent while the patterning is preserved in a subpopulation of neurons, which carries information about stimulus frequency. The ability of human and monkeys to perceive stimulus frequency above $100 \mathrm{~Hz}$ is thus mediated by the temporally patterned responses of this subpopulation of phase-locking neurons (149), a range of frequencies that may be implicated in the perception of texture $(12,379)$.

The responses of LPC neurons to mechanical sinusoids also exhibit phase locking, though weaker than that observed in APC. Indeed, vibration-sensitive LPC neurons phase lock to sinusoids with frequencies below $10 \mathrm{~Hz}$, though some can follow frequencies up to 50 to 75 $\mathrm{Hz}$, and fewer still up to $300 \mathrm{~Hz}(36)$. On the other hand, frequency is robustly encoded in the firing rates of LPC neurons, with rates either monotonically increasing or decreasing with increases in frequency (311), at least in the flutter range ( $<50 \mathrm{~Hz})$. The weak phase locking and strong rate coding of frequency in LPC has been interpreted as implying that frequency is encoded entirely in neuronal firing rates (329), which implies a progressive conversion from a temporal to rate code as one ascends the somatosensory neuraxis. This progression of neural codes has also been observed along the auditory neuraxis and may reflect a general principle of sensory processing (323).

Amplitude-At the somatosensory periphery, the strength of the response of most tactile fibers to a vibration is dependent not only on its amplitude but also on its frequency, so the amplitude information carried in the firing rates of any one population of tactile fibers is ambiguous. Rather, the intensity of skin vibrations is encoded in the firing rate evoked in all 
tactile nerve fibers, weighted by fiber type (252). In APC, neuronal responses to skin vibrations are also frequency-dependent up to about $50 \mathrm{~Hz}$. Over this frequency range, firing rates are modulated by stimulus amplitude, but also by stimulus frequency, as discussed above $(152,329)$ so it is unclear how these two stimulus dimensions can be independently decoded by downstream structures. In contrast, the firing rates of APC neurons evoked by high-frequency skin vibrations (above $50 \mathrm{~Hz}$ ) increase with vibratory amplitude-with rate intensity functions well approximated using a rectified logarithmic function—but do not depend on stimulus frequency (149). Therefore, spike count (at the single unit or population level) faithfully encodes vibratory amplitude independent of frequency at frequencies above about $50 \mathrm{~Hz}$.

\section{Tangential/shear forces}

When we manipulate objects, forces are not just exerted nor- mal to the surface of the skin but also parallel to it. The normal force-which corresponds to grip force in object grasping - is the force applied perpendicularly to the object surface. The tangential forcecorresponding to load force-is the reaction force acting parallel to the object's surface and often exerted by gravity (184). The responses of tactile afferents to tangential forces are in part dependent on the direction in which the tangential forces are exerted: Afferents respond maximally to forces exerted in a specific direction and less so to forces exerted in other directions $(19,381)$, and their responses are also modulated by the magnitude of the tangential force (381). The majority of APC neurons (85\%) produce responses that are dependent on the magnitude and direction of shear forces applied on or near their RFs (110). In the context of active movements, some neurons encode normal forces, others tangential forces, and some both (326-328). Interestingly, some neurons seem to carry information about friction, the ratio between tangential and normal force needed to achieve movement (111).

\section{Shape}

When we grasp an object, we can sense its three-dimensional structure based on somatosensory signals from the hand (390). Stereognosis relies on the integration of cutaneous information about local shape at each point of contact between skin and object and proprioceptive information about global shape from the relative position of these different contact points. In this section, we examine how information about local shapestemming from local deformations of the skin-is processed in somatosensory cortex. In the stereognosis section below, we discuss what little is known about stereognosis.

In both vision and touch, the shape of objects is reflected in a spatial pattern of activation across the receptor sheet, in the retina and in the skin, respectively $(142,190)$ (Fig. 10A). In primary visual cortex, a preponderance of neurons respond preferentially to the presence of an edge at a specific orientation in their RF, with a smooth drop off in response strength when the orientation of the bar deviates from this preferred orientation. In other words, the visual scene is parsed into a set of oriented contours, which forms the basis for down- stream processing, a representation that is thought to be optimal given the statistics of the visual world and sparseness constraints (267). Similarly, a large fraction of APC neurons (40\% $-60 \%$ ) exhibit orientation tuning for edges indented into the skin (Fig. 10B), with a slightly 
larger fraction in area 1 than area $3 \mathrm{~b}(11)$. As the tuning width of $\mathrm{V} 1$ neurons is invariant with respect to contrast, the tuning width of APC neurons is invariant with respect to depth of indentation, the tactile equivalent of visual contrast. The two sensory systems thus seem to implement similar mechanisms to extract orientation information, a phenomenon that can be at least in part attributed to the RF structure of APC and V1 neurons: RFs consist of excitatory regions flanked by inhibitory ones (or vice versa) and can be approximated using Gabor filters. Orientation tuning is somewhat broader in APC than in V1 and, perceptually, angular acuity is coarser in touch than vision for stimuli of comparable size presented passively (40 vs. $20 \circ$ angular threshold in vision and touch, respectively) (14). Interestingly, tactile orientation acuity is much higher when measured in the context of an active orienting task (291).

One of the well-known principles that governs the processing of visual shape is that of hierarchical processing: Neurons at successive layers of processing have progressively larger RFs and progressively more complex feature selectivity that is progressively more invariant with respect to other stimulus features. The same principle operates in the processing of tactile shape along the somatosensory neuraxis. Indeed, neurons in area 2 exhibit tuning for curved shapes - comprising multiple orientations-a complex selectivity that is not observed in areas $3 \mathrm{~b}$ and 1 and is even more pronounced in LPC $(389,391)$ (Fig. 10C). Furthermore, neurons in LPC exhibit orientation tuning over wide swaths of skin, with a consistent orientation preference across their RFs, reflecting increased position-invariance with respect to their APC counterparts (107) (Fig. 10D). Lesions of LPC lead to an impairment in shape discrimination, as do lesions in area 2 (254), confirming that these two areas are part of a tactile shape processing pathway.

Motion

Tool use and, more generally, object interactions often involve motion between skin and object. Furthermore, to sense the shape of an object or its texture requires movement between skin and object (221). Not surprisingly, then, cutaneous cues convey information about the velocity of relative movement between skin and surface. Indeed, human subjects can discriminate the direction $(100,102,277)$ or the speed $(15,101,382)$ of movement across the skin.

As is the case with shape perception, the neural mechanisms underlying motion perception are remarkably analogous in vision and touch $(268,275)$. Indeed, a subpopulation of APC neurons is tuned for motion direction $(65,126,276,376)$, as are many V1 neurons (Fig. 11A). In area $3 \mathrm{~b}$, direction- selective neurons are maximally sensitive to oriented bars moving across their RFs but these neurons cannot signal the direction of a stimulus comprising multiple orientations. Indeed, given their small RFs, they are subject to the aperture problem (Fig. 11B). That is, any one straight edge of a moving object conveys information only about the motion component perpendicular to that edge's orientation. Due to its small RF, a single neuron in area $3 \mathrm{~b}$ will respond to only one of an object's many edges, and will therefore convey erroneous information about the object's global direction of motion (Fig. 11C). Most direction selective neurons in primary visual cortex are subject to the same limitation. 
In contrast, some neurons in area 1 integrate information across locally ambiguous motion cues and therefore carry a global motion signal (276) (Fig. 11D). This ability to recover global motion is analogous to that of direction selective neurons in medial temporal cortex, a brain region specialized for visual motion processing. In fact, the algorithm that is implemented in somatosensory cortex to compute the global direction of tactile motion seems to be identical to its visual counterpart: Motion signals from edges, subject to the aperture problem, and motion signals from terminators (intersections, corners), which convey more reliable information about motion, are integrated using a vector average computation to estimate the global direction of motion. Finally, the responses of APC neurons can account for the ability of human observers to judge the direction of movement across a variety of psychophysical paradigms $(275,276)$, as has been found with MT neurons $(28,29)$.

APC neurons are sensitive not only to motion direction but also to motion speed. Indeed, the responses of a large fraction of neurons increase as the speed at which a textured surface is scanned across the skin increases (78). Most of these speed-sensitive neurons also modulate their response to surface texture so the speed signal is confounded by a texture one, particularly in area $3 b$. This ambiguity between speed and texture is also reflected in psychophysical judgments of speed, which are also influenced by texture (77). Interestingly, judgments of texture are largely independent of speed $(24,220,242)$.

\section{Texture}

Our sense of touch endows us with an exquisite sensitivity to surface microstructure which allows us to distinguish satin, from silk, from sandpaper. In fact, we can discriminate textures with element sizes differing in the tens of nanometers or with spatial periods differing in the hundreds of nanometers (337). Tangible textures thus span a huge range of spatial scales from tens of nanometers to about a centimeter-almost six orders of magnitude. This wide dynamic range is possible because texture perception relies on two distinct mechanisms, each best suited to encode texture over a subrange. The coarse features of a texture produce millimeter-scale deformations in the skin, which evoke a spatial pattern of activation in SA1 (and perhaps RA) fibers. This spatial code can account for the roughness of surfaces that comprise only such features, for example, gratings and Braillelike embossed dot patterns $(62,63,141)$. However, SA1 fibers are almost completely insensitive to finer textural elements. The perception of these fine features requires movement between skin and sur- face (155), which in turn elicits texture- and speeddependent vibrations in the skin $(12,13,75,235)$. These texture-elicited vibrations evoke temporal spiking patterns in mechanoreceptive afferents, particularly RA and PC fibers, which carry information about fine texture at millisecond time scales $(233,379)$. This combination of spatial coding for coarse textural features and temporal coding for fine ones accounts for the wide dynamic range of tangible textures.

The cortical mechanisms that mediate tactile texture perception have not been conclusively elucidated. To date, experiments investigating texture coding in cortex used gratings $(37,74$, $335,377)$ and Braille-like embossed dot patterns $(25,53)$ as stimuli, which robustly engage SA1 fibers and discount the contribution of signals from other nerve fibers (379). With this 
caveat, the responses of APC neurons to gratings and dot patterns have been shown to be modulated by the spatial period of the stimuli. However, a subset of these neurons seems to track the perceived roughness of such textures $(25,53)$, consistent with the hypothesis that they are causally implicated in texture perception. Furthermore, lesions of area 1 result in pronounced deficits in texture dis- crimination $(296,333,334)$, so this area may be part of a pathway specialized for texture processing.

The RF structure of cortical neurons may provide clues as to how texture information is encoded in cortex. As mentioned above, many neurons in APC have RFs comprising excitatory subfields flanked by inhibitory ones (82). The precise structure and scale of these RFs varies from neuron to neuron, so APC neurons can be thought of as spatial filters, each differentially sensitive to a textured surface depending on its spatial proper- ties. This category of neurons is well suited to encode coarse spatial features. Some APC neurons integrate signals from RA and PC fibers and do so in different ways (322). These neurons can be thought of as temporal filters, which each respond to skin vibrations, and by extension textures comprising fine features, in different ways. Neurons with idiosyncratic spatial or temporal RF properties thus respond idiosyncratically to a textured surface depending on the spatial scale of its coarse features and on the properties of the vibrations that are elicited in the skin by its fine features, respectively.

LPC responses to gratings are modulated by groove width as well as contact force, and/or scanning speed (290). An individual neuron is likely to respond to two or even three of these parameters, sometimes in an additive manner, and sometimes in more complex ways. LPC is implicated in texture perception as evidenced by the modulation of LPC responses by both groove width and contact force, two parameters known to determine the perceived roughness of gratings $(219,222,358)$, and by the impairment in roughness discrimination caused by lesions of LPC (254). Furthermore, some LPC neurons encode the presence, but not magnitude, of a change in the spatial pattern of a texture, in a same/different task, another example of task-specific modulation (181).

\section{Stereognosis}

A fascinating aspect of somatosensation is that it comprises a deformable sensory sheet: changes in hand posture recon- figure the positions of cutaneous mechanoreceptors with respect to one another. To interpret signals from cutaneous mechanoreceptors thus requires taking into account their positions relative to one another $(156,305)$. This integration of touch and proprioception is particularly critical for stereognosis, the ability to sense the three-dimensional structure of objects grasped in the hand: Cutaneous input from each fingertip contacting the object provides a snapshot of its shape at each contact point (local edge orientation or surface curvature, e.g.), and the relative position of the fingertips conveys information of the size and global shape of the object, as well as about the relative position of the local features relative to one another.

Virtually nothing is known about how this takes place in the somatosensory system. However, area 2 is the first location along the somatosensory neuraxis where neurons exhibit both cutaneous and proprioceptive responses $(165,171,172,206)$. That is, their firing rates are modulated both by light touch and joint configuration (Fig. 12) so the process of 
constructing a three-dimensional representation of objects likely begins there. Some evidence suggests that cutaneous and proprioceptive inputs interact in complex ways in area 2 , and the temporal progression of these interactions may reflect the dynamics of a circuit involved in stereognosis (206). How- ever, stereognosis requires active movements (221) but the challenges associated with tracking both hand postures and contact events have, to date, precluded the study of active stereognosis.

\section{Attention and Decision Making in the Somatosensory System}

Our bodies are constantly and simultaneously touched in many ways - through contact with our clothes, the ground, grasped objects, etc.-most of which are of little relevance at any given time. As is the case in other sensory modalities, certain sources of sensory input can be magnified relative to others through the deployment of attention. The consequences of attention on neuronal responses are typically probed by presenting a stimulus that is relevant to the performance of a task (and so attention is deployed toward it) or that is not (and so attention is diverted away from it, to another sensory stimulus, e.g.). Comparison of responses to the same stimulus in the attended versus unattended conditions, then, reveals the effects of attention. In visual cortex, for example, responses to the attended stimulus have been shown to be enhanced relative to those to the same stimulus, unattended (232, 247, 368).

Attention is thought to enhance the contrast of behaviorally relevant inputs by increasing the gain for cells that play a role in detecting a stimulus at a particular location on the skin (52). Responses of neurons in the early stages of somatosensory processing to a stimulus are relatively impervious to modulations by behavioral relevance. Indeed, responses to a stimulus in VP (VPL and VPM, thalamus) are equivalent whether the animal is attending to it or not $(41,367,372)$. As few as $16 \%$ and as many $50 \%$ of APC neurons have been reported to show attentional modulation $(38,157,244)$. Caudal APC exhibits a greater degree of attentional modulation than does rostral APC, again consistent with their respective positions along the somatosensory hierarchy $(167,168,244)$ as attentional effects tend to be stronger in higher sensory areas (239). The type and magnitude of these effects varies across studies, with some reporting that nearly all attentionally modulated neurons show enhanced activity $(157,244)$ and others observing mostly suppressed activity $(38)$. The proportion of attention-sensitive cells is greater in LPC than in APC, ranging from $60 \%$ to $80 \%(39,157$, 244) and the magnitude of the attentional effects are greater in LPC. Enhancement of activity seen in LPC seems to target neurons that encode behaviorally relevant stimulus features, for example, texture, while attentional gain increases in APC neurons are less stimulus dependent (244), perhaps reflecting the weaker feature selectivity at earlier stages of cortical processing.

Increases in neural synchrony constitute another neural correlate of attention in the sensory cortices $(318,344)$. That is, the degree to which nearby neurons fire in synchrony increases with selective attention. Such observations have been made in APC (256), in LPC (318, 344), in posterior parietal cortex (79), and in other sensory modalities (e.g., visual cortex, 120). 


\section{Affective Touch}

Touch plays a critical role in emotion and affective communication: we touch the people we care about and derive comfort from the touch of a loved one (153). The importance of touch is highlighted in studies showing that the texture of a mother surrogate has a major impact on its effectiveness as a surrogate, and deprivation of affective touch during development leads to severe emotional problems $(147,148,378)$. Affective touch is mediated by fundamentally different neural mechanisms than is discriminative touch (241). First, affective touch may rely, at least in part, on different receptors. Indeed, C-tactile afferents, which innervate the hairy skin, respond most strongly to stimuli brushed across the skin that are experienced as pleasant (229), suggesting that these nerve fibers convey information about the affective quality of a stim- ulus rather than its physical properties. Second, signals from these fibers have been shown to bypass $\operatorname{APC}(45,265,266)$ and instead target the insula, which is associated with affective coding $(22,248)$. While C-tactile afferent fibers do not innervate the glabrous skin, it is commonly observed that touch with the glabrous skin can also be perceived as pleasant $(208,209)$. Pleasant touch involving the glabrous skin may thus be processed separately from its hairy skin counterpart, the former by somatosensory cortex, the latter by the limbic system $(134,240)$. Affective touch with the glabrous skin typically involves self-generated movement while affective touch with the hairy skin results from external stimulation, which may explain why the two categories of touch are processed separately.

\section{Artificial Somatosensation through Intracortical Microstimution in APC}

When Wilder Penfield and colleagues applied electrical stimuli to the surface of APC searching for epileptic foci, patients reported tactile sensations, the location of which depended systematically on where the stimulus was delivered (278). Later, Romo and colleagues showed that monkeys could learn to distinguish the frequency of low-amplitude electrical pulse trains delivered to APC (312). In other words, changes in one stimulation parameter-frequency—systematically changed the evoked sensory experience. While this work had important scientific implications about how stimulus information is encoded in the nervous system, it also laid the foundation for somatosensory neuroprostheses. Indeed, one approach to restoring some independence to tetraplegic patients—-who are paralyzed and insensate from the neck down-is to equip them with prosthetic arms that they can control by thought alone. The development of anthropomorphic robotic limbs and of algorithms to decode intended movements from brain signals led to a much more sophisticated movement repertoire (61). This newfound function established the need to restore somatosensation, without which movements are slow, clumsy, and effortful $(139,324)$.

In experiments with monkeys (352), intracortical microstimulation (ICMS) was shown to elicit percepts that are highly localized—to a single fingerpad or palmar whorl-much more so than are percepts evoked by electrical stimulation of the surface of APC, as in Penfield's experiments $(191,352)$. The somatotopic map within APC can thus be exploited to intuitively convey information about the points of contact between prosthetic hand and object. Furthermore, changes in ICMS amplitude produce systematic changes in the magnitude of the evoked sensation, a phenomenon that can be used to intuitively convey 
information about contact pressure $(18,205,352,353)$. The success of primate studies has led to the deployment of this approach in human patients, who report tactile sensations that are nearly natural $(108,207)$.

The development of artificial proprioception is more challenging because much less is known about the cortical basis for natural proprioception. However, monkeys are able to detect and discriminate different patterns of electrical stimulation applied to area 3a (230), and some evidence even suggests that stimulation of neurons that are selective for a particular direction of limb movement biases the monkeys' perceived limb movement toward that direction of movement (360). This latter finding suggests that it may be possible to create sensations of directed limb movement by stimulating populations of APC neurons with consistent preferred directions to track the movements of the prosthesis. If tapping into natural proprioceptive representations proves too challenging, it may be possible to develop novel but systematic mappings between limb state and ICMS-evoked patterns of neuronal activation that the patients would have to learn (69). Whether learning-based approaches will scale to accommodate the complexity of a limb remains to be seen (76).

The inclusion of artificial touch and proprioception in brain-controlled prostheses will be an important step in improving the dexterity conferred to their users.

\section{Acknowledgements}

We wish to thank Kenzie Green, Masha Boyarinova, and Molly O’Donnell for their help in figure preparation and Leah Krubitzer for comments on an earlier version of this manuscript. This work was supported by NINDS grants NS101325 and NS082865.

\section{References}

1. Ackerley R, Backlund Wasling H, Liljencrantz J, Olausson H, Johnson RD, Wessberg J. Human Ctactile afferents are tuned to the temperature of a skin-stroking caress. J Neurosci 34: 2879-2883, 2014. [PubMed: 24553929]

2. Ageranioti-Be'langer SA, Chapman CE. Discharge properties of neurones in the hand area of primary somatosensory cortex in monkeys in relation to the performance of an active tactile discrimination task. II. Area 2 as compared to areas 3b and 1. Exp brain Res 91: 207-228, 1992. [PubMed: 1459224]

3. Agnew Z, Wise RJS. Separate areas for mirror responses and agency within the parietal operculum. J Neurosci 28(47): 12268-12273, 2008. [PubMed: 19020020]

4. Andersen RA, Asanuma C, Essick GK, Siegel RM. Corticocortical connections of anatomically and physiologically defined subdivisions within the inferior parietal lobule. J Comp Neurol 296: 65113, 1990. [PubMed: 2358530]

5. Andersen RA, Buneo CA. Intentional maps in posterior parietal cortex. Annu Rev Neurosci 25: 189-220, 2002. [PubMed: 12052908]

6. Apkarian AV, Shi T. Squirrel monkey lateral thalamus. I. Somatic nociresponsive neurons and their relation to spinothalamic terminals. J Neurosci 14: 6779-6795, 1994. [PubMed: 7965079]

7. Ashaber M, Pa'lfi E, Friedman RM, Palmer C, Ja'kli B, Chen LM, Ka'ntor O, Roe AW, Ne'gyessy L. Connectivity of somatosensory cortical area 1 forms an anatomical substrate for the emergence of multifinger receptive fields and complex feature selectivity in the squirrel monkey (Saimiri sciureus). J Comp Neurol 522: 1769-1785, 2014. [PubMed: 24214200]

8. Augurelle A-S, Smith AM, Lejeune T, Thonnard J-L. Importance of cutaneous feedback in maintaining a secure grip during manipulation of hand-held objects. J Neurophysiol 89: 665-671, 2003. [PubMed: 12574444] 
9. Bell J, Bolanowski SJ, Holmes MH. The structure and function of Pacinian corpuscles: A review. Prog Neurobiol 42: 79-128, 1994. [PubMed: 7480788]

10. Bengtsson F, Brasselet R, Johansson RS, Arleo A, Jo“rntell H. Integration of sensory quanta in cuneate nucleus neurons in vivo. PLoS One 8: e56630, 2013. [PubMed: 23409195]

11. Bensmaia SJ, Denchev PVPV, Dammann JF, III, Craig JC, Hsiao SS, Dammann JF. The representation of stimulus orientation in the early stages of somatosensory processing. J Neurosci 28: 776-786, 2008. [PubMed: 18199777]

12. Bensmaia SJ, Hollins M. The vibrations of texture. Somatosens Mot Res 20: 33-43, 2003. [PubMed: 12745443]

13. Bensmaia SJ, Hollins M. Pacinian representations of fine surface texture. Percept Psychophys 67: 842-854, 2005. [PubMed: 16334056]

14. Bensmaia SJ, Hsiao SS, Denchev PV, Killebrew JH, Craig JC. The tactile perception of stimulus orientation. Somatosens Mot Res 25: 49-59, 2008. [PubMed: 18344147]

15. Bensmaia SJ, Killebrew JH, Craig JC. Influence of visual motion on tactile motion perception. J Neurophysiol 96: 1625-1637, 2006. [PubMed: 16723415]

16. Bensmaia SJ, Tillery SIH. Tactile feedback from the hand. Springer Tracts Adv Robot 95: 143157, 2014.

17. Bentivoglio M, Rustioni A. Corticospinal neurons with branching axons to the dorsal column nuclei in the monkey. J Comp Neurol 253: 260-276, 1986. [PubMed: 3793994]

18. Berg JA, Dammann JF, Tenore FV, Tabot GA, Boback JL, Manfredi LR, Peterson ML, Katyal KD, Johannes MS, Makhlin A, Wilcox R, Franklin RK, Vogelstein RJ, Hatsopoulos NG, Bensmaia SJ. Behavioral demonstration of a somatosensory neuroprosthesis. IEEE Trans Neural Syst Rehabil Eng 21: 500-507, 2013. [PubMed: 23475375]

19. Birznieks I, Jenmalm P, Goodwin AW, Johansson RS. Encoding of direction of fingertip forces by human tactile afferents. J Neurosci 21: 8222-8237, 2001. [PubMed: 11588194]

20. Birznieks I, Macefield VG, Westling G, Johansson RS. Slowly adapting mechanoreceptors in the borders of the human fingernail encode fingertip forces. J Neurosci 29: 9370-9379, 2009. [PubMed: 19625527]

21. Birznieks I, Vickery RM. Spike timing matters in novel neuronal code involved in vibrotactile frequency perception. Curr Biol 27(10): 1485-1490.e2, 2017. doi: 10.1016/j.cub.2017.04.011. [PubMed: 28479322]

22. Bjo“rnsdotter M, Lo “ken L, Olausson H, Vallbo AB, Wessberg J. Somatotopic organization of gentle touch processing in the posterior insular cortex. J Neurosci 29: 9314-9320, 2009. [PubMed: 19625521]

23. Blankenburg F Evidence for a rostral-to-caudal somatotopic organization in human primary somatosensory cortex with mirror-reversal in areas 3b and 1. Cereb Cortex 13: 987-993, 2003. [PubMed: 12902398]

24. Boundy-Singer ZM, Saal HP, Bensmaia SJ. Speed invariance of tactile texture perception. J Neurophysiol 118: 2371-2377, 2017. [PubMed: 28724777]

25. Bourgeon S, Dépeault A, Meftah E-M, Chapman CE. Tactile texture signals in primate primary somatosensory cortex and their relation to subjective roughness intensity. J Neurophysiol 115 : 1767-1785, 2016. [PubMed: 26763776]

26. Breveglieri R Somatosensory cells in area PEc of macaque posterior parietal cortex. J Neurosci 26: 3679-3684, 2006. [PubMed: 16597722]

27. Brisben AJ, Hsiao SS, Johnson KO. Detection of vibration transmitted through an object grasped in the hand. J Neurophysiol 81: 1548-1558, 1999. [PubMed: 10200190]

28. Britten KH, Newsome WT, Shadlen MN, Celebrini S, Movshon JA. A relationship between behavioral choice and the visual responses of neurons in macaque MT. Vis Neurosci 13: 87-100, 1996. [PubMed: 8730992]

29. Britten KH, Shadlen MN, Newsome WT, Movshon JA. The analysis of visual motion: A comparison of neuronal and psychophysical performance. J Neurosci 12: 4745-4765, 1992. [PubMed: 1464765]

30. Burke D, Gandevia SC, Macefield G. Responses to passive movement of receptors in joint, skin and muscle of the human hand. J Physiol 402: 347-361, 1988. [PubMed: 2976823] 
31. Burton H Corticothalamic connections from the second somatosensory area and neighboring regions in the lateral sulcus of macaque monkeys. Brain Res 309: 367-372, 1984.

32. Burton H, Carlson M. Second somatic sensory cortical area (sii) in a prosimian primate, galago crassicaudatus. J Comp Neurol 247: 200-220, 1986. [PubMed: 3722439]

33. Burton H, Fabri M. Ipsilateral intracortical connections of physiologically defined cutaneous representations in areas $3 \mathrm{~b}$ and 1 of macaque monkeys: Projections in the vicinity of the central sulcus. J Comp Neurol 355: 508-538, 1995. [PubMed: 7636029]

34. Burton H, Fabri M, Alloway K. Cortical areas within the lateral sulcus connected to cutaneous representations in areas $3 \mathrm{~b}$ and 1: A revised interpretation of the second somatosensory area in macaque monkeys. J Comp Neurol 355: 539-562, 1995. [PubMed: 7636030]

35. Burton H, Sinclair RJ. Second somatosensory cortical areas in macaque monkeys. 1. Neuronal response to controlled, punctate indentations of glabrous skin on the hand. Brain Res 520: 262271, 1990. [PubMed: 2207635]

36. Burton H, Sinclair RJ. Second somatosensory cortical area in macaque monkeys: 2. Neuronal responses to punctate vibrotactile stimulation of glabrous skin on the hand. Brain Res 538: 127135, 1991. [PubMed: 2018924]

37. Burton H, Sinclair RJ. Representation of tactile roughness in thalamus and somatosensory cortex. Can J Physiol Pharmacol 72: 546-557, 1994. [PubMed: 7954085]

38. Burton H, Sinclair RJ. Tactile-spatial and cross-modal attention effects in the primary somatosensory cortical areas 3b and 1-2 of rhesus monkeys. Somatosens Mot Res 17: 213-228, 2000. [PubMed: 10994592]

39. Burton H, Sinclair RJ, Hong SY, Pruett JR, Whang KC. Tactile-spatial and cross-modal attention effects in the second somatosensory and $7 \mathrm{~b}$ cortical areas of rhesus monkeys. Somatosens Mot Res 14: 237-267, 1997. [PubMed: 9443366]

40. Bushnell MC, Duncan GH. Mechanical response properties of ventroposterior medial thalamic neurons in the alert monkey. Exp Brain Res 67: 4-7, 1987.

41. Camarillo L, Luna R, Na'cher V, Romo R. Coding perceptual discrimination in the somatosensory thalamus. Proc Natl Acad Sci Unites States Am 109: 21093-21098, 2012.

42. Caminiti R, Borra E, Visco-Comandini F, Battaglia-Mayer A, Averbeck BB, Luppino G. Computational architecture of the parieto-frontal network underlying cognitive-motor control in monkeys. eNeuro 4: ENEURO.0306-16.2017, 2017.

43. Cappe C, Morel A, Rouiller EM. Thalamocortical and the dual pattern of corticothalamic projections of the posterior parietal cortex in macaque monkeys. Neuroscience 146: 1371-1387, 2007. [PubMed: 17395383]

44. Carlson M Characteristics of sensory deficits following lesions of Brodmann's areas 1 and 2 in the postcentral gyrus of Mococo mulatto. Brain Res 204: 424-430, 1981. [PubMed: 7459637]

45. Case LK, Laubacher CM, Olausson H, Wang B, Spagnolo PA, Bushnell MC. Encoding of touch intensity but not pleasantness in human primary somatosensory cortex. J Neurosci 36: 5850-5860, 2016. [PubMed: 27225773]

46. Cauna N Nerve supply and nerve endings in Meissner's corpuscles. Am J Anat 99: 315-350, 1956. [PubMed: 13372495]

47. Cauna $\mathrm{N}$ The mode of termination of the sensory nerves and its significance. J Comp Neurol 113: 169-209, 1959. [PubMed: 13808524]

48. Cauna N, Ross LL. The fine structure of Meissner's touch corpuscles of human fingers. J Biophys Biochem Cytol 8: 467-482, 1960. [PubMed: 13691669]

49. Cavada C, Goldman-Rakic PS. Posterior parietal cortex in rhesus monkey: II. Evidence for segregated corticocortical networks linking sensory and limbic areas with the frontal lobe. J Comp Neurol 287: 422-445, 1989. [PubMed: 2477406]

50. Cavada C, Goldman-Rakic PS. Posterior parietal cortex in rhesus mon- key: I. Parcellation of areas based on distinctive limbic and sensory corticocortical connections. J Comp Neurol 287: 393-421, 1989. [PubMed: 2477405]

51. Chapman CE, Bushnell MC, Miron D, Duncan GH, Lund JP. Sensory perception during movement in man. Exp Brain Res 68: 516-524, 1987. [PubMed: 3691723] 
52. Chapman CE, Meftah E-M. Independent controls of attentional influences in primary and secondary somatosensory cortex. J Neurophysiol 94: 4094-4107, 2005. [PubMed: 16148278]

53. Chapman CE, Tremblay F, Jiang W, Belingard L, Meftah E-M. Central neural mechanisms contributing to the perception of tactile roughness. Behav Brain Res 135: 225-233, 2002. [PubMed: 12356453]

54. Cheema S, Whitsel BL, Rustioni A. The corticocuneate pathway in the cat: Relations among terminal distribution patterns, cytoarchitecture, and single neuron functional properties. Somatosens Res 1: 169-205, 1983. [PubMed: 6679919]

55. Chen J, Reitzen SD, Kohlenstein JB, Gardner EP. Neural representation of hand kinematics during prehension in posterior parietal cortex of the macaque monkey. J Neurophysiol 102: 3310-3328, 2009. [PubMed: 19793876]

56. Chen LM, Friedman RM, Ramsden BM, LaMotte RH, Roe AW. Fine- scale organization of SI (area $3 b$ ) in the squirrel monkey revealed with intrinsic optical imaging. J Neurophysiol 86: $3011-$ 3029, 2001. [PubMed: 11731557]

57. Chen LM, Friedman RM, Roe AW. Optical imaging of a tactile illusion in area $3 b$ of the primary somatosensory cortex. Science 302: 881-885, 2003. [PubMed: 14500850]

58. Cheney PD, Preston JB. Classification and response characteristics of muscle spindle afferents in the primate. J Neurophysiol 39: 1-8, 1976. [PubMed: 129542]

59. Cohen DA, Prud'homme MJ, Kalaska JF. Tactile activity in primate primary somatosensory cortex during active arm movements: Correlation with receptive field properties. J Neurophysiol 71: 161172, 1994. [PubMed: 8158225]

60. Cohen YE, Cohen IS, Gifford GW. Modulation of LIP activity by predictive auditory and visual cues. Cereb Cortex 14: 1287-1301, 2004. [PubMed: 15166102]

61. Collinger JL, Wodlinger B, Downey JE, Wang W, Tyler-Kabara EC, Weber DJ, McMorland AJC, Velliste M, Boninger ML, Schwartz AB. High-performance neuroprosthetic control by an individual with tetraplegia. Lancet 381: 557-564, 2013. [PubMed: 23253623]

62. Connor CE, Hsiao SS, Phillips JR, Johnson KO. Tactile roughness: Neural codes that account for psychophysical magnitude estimates. J Neurosci 10: 3823-3836, 1990. [PubMed: 2269886]

63. Connor CE, Johnson KO. Neural coding of tactile texture: Comparison of spatial and temporal mechanisms for roughness perception. J Neurosci 12: 3414-3426, 1992. [PubMed: 1527586]

64. Cooke DF, Goldring AB, Baldwin MKL, Recanzone GH, Chen A, Pan T, Simon SI, Krubitzer LA. Reversible deactivation of higher-order posterior parietal areas. I. Alterations of receptive field characteristics in early stages of neocortical processing. J Neurophysiol 112: 2529-2544, 2014. [PubMed: 25143546]

65. Costanzo RM, Gardner EP. A quantitative analysis of responses of direction-sensitive neurons in somatosensory cortex of awake monkeys. J Neurophysiol 43: 1319-1341, 1980. [PubMed: 6768849]

66. Costanzo RM, Gardner EP. Multiple-joint neurons in somatosensory cortex of awake monkeys. Brain Res 214: 321-333, 1981. [PubMed: 7237174]

67. Craig AD. Retrograde analyses of spinothalamic projections in the macaque monkey: Input to ventral posterior nuclei. J Comp Neurol 499: 965-978, 2006. [PubMed: 17072832]

68. Cusick CG, Gould HJ. Connections between area $3 \mathrm{~b}$ of the somatosensory cortex and subdivisions of the ventroposterior nuclear complex and the anterior pulvinar nucleus in squirrel monkeys. J Comp Neurol 292: 83-102, 1990. [PubMed: 1690224]

69. Dadarlat MC, O’Doherty JE, Sabes PN. A learning-based approach to artificial sensory feedback leads to optimal integration. Nat Neurosci 18: 138-144, 2015. [PubMed: 25420067]

70. Darian-Smith C, Darian-Smith I, Burman K, Ratcliffe N. Ipsilateral cortical projections to areas 3a, 3b, and 4 in the macaque monkey. J Comp Neurol 335: 200-213, 1993. [PubMed: 8227514]

71. Darian-Smith C, Darian-Smith I, Cheema SS. Thalamic projections to sensorimotor cortex in the macaque monkey: Use of multiple retrograde fluorescent tracers. J Comp Neurol 299: 17-46, 1990. [PubMed: 1698837]

72. Darian-Smith C, Tan A, Edwards S. Comparing thalamocortical and corticothalamic microstructure and spatial reciprocity in the macaque ventral posterolateral nucleus (VPLc) and medial pulvinar. J Comp Neurol 410: 211-234, 1999. [PubMed: 10414528] 
73. Darian-Smith I The sense of touch: Performance and peripheral neural processes. In: Comprehensive Physiology Hoboken, NJ, USA: John Wiley \& Sons, Inc, 2011.

74. Darian-Smith I, Sugitani M, Heywood J, Karita K, Goodwin AW. Touching textured surfaces: Cells in somatosensory cortex respond both to finger movement and to surface features. Science 218: 906-909, 1982. [PubMed: 7134982]

75. Delhaye BP, Hayward V, Lefe 'vre P, Thonnard J-L. Texture-induced vibrations in the forearm during tactile exploration. Front Behav Neurosci 6: 37, 2012. [PubMed: 22783177]

76. Delhaye BP, Saal HP, Bensmaia SJ. Key considerations in designing a somatosensory neuroprosthesis. J Physiol 110: 402-408, 2016.

77. De'peault A, Meftah E-M, Chapman CE. Tactile speed scaling: Contributions of time and space. J Neurophysiol 99: 1422-1434, 2008. [PubMed: 18199814]

78. De'peault A, Meftah el-M, Chapman CE. Neuronal correlates of tactile speed in primary somatosensory cortex. J Neurophysiol 110(7): 1554-1566, 2013. doi: 10.1152/jn.00675.2012. [PubMed: 23843433]

79. Desmedt JE, Tomberg C. Transient phase-locking of $40 \mathrm{~Hz}$ electrical oscillations in prefrontal and parietal human cortex reflects the process of conscious somatic perception. Neurosci Lett 168: 126-129, 1994. [PubMed: 8028764]

80. DiCarlo JJ, Johnson KO. Velocity invariance of receptive field structure in somatosensory cortical area $3 b$ of the alert monkey. J Neurosci 19: 401-419, 1999. [PubMed: 9870969]

81. DiCarlo JJ, Johnson KO. Spatial and temporal structure of receptive fields in primate somatosensory area $3 \mathrm{~b}$ : Effects of stimulus scanning direction and orientation. J Neurosci 20: 495510, 2000. [PubMed: 10627625]

82. DiCarlo JJ, Johnson KO, Hsiao SS. Structure of receptive fields in area $3 b$ of primary somatosensory cortex in the alert monkey. J Neurosci 18: 2626-2645, 1998. [PubMed: 9502821]

83. Dimitriou M, Edin BB. Discharges in human muscle spindle afferents during a key-pressing task. J Physiol 586: 5455-5470, 2008. [PubMed: 18801840]

84. Dimitriou M, Edin BB. Discharges in human muscle receptor afferents during block grasping. J Neurosci 28: 12632-12642, 2008. [PubMed: 19036957]

85. Disbrow E Thalamocortical connections of the parietal ventral area (PV) and the second somatosensory area (S2) in macaque monkeys. Thalamus Relat Syst 1: 289-302, 2002.

86. Disbrow E, Litinas E, Recanzone GH, Padberg J, Krubitzer LA. Cortical connections of the second somatosensory area and the parietal ventral area in macaque monkeys. J Comp Neurol 462: 382399, 2003. [PubMed: 12811808]

87. Disbrow E, Roberts T, Krubitzer LA. Somatotopic organization of cortical fields in the lateral sulcus of Homo sapiens: Evidence for SII and PV. J Comp Neurol 418: 1-21, 2000. [PubMed: 10701752]

88. Disbrow E, Roberts T, Poeppel D, Krubitzer LA. Evidence for interhemispheric processing of inputs from the hands in human S2 and PV. J Neurophysiol 85: 2236-2244, 2001. [PubMed: 11353038]

89. Dong WK, Chudler EH, Sugiyama K, Roberts VJ, Hayashi T. Somatosensory, multisensory, and task-related neurons in cortical area $7 \mathrm{~b}(\mathrm{PF})$ of unanesthetized monkeys. J Neurophysiol 72: $542-$ 564, 1994. [PubMed: 7983518]

90. Dykes RW. Parallel processing of somatosensory information: A theory. Brain Res Rev 6: 47-115, 1983.

91. Dykes RW, Rasmusson DD, Sretavan D, Rehman NB. Submodality segregation and receptive-field sequences in cuneate, gracile, and external cuneate nuclei of the cat. J Neurophysiol 47: 389-416, 1982. [PubMed: 6461730]

92. Edin BB. Quantitative analysis of static strain sensitivity in human mechanoreceptors from hairy skin. J Neurophysiol 67: 1105-1113, 1992. [PubMed: 1597700]

93. Edin BB. Cutaneous afferents provide information about knee joint movements in humans. $\mathrm{J}$ Physiol 531: 289-297, 2001. [PubMed: 11179411]

94. Edin BB. Quantitative analyses of dynamic strain sensitivity in human skin mechanoreceptors. J Neurophysiol 92: 3233-3243, 2004. [PubMed: 15548636] 
95. Edin BB, Vallbo AB. Dynamic response of human muscle spindle afferents to stretch. J Neurophysiol 63: 1297-1306, 1990. [PubMed: 2141632]

96. Edin BB, Vallbo AB. Muscle afferent responses to isometric con- tractions and relaxations in humans. J Neurophysiol 63: 1307-1313, 1990. [PubMed: 2358878]

97. Eickhoff SB, Amunts K, Mohlberg H, Zilles K. The human parietal operculum. II. Stereotaxic maps and correlation with functional imaging results. Cereb Cortex 16: 268-279, 2006. [PubMed: 15888606]

98. Eickhoff SB, Schleicher A, Zilles K, Amunts K. The human parietal operculum. I. Cytoarchitectonic mapping of subdivisions. Cereb Cortex 16: 254-267, 2006. [PubMed: 15888607]

99. Ergenzinger ER, Glasier MM, Hahm JO, Pons TP. Cortically induced thalamic plasticity in the primate somatosensory system. Nat Neurosci 1: 226-229, 1998. [PubMed: 10195147]

100. Essick GK, Bredehoeft KR, McLaughlin DF, Szaniszlo JA. Directional sensitivity along the upper limb in humans. Somatosens Mot Res 8: 13-22, 1991. [PubMed: 2048360]

101. Essick GK, Franze'n O, Whitsel BL, Franzen O, Whitsel BL. Discrimination and scaling of velocity of stimulus motion across the skin. Somatosens Mot Res 6: 21-40, 1988. [PubMed: 3242342]

102. Essick GK, Whitsel BL. Assessment of the capacity of human subjects and S-I neurons to distinguish opposing directions of stimulus motion across the skin. Brain Res Rev 10: 187-212, 1985.

103. Etzel JA, Gazzola V, Keysers C, Rotte M, Drescher D. Testing simulation theory with crossmodal multivariate classification of fMRI data. PLoS One 3: e3690, 2008. [PubMed: 18997869]

104. Felleman DJ, Van Essen DC. Distributed hierarchical processing in the primate cerebral cortex. Cereb Cortex 1: 1-47, 1991. [PubMed: 1822724]

105. Fitzgerald PJ, Lane JW, Thakur PH, Hsiao SS. Receptive field properties of the macaque second somatosensory cortex: Evidence for multiple functional representations. J Neurosci 24: 1119311204, 2004. [PubMed: 15590936]

106. Fitzgerald PJ, Lane JW, Thakur PH, Hsiao SS. Receptive field (RF) properties of the macaque second somatosensory cortex: RF size, shape, and somatotopic organization. J Neurosci 26: 6485-6495, 2006. [PubMed: 16775136]

107. Fitzgerald PJ, Lane JW, Thakur PH, Hsiao SS. Receptive field properties of the macaque second somatosensory cortex: Representation of orientation on different finger pads. J Neurosci 26: 6473-6484, 2006. [PubMed: 16775135]

108. Flesher SN, Collinger JL, Foldes ST, Weiss JM, Downey JE, Tyler Kabara EC, Bensmaia SJ, Schwartz AB, Boninger ML, Gaunt RA. Intracortical microstimulation of human somatosensory cortex. Sci Transl Med 8: 361ra141, 2016.

109. Fogassi L, Luppino G. Motor functions of the parietal lobe. Curr Opin Neurobiol 15: 626-631, 2005. [PubMed: 16271458]

110. Fortier-Poisson P, Langlais JS, Smith AM. Correlation of fingertip shear force direction with somatosensory cortical activity in monkey. J Neurophysiol 115: 100-111, 2016. [PubMed: 26467520]

111. Fortier-Poisson P, Smith AM. Neuronal activity in somatosensory cortex related to tactile exploration. J Neurophysiol 115: 112-126, 2016. [PubMed: 26467519]

112. Freeman AW, Johnson KO. A model accounting for effects of vibratory amplitude on responses of cutaneous mechanoreceptors in macaque monkey. J Physiol 323: 43-64, 1982. [PubMed: 7097579]

113. Freeman AW, Johnson KO. Cutaneous mechanoreceptors in macaque monkey: Temporal discharge patterns evoked by vibration, and a receptor model. J Physiol 323: 21-41, 1982. [PubMed: 7097573]

114. Freund HJ. The parietal lobe as a sensorimotor interface: A perspective from clinical and neuroimaging data. Neuroimage 14: S142-S146, 2001. [PubMed: 11373146]

115. Friedman DP, Jones EG. Thalamic input to areas 3a and 2 in monkeys. J Neurophysiol 45: 59-85, 1981. [PubMed: 7205345] 
116. Friedman DP, Murray EA. Thalamic connectivity of the second somatosensory area and neighboring somatosensory fields of the lateral sulcus of the macaque. J Comp Neurol 252: 348373, 1986. [PubMed: 3793981]

117. Friedman DP, Murray EA, O’Neill JB, Mishkin M. Cortical connections of the somatosensory fields of the lateral sulcus of macaques: Evidence for a corticolimbic pathway for touch. J Comp Neurol 252: 323-347, 1986. [PubMed: 3793980]

118. Friedman RM, Chen LM, Roe AW. Modality maps within primate somatosensory cortex. Proc Natl Acad Sci U S A 101: 12724-12729, 2004. [PubMed: 15308779]

119. Friedman RM, Chen LM, Roe AW. Responses of areas $3 b$ and 1 in anesthetized squirrel monkeys to single- and dual-site stimulation of the digits. J Neurophysiol 100: 3185-3196, 2008. [PubMed: 18922955]

120. Fries P, Reynolds JH, Rorie AE, Desimone R. Modulation of oscillatory neuronal synchronization by selective visual attention. Science 291: 1560-1563, 2001. [PubMed: 11222864]

121. Frohlich PF, Meston CM. Tactile sensitivity in women with sexual arousal disorder. Arch Sex Behav 34: 207-217, 2005. [PubMed: 15803254]

122. Fyffe RE, Cheema SS, Rustioni A. Intracellular staining study of the feline cuneate nucleus. I. Terminal patterns of primary afferent fibers. J Neurophysiol 56: 1268-1283, 1986. [PubMed: 3794769]

123. Gardner EP. Dorsal and ventral streams in the sense of touch. Senses A Compr Ref 6: 233-258, 2010.

124. Gardner EP, Babu KS, Reitzen SD, Ghosh S, Brown AS, Chen J, Hall AL, Herzlinger MD, Kohlenstein JB, Ro JY. Neurophysiology of prehension. I. Posterior parietal cortex and objectoriented hand behaviors. J Neurophysiol 97: 387-406, 2007. [PubMed: 16971679]

125. Gardner EP, Costanzo RM. Temporal integration of multiple-point stimuli in primary somatosensory cortical receptive fields of alert monkeys. J Neurophysiol 43: 444-468, 1980. [PubMed: 6770054]

126. Gardner EP, Costanzo RM. Neuronal mechanisms underlying direction sensitivity of somatosensory cortical neurons in awake monkeys. J Neurophysiol 43: 1342-1354, 1980. [PubMed: 6768850]

127. Gardner EP, Costanzo RM. Properties of kinesthetic neurons in somatosensory cortex of awake monkeys. Brain Res 214: 301-319, 1981. [PubMed: 7237173]

128. Gardner EP, Debowy DJ, Ro JY, Ghosh S, Srinivasa Babu K. Sensory monitoring of prehension in the parietal lobe: A study using digital video. Behav Brain Res 135: 213-224, 2002. [PubMed: 12356452]

129. Gardner EP, Ro JY, Debowy D, Ghosh S. Facilitation of neuronal activity in somatosensory and posterior parietal cortex during prehension. Exp Brain Res 127: 329-354, 1999. [PubMed: 10480270]

130. Garraghty PE, Florence SL, Kaas JH. Ablations of areas 3a and 3b of monkey somatosensory cortex abolish cutaneous responsivity in area 1. Brain Res 528: 165-169, 1990. [PubMed: 2245335]

131. Garraghty PE, Florence SL, Tenhula WN, Kaas JH. Parallel thalamic activation of the first and second somatosensory areas in prosimian primates and tree shrews. J Comp Neurol 311: 289299, 1991. [PubMed: 1753020]

132. Garraghty PE, Pons TP, Kaas JH. Ablations of areas 3b (SI proper) and 3a of somatosensory cortex in marmosets deactivate the second and parietal ventral somatosensory areas. Somat Mot Res 7: 125-135, 1990.

133. Garraghty PE, Pons TP, Sur M, Kaas JH. The arbors of axons terminating in middle cortical layers of somatosensory area 3b in owl monkeys. Somatosens Mot Res 6: 401-411, 1989. [PubMed: 2756803]

134. Gazzola V, Spezio ML, Etzel JA, Castelli F, Adolphs R, Keysers C. Primary somatosensory cortex discriminates affective significance in social touch. Proc Natl Acad Sci U S A 109: 10, 2012.

135. Geyer S, Schleicher A, Zilles K. Areas 3a, 3b, and 1 of human primary somatosensory cortex. Neuroimage 10: 63-83, 1999. [PubMed: 10385582] 
136. Geyer S, Schormann T, Mohlberg H, Zilles K. Areas 3a, 3b, and 1 of human primary somatosensory cortex. Part 2. Spatial normalization to standard anatomical space. Neuroimage 11: 684-696, 2000. [PubMed: 10860796]

137. Gharbawie OA, Stepniewska I, Kaas JH. Cortical connections of functional zones in posterior parietal cortex and frontal cortex motor regions in new world monkeys. Cereb Cortex 21: 19812002, 2011. [PubMed: 21263034]

138. Gharbawie OA, Stepniewska I, Qi H-X, Kaas JH. Multiple parietal- frontal pathways mediate grasping in macaque monkeys. J Neurosci 31: 11660-11677, 2011. [PubMed: 21832196]

139. Ghez C, Gordon J, Ghilardi MF, Sainburg R. Contributions of Vision and Proprioception to Accuracy in Limb Movements The MIT Press, Cambridge, MA, US, 1995.

140. Goldring AB, Cooke DF, Baldwin MKL, Recanzone GH, Gordon AG, Pan T, Simon SI, Krubitzer LA. Reversible deactivation of higher-order posterior parietal areas. II. Alterations in response properties of neurons in areas 1 and 2. J Neurophysiol 112: 2545-2560, 2014. [PubMed: 25143537]

141. Goodman JM, Bensmaia SJ. A variation code accounts for the perceived roughness of coarsely textured surfaces. Sci Rep 7: 46699, 2017. [PubMed: 28440308]

142. Goodwin AW, Wheat HE. How is tactile information affected by parameters of the population such as non-uniform fiber sensitivity, innervation geometry and response variability? Behav Brain Res 135: 5-10, 2002. [PubMed: 12356427]

143. Grefkes C, Fink GR. The functional organization of the intraparietal sulcus in humans and monkeys. J Anat 207: 3-17, 2005. [PubMed: 16011542]

144. Gregoriou GG, Borra E, Matelli M, Luppino G. Architectonic organization of the inferior parietal convexity of the macaque monkey. J Comp Neurol 496: 422-451, 2006. [PubMed: 16566007]

145. Grigg P, Greenspan BJ. Response of primate joint afferent neurons to mechanical stimulation of knee joint. J Neurophysiol 40: 1-8, 1977. [PubMed: 401873]

146. Guest S, Catmur C, Lloyd D, Spence C. Audiotactile interactions in roughness perception. Exp Brain Res 146: 161-171, 2002. [PubMed: 12195518]

147. Hansen EW. The development of maternal and infant behavior in the rhesus monkey. Behaviour 27: 107-148, 1966. [PubMed: 4957207]

148. Harlow HF. The nature of love. Am Psychol 13: 673-685, 1958.

149. Harvey MA, Saal HP, Dammann JF, III, Bensmaia SJ, Dammann JF. Multiplexing stimulus information through rate and temporal codes in primate somatosensory cortex. PLoS Biol 11: e1001558, 2013. [PubMed: 23667327]

150. Hayward V, Terekhov AV, Wong S, Geborek P, Bengtsson F, Jo“rntell H. Spatio-temporal skin strain distributions evoke low variability spike responses in cuneate neurons. J R Soc Interface 11: 20131015, 2014.

151. Herna'ndez A, Na'cher V, Luna R, Zainos A, Lemus L, Alvarez M, Va'zquez Y, Camarillo L, Romo R. Decoding a perceptual decision process across cortex. Neuron 66: 300-314, 2010. [PubMed: 20435005]

152. Herna'ndez A, Zainos A, Romo R. Neuronal correlates of sensory dis- crimination in the somatosensory cortex. Proc Natl Acad Sci U S A 97: 6191-6196, 2000. [PubMed: 10811922]

153. Hertenstein M The communicative functions of touch in adulthood. In: Hertenstein MJ, Weiss SJ, editors. The Handbook of Touch: Neuroscience, Behavioral, and Health Perspectives New York, USA: Springer, 2011, pp. 299-327.

154. Hihara S, Taoka M, Tanaka M, Iriki A. Visual responsiveness of neurons in the secondary somatosensory area and its surrounding parietal operculum regions in awake macaque monkeys. Cereb Cortex 25: 4535-4550, 2015. [PubMed: 25962920]

155. Hollins M, Risner SR. Evidence for the duplex theory of tactile texture perception. Percept Psychophys 62: 695-705, 2000. [PubMed: 10883578]

156. Hsiao SS. Central mechanisms of tactile shape perception. Curr Opin Neurobiol 18: 418-424, 2008. [PubMed: 18809491]

157. Hsiao SS, O'Shaughnessy DM, Johnson KO. Effects of selective attention on spatial form processing in monkey primary and secondary somatosensory cortex. J Neurophysiol 70: 444 447, 1993. [PubMed: 8360721] 
158. Huerta MF, Pons TP. Primary motor cortex receives input from area 3a in macaques. Brain Res 537: 367-371, 1990. [PubMed: 2085789]

159. Huffman KJ, Krubitzer LA. Area 3a: Topographic organization and cortical connections in marmoset monkeys. Cereb Cortex 11: 849-867, 2001. [PubMed: 11532890]

160. Hulliger M The mammalian muscle spindle and its central control. Rev Physiol Biochem Pharmacol 101: 1-110, 1984. [PubMed: 6240757]

161. Hummelsheim H, Wiesendanger R, Wiesendanger M, Bianchetti M. The projection of lowthreshold muscle afferents of the forelimb to the main and external cuneate nuclei of the monkey. Neuroscience 16: 979-987, 1985. [PubMed: 4094698]

162. Hwang EJ, Hauschild M, Wilke M, Andersen RA. Inactivation of the parietal reach region causes optic ataxia, impairing reaches but not saccades. Neuron 76: 1021-1029, 2012. [PubMed: 23217749]

163. Hyva"rinen J. Regional distribution of functions in parietal association area 7 of the monkey. Brain Res 206: 287-303, 1981. [PubMed: 7214136]

164. Hyvärinen J. Posterior parietal lobe of the primate brain. Physiol Rev 62: 1060-1129, 1982. [PubMed: 6806834]

165. Hyva rinen J, Poranen A. Receptive field integration and submodality convergence in the hand area of the post-central gyrus of the alert monkey. J Physiol 283: 539-556, 1978. [PubMed: 102768]

166. Hyva“rinen J, Poranen A. Movement-sensitive and direction and orientation-selective cutaneous receptive fields in the hand area of the post-central gyrus in monkeys. J Physiol 283: 523-537, 1978. [PubMed: 102767]

167. Hyva“rinen J,Poranen A, Jokinen Y. Influence of attentive behavior on neuronal responses to vibration in primary somatosensory cortex of the monkey. J Neurophysiol 43: 870-882, 1980. [PubMed: 6766999]

168. Iriki A, Tanaka M, Iwamura Y. Attention-induced neuronal activity in the monkey somatosensory cortex revealed by pupillometrics. Neurosci Res 25: 173-181, 1996. [PubMed: 8829154]

169. Iwamura Y Hierarchical somatosensory processing. Curr Opin Neurobiol 8: 522-528, 1998. [PubMed: 9751655]

170. Iwamura Y, Iriki A, Tanaka M. Bilateral hand representation in the postcentral somatosensory cortex. Nature 369: 554-556, 1994. [PubMed: 8202155]

171. Iwamura Y, Tanaka M. Postcentral neurons in hand region of area 2: Their possible role in the form discrimination of tactile objects. Brain Res 150: 662-666, 1978. [PubMed: 98206]

172. Iwamura Y, Tanaka M, Sakamoto M, Hikosaka O. Converging patterns of finger representation and complex response properties of neurons in area 1 of the first somatosensory cortex of the conscious monkey. Exp Brain Res 51: 327-337, 1983.

173. Iwamura Y, Tanaka M, Sakamoto M, Hikosaka O. Functional subdivisions representing different finger regions in area 3 of the first somatosensory cortex of the conscious monkey. Exp Brain Res 51: 569-576, 1983.

174. Iwamura Y, Tanaka M, Sakamoto M, Hikosaka O. Diversity in receptive field properties of vertical neuronal arrays in the crown of the postcentral gyrus of the conscious monkey. Exp Brain Res 58: 400-411, 1985. [PubMed: 3996503]

175. Iwamura Y, Tanaka M, Sakamoto M, Hikosaka O. Vertical neuronal arrays in the postcentral gyrus signaling active touch: A receptive field study in the conscious monkey. Exp Brain Res 58: 412-420, 1985. [PubMed: 3996504]

176. Iwamura Y, Tanaka M, Sakamoto M, Hikosaka O. Rostrocaudal gradients in the neuronal receptive field complexity in the finger region of the alert monkey's postcentral gyrus. Exp Brain Res 92: 360-368, 1993. [PubMed: 8454001]

177. Jain N, Catania KC, Kaas JH. Deactivation and reactivation of somatosensory cortex after dorsal spinal cord injury. Nature 386: 495-498, 1997. [PubMed: 9087408]

178. Jain N, Catania KC, Kaas JH. A histologically visible representation of the fingers and palm in primate area $3 \mathrm{~b}$ and its immutability following long-term deafferentations. Cereb Cortex 8: 227236, 1998. [PubMed: 9617917] 
179. Jain N, Florence SL, Kaas JH. Reorganization of Somatosensory cortex after nerve and spinal cord injury. News Physiol Sci 13: 143-149, 1998. [PubMed: 11390778]

180. Jeannerod M, Arbib MA, Rizzolatti G, Sakata H. Grasping objects: The cortical mechanisms of visuomotor transformation. Trends Neurosci 18: 314-320, 1995. [PubMed: 7571012]

181. Jiang W, Tremblay F, Chapman CE. Neuronal encoding of texture changes in the primary and the secondary somatosensory cortical areas of monkeys during passive texture discrimination. $\mathrm{J}$ Neurophysiol 77: 1656-1662, 1997. [PubMed: 9084631]

182. Johansson RS. Tactile sensibility in the human hand: Receptive field characteristics of mechanoreceptive units in the glabrous skin area. J Physiol 281: 101-125, 1978. [PubMed: 702358]

183. Johansson RS, Flanagan JR. Somatosensation. In: Gardner E, Kaas JH, editors. The Senses: A Comprehensive Reference San Diego: Academic Press, 2008, pp. 67-86.

184. Johansson RS, Flanagan JR. Coding and use of tactile signals from the fingertips in object manipulation tasks. Nat Rev Neurosci 10: 345-359, 2009. [PubMed: 19352402]

185. Johansson RS, Landstro“m U, Lundstro“m R. Sensitivity to edges of mechanoreceptive afferent units innervating the glabrous skin of the human head. Brain Res 244: 27-235, 1982. [PubMed: 6288181]

186. Johansson RS, Landstr"om U, Lundstrom R, Landstrom U. Responses of mechanoreceptive afferent units in the glabrous skin of the human hand to sinusoidal skin displacements. Brain Res 244: 17-25, 1982. [PubMed: 6288178]

187. Johansson RS, Vallbo AB. Tactile sensibility in the human hand: Relative and absolute densities of four types of mechanoreceptive units in glabrous skin. J Physiol 286: 283-300, 1979. [PubMed: 439026]

188. Johansson RS, Vallbo AB. Spatial properties of the population of mechanoreceptive units in the glabrous skin of the human hand. Brain Res 184: 353-366, 1980. [PubMed: 7353161]

189. Johnson KO. The roles and functions of cutaneous mechanoreceptors. Curr Opin Neurobiol 11: 455-461, 2001. [PubMed: 11502392]

190. Johnson KO, Lamb GD. Neural mechanisms of spatial tactile discrimination: Neural patterns evoked by braille-like dot patterns in the monkey. J Physiol 310: 117-144, 1981. [PubMed: 7230030]

191. Johnson LA, Wander JD, Sarma D, Su DK, Fetz EE, Ojemann JG. Direct electrical stimulation of the somatosensory cortex in humans using electrocorticography electrodes: A qualitative and quantitative report. J Neural Eng 10: 36021, 2013.

192. Jones EG. Lamination and differential distribution of thalamic afferents within the sensory-motor cortex of the squirrel monkey. J Comp Neurol 160: 167-203, 1975. [PubMed: 803517]

193. Jones EG. Lack of collateral thalamocortical projections to fields of the first somatic sensory cortex in monkeys. Exp Brain Res 52: 375-384, 1983. [PubMed: 6653699]

194. Jones EG, Coulter JD, Hendry SHC. Intracortical connectivity of archi- tectonic fields in the somatic sensory, motor and parietal cortex of monkeys. J Comp Neurol 181: 291-347, 1978. [PubMed: 99458]

195. Jones EG, Friedman DP. Projection pattern of functional components of thalamic ventrobasal complex on monkey somatosensory cortex. J Neurophysiol 48: 521-544, 1982. [PubMed: 7119861]

196. Jo“rntell H,Bengtsson F, Geborek P, Spanne A, Terekhov AV, Hayward V. Segregation of tactile input features in neurons of the cuneate nucleus. Neuron 83: 1-15, 2014. [PubMed: 24991948]

197. Kaas JH. What, if anything, is SI? Organization of first somatosensory area of cortex. Physiol Rev 63: 206-231, 1983. [PubMed: 6401864]

198. Kaas JH, Gharbawie OA, Stepniewska I. The organization and evolution of dorsal stream multisensory motor pathways in primates. Front Neuroanat 5: 34, 2011. [PubMed: 21716641]

199. Kaas JH, Nelson RJ, Sur M, Lin CS, Merzenich MM. Multiple representations of the body within the primary somatosensory cortex of primates. Science 204: 521-523, 1979. [PubMed: 107591]

200. Kalaska JF, Caminiti R, Georgopoulos AP. Cortical mechanisms related to the direction of twodimensional arm movements: Relations in parietal area 5 and comparison with motor cortex. Exp Brain Res 51: 247-260, 1983. [PubMed: 6617794] 
201. Kalaska JF, Cohen DAD, Prud'homme M, Hyde ML. Parietal area 5 neuronal activity encodes movement kinematics, not movement dynamics. Exp Brain Res 80: 351-364, 1990. [PubMed: 2113482]

202. Kalaska JF, Scott SH, Cisek P, Sergio LE. Cortical control of reaching movements. Curr Opin Neurobiol 7: 849-859, 1997. [PubMed: 9464979]

203. Keysers C, Kaas JH, Gazzola V. Somatosensation in social perception. Nat Rev Neurosci 11: 417-428, 2010. [PubMed: 20445542]

204. Kim JH, Greenspan JD, Coghill RC, Ohara S, Lenz FA. Lesions limited to the human thalamic principal somatosensory nucleus (ventral caudal) are associated with loss of cold sensations and central pain. J Neurosci 27: 4995-5004, 2007. [PubMed: 17475808]

205. Kim S, Callier T, Tabot GA, Gaunt RA, Tenore FV, Bensmaia SJ. Behavioral assessment of sensitivity to intracortical microstimulation of primate somatosensory cortex. Proc Natl Acad Sci 112: 15202-15207, 2015. [PubMed: 26504211]

206. Kim SS, Gomez-Ramirez M, Thakur PH, Hsiao SS. Multimodal interactions between proprioceptive and cutaneous signals in primary somatosensory cortex. Neuron 86(2): 555-566, 2015. doi: 10.1016/j.neuron.2015.03.020. [PubMed: 25864632]

207. Klaes C, Shi Y, Kellis S, Minxha J, Revechkis B, Andersen RA. A cognitive neuroprosthetic that uses cortical stimulation for somatosensory feedback. J Neural Eng 11: 56024, 2014.

208. Klocker A, Arnould C, Penta M, Thonnard J-L. Rasch-built measure of pleasant touch through active fingertip explorations. Front Neurorobot 6: 1-9, 2012. [PubMed: 22393319]

209. Klo“cker A,Wiertlewski M, The'ate V Hayward V, Thonnard J-L. Physical factors influencing pleasant touch during tactile exploration. PLoS One 8: e79085, 2013. [PubMed: 24244425]

210. Knibesto“1 M. Stimulus-response functions of rapidly adapting mechanoreceptors in human glabrous skin area. J Physiol 232: 427-452, 1973. [PubMed: 4759677]

211. Knibesto"1 M. Stimulus-response functions of slowly adapting mechanoreceptors in the human glabrous skin area. J Physiol 245: 63-80, 1975. [PubMed: 1127614]

212. Krubitzer LA, Baldwin MKL. Revisiting Kaas and colleagues-The homunculus: The discovery of multiple representations within the "primary" somatosensory cortex. In: Kolb B, Whishaw I, editors. Revisiting the Classic Studies in Behavioral Neuroscience Los Angeles: Sage, 2017, pp. $33-54$.

213. Krubitzer LA, Calford MB. Five topographically organized fields in the somatosensory cortex of the flying fox: Microelectrode maps, myeloarchitecture, and cortical modules. J Comp Neurol 317: 1-30, 1992. [PubMed: 1573055]

214. Krubitzer LA, Clarey J, Tweedale R, Elston G, Calford MB. A redefinition of somatosensory areas in the lateral sulcus of macaque monkeys. J Neurosci 15: 3821-3839, 1995. [PubMed: 7751949]

215. Krubitzer LA, Huffman KJ, Disbrow E, Recanzone G. Organization of area 3a in macaque monkeys: Contributions to the cortical phenotype. J Comp Neurol 471: 97-111, 2004. [PubMed: 14983479]

216. Krubitzer LA, Kaas JH. The organization and connections of somatosensory cortex in marmosets. J Neurosci 10: 952-974, 1990. [PubMed: 2108231]

217. Krubitzer LA, Kaas JH. The somatosensory thalamus of monkeys: Cortical connections and a redefinition of nuclei in marmosets. J Comp Neurol 319: 123-140, 1992. [PubMed: 1375605]

218. de Lafuente V, Romo R. Neural correlate of subjective sensory experience gradually builds up across cortical areas. Proc Natl Acad Sci U S A 103: 14266-14271, 2006. [PubMed: 16924098]

219. Lederman SJ. Tactile roughness of grooved surfaces: The touching process and effects of macro and microsurface structure. Percept Psy chophys 16: 385-395, 1974.

220. Lederman SJ. Tactual roughness perception: Spatial and temporal determinants. Can J Psychol 37: 498-511, 1983.

221. Lederman SJ, Klatzky RL. Hand movements: A window into haptic object recognition. Cogn Psychol 19: 342-368, 1987. [PubMed: 3608405]

222. Lederman SJ, Taylor MM. Fingertip force, surface geometry, and the perception of roughness by active touch. Percept Psychophys 12: 401-408, 1972. 
223. Leinonen L, Hyva rinen J, Nyman G, Linnankoski I, I. Functional properties of neurons in lateral part of associative area 7 in awake monkeys. Exp Brain Res 34: 299-320, 1979. [PubMed: 105918]

224. Leinonen L, Nyman G, II. Functional properties of cells in anterolateral part of area 7 associative face area of awake monkeys. Exp Brain Res 34: 321-333, 1979. [PubMed: 105919]

225. Lenz FA, Seike M, Lin YC, Baker FH, Rowland LH, Gracely RH, Richardson RT. Neurons in the area of human thalamic nucleus ventralis caudalis respond to painful heat stimuli. Brain Res 623: 235-240, 1993. [PubMed: 8221105]

226. Lewis JW, Van Essen DC. Mapping of architectonic subdivisions in the macaque monkey, with emphasis on parieto-occipital cortex. J Comp Neurol 428: 79-111, 2000. [PubMed: 11058226]

227. Lewis JW, Van Essen DC. Corticocortical connections of visual, sensorimotor, and multimodal processing areas in the parietal lobe of the macaque monkey. J Comp Neurol 428: 112-137, 2000. [PubMed: 11058227]

228. Liu XB, Honda CN, Jones EG. Distribution of four types of synapse on physiologically identified relay neurons in the ventral posterior thalamic nucleus of the cat. J Comp Neurol 352: 69-91, 1995. [PubMed: 7714240]

229. Lo"ken LS, Wessberg J, Morrison I, McGlone F, Olausson H. Coding of pleasant touch by unmyelinated afferents in humans. Nat Neurosci 12: 547-548, 2009. [PubMed: 19363489]

230. London BM, Jordan LR, Jackson CR, Miller LE. Electrical stimulation of the proprioceptive cortex (area 3a) used to instruct a behaving monkey. IEEE Trans Neural Syst Rehabil Eng 16: 32-36, 2008. [PubMed: 18303803]

231. London BM, Miller LE. Responses of somatosensory area 2 neurons to actively and passively generated limb movements. J Neurophysiol 109: 1505-1513, 2013. [PubMed: 23274308]

232. Luck SJ, Chelazzi L, Hillyard SA, Desimone R. Neural mechanisms of spatial selective attention in areas V1, V2, and V4 of macaque visual cortex. J Neurophysiol 77: 24-42, 1997. [PubMed: 9120566]

233. Mackevicius EL, Best MD, Saal HP, Bensmaia SJ. Millisecond precision spike timing shapes tactile perception. J Neurosci 32: 15309-15317, 2012. [PubMed: 23115169]

234. Makous JC, Friedman RM, Vierck CJ. Effects of a dorsal column lesion on temporal processing within the somatosensory system of primates. Exp Brain Res 112: 253-267, 1996. [PubMed: 8951394]

235. Manfredi LR, Saal HP, Brown KJ, Zielinski MC, Dammann JF, Polashock VS, Bensmaia SJ. Natural scenes in tactile texture. J Neuro- physiol 111: 1792-1802, 2014.

236. Marasco PD, Kim K, Colgate JE, Peshkin MA, Kuiken TA. Robotic touch shifts perception of embodiment to a prosthesis in targeted rein- nervation amputees. Brain 134: 747-758, 2011. [PubMed: 21252109]

237. Marconi B, Genovesio A, Battaglia-Mayer A, Ferraina S, Squatrito S, Molinari M, Lacquaniti F, Caminiti R. Eye-hand coordination during reaching. I. Anatomical relationships between parietal and frontal cortex. Cereb Cortex 11: 513-527, 2001. [PubMed: 11375913]

238. Matthews BH. Nerve endings in mammalian muscle. J Physiol 78: 1-53, 1933. [PubMed: 16994401]

239. Maunsell JHR, Cook EP. The role of attention in visual processing. Philos Trans R Soc B Biol Sci 357: 1063-1072, 2002.

240. Mcglone F, Olausson H, Boyle JA, Jones-Gotman M, Dancer C, Guest S, Essick GK. Touching and feeling: Differences in pleasant touch processing between glabrous and hairy skin in humans. Eur J Neurosci 35: 1782-1788, 2012. [PubMed: 22594914]

241. McGlone F, Reilly D. The cutaneous sensory system. Neurosci Biobe- hav Rev 34: 148-159, 2010.

242. Meftah E-M, Belingard L, Chapman CE. Relative effects of the spatial and temporal characteristics of scanned surfaces on human perception of tactile roughness using passive touch. Exp brain Res 132: 351-361, 2000. [PubMed: 10883383]

243. Meftah E-M, Bourgeon S, Chapman CE. Instructed delay discharge in primary and secondary somatosensory cortex within the context of a selective attention task. J Neurophysiol 101: 26492667, 2009. [PubMed: 19225170] 
244. Meftah E-M, Shenasa J, Chapman CE. Effects of a cross-modal manipulation of attention on somatosensory cortical neuronal responses to tactile stimuli in the monkey. J Neurophysiol 88 : 3133-3149, 2002. [PubMed: 12466436]

245. Mima T, Nagamine T, Nakamura K, Shibasaki H. Attention modulates both primary and second somatosensory cortical activities in humans: A magnetoencephalographic study. J Neurophysiol 80: 2215-2221, 1998. [PubMed: 9772274]

246. Mishkin M Analogous neural models for tactual and visual learning. Neuropsychologia 17: 139151, 1979. [PubMed: 111155]

247. Moran J, Desimone R. Selective attention gates visual processing in the extrastriate cortex. Science 229: 782-784, 1985. [PubMed: 4023713]

248. Morrison I, Bjo“rnsdotter M, Olausson H. Vicarious responses to social touch in posterior insular cortex are tuned to pleasant caressing speeds. J Neurosci 31: 9554-9562, 2011. [PubMed: 21715620]

249. Mountcastle VB. Central nervous mechanisms in mechanoreceptive sensibility. In: Comprehensive Physiology Hoboken, NJ, USA: John Wiley \& Sons, Inc, 2011, pp. 33-89.

250. Mountcastle VB, Lynch JC, Georgopoulos A, Sakata H, Acun a C. Posterior parietal association cortex of the monkey: Command functions for operations within extrapersonal space. $\mathrm{J}$ Neurophysiol 38: 871-908, 1975. [PubMed: 808592]

251. Mountcastle VB, Talbot WH, Sakata H, Hyvärinen J. Cortical neuronal mechanisms in fluttervibration studied in unanesthetized monkeys. Neuronal periodicity and frequency discrimination. J Neurophysiol 32: 452-484, 1969. [PubMed: 4977839]

252. Muniak MA, Ray S, Hsiao SS, Dammann JF, Bensmaia SJ. The neural coding of stimulus intensity: linking the population response of mechanoreceptive afferents with psychophysical behavior. J Neurosci 27: 11687-11699, 2007. [PubMed: 17959811]

253. Murata A, Gallese V, Luppino G, Kaseda M, Sakata H. Selectivity for the shape, size, and orientation of objects for grasping in neurons of monkey parietal area AIP. J Neurophysiol 83: 2580-2601, 2000. [PubMed: 10805659]

254. Murray EA, Mishkin M. Relative contributions of SII and area 5 to tactile discrimination in monkeys. Behav Brain Res 11: 67-83, 1984. [PubMed: 6696789]

255. Murray JD, Bernacchia A, Freedman DJ, Romo R, Wallis JD, Cai X, Padoa-Schioppa C, Pasternak T, Seo H, Lee D, Wang X-J. A hierarchy of intrinsic timescales across primate cortex. Nat Neurosci 17: 1661-1663, 2014. [PubMed: 25383900]

256. Murthy VN, Fetz EE. Coherent 25- to 35-Hz oscillations in the sensorimotor cortex of awake behaving monkeys. Proc Natl Acad Sci U S A 89: 5670-5674, 1992. [PubMed: 1608977]

257. Nakatani M, Maksimovic S, Baba Y, Lumpkin EA. Mechanotransduction in epidermal Merkel cells. Pflugers Arch 467(1): 101-108, 2015. doi: 10.1007/s00424-014-1569-0. [PubMed: 25053537]

258. Neal JW, Pearson RC, Powell TPS. The cortico-cortical connections of area-7b, PF, in the parietal lobe of the monkey. Brain Res 419: 341-346, 1987. [PubMed: 2445426]

259. Neal JW, Pearson RCA, Powell TPS. The ipsilateral cortico-cortical connections of area 7b, PF, in the parietal and temporal lobes of the monkey. Brain Res 524: 119-132, 1990. [PubMed: 1698108]

260. Nelson RJ. Activity of monkey primary somatosensory cortical neurons changes prior to active movement. Brain Res 406: 402-407, 1987. [PubMed: 3567637]

261. Nelson RJ, Sur M, Felleman DJ, Kaas JH. Representations of the body surface in postcentral parietal cortex of Macaca fascicularis. J Comp Neurol 192: 611-643, 1980. [PubMed: 7419747]

262. Newman HF. Vibratory sensitivity of the penis. Fertil Steril 21: 791-793, 1970. [PubMed: 5474221]

263. Niu J, Ding L, Li J, Kim H, Liu J, Li H, Moberly A, Badea T, Duncan I, Son Y-J, Scherer S, Luo W. Modality-based organization of ascending somatosensory axons in the direct dorsal column pathway. J Neurosci 33: 17691-17709, 2013. [PubMed: 24198362]

264. Nolano M, Provitera V, Crisci C, Stancanelli A, Wendelschafer-Crabb G, Kennedy WR, Santoro L. Quantification of myelinated endings and mechanoreceptors in human digital skin. Ann Neurol 54: 197-205, 2003. [PubMed: 12891672] 
265. Olausson H, Cole J, Rylander K, McGlone F, Lamarre Y, Wallin BG, Kra“mer H, Wessberg J, Elam M, Bushnell MC, Vallbo AB. Functional role of unmyelinated tactile afferents in human hairy skin: Sympathetic response and perceptual localization. Exp Brain Res 184: 135-140, 2008. [PubMed: 17962926]

266. Olausson H, Lamarre Y, Backlund H, Morin C, Wallin BGG, Starck G, Ekholm S, Strigo I, Worsley K, Vallbo AB, Bushnell MCC. Unmyelinated tactile afferents signal touch and project to insular cortex. Nat Neurosci 5: 900-904, 2002. [PubMed: 12145636]

267. Olshausen BA, Field DJ. Emergence of simple-cell receptive field properties by learning a sparse code for natural images. Nature 381: 607-609, 1996. [PubMed: 8637596]

268. Pack CC, Bensmaia SJ. Seeing and feeling motion: Canonical computations in vision and touch. PLOS Biol 13: e1002271, 2015. [PubMed: 26418156]

269. Padberg J, Cerkevich C, Engle J, Rajan AT, Recanzone G, Kaas JH, Krubitzer LA. Thalamocortical connections of parietal somatosensory cortical fields in macaque monkeys are highly divergent and convergent. Cereb Cortex 19: 2038-2064, 2009. [PubMed: 19221145]

270. Padberg J, Recanzone G, Engle J, Cooke D, Goldring A, Krubitzer LA. Lesions in posterior parietal area 5 in monkeys result in rapid behavioral and cortical plasticity. J Neurosci 30: 1291812935, 2010. [PubMed: 20881111]

271. Pandya DN, Seltzer B. Intrinsic connections and architectonics of posterior parietal cortex in the rhesus monkey. J Comp Neurol 204: 196-210, 1982. [PubMed: 6276450]

272. Pearson RCA, Brodal P, Powell TPS. The projection of the thalamus upon the parietal lobe in the monkey. Brain Res 144: 143-148, 1978. [PubMed: 76498]

273. Pearson RCA, Powell TPS. The projection of the primary somatic sensory cortex upon area 5 in the monkey. Brain Res Rev 9: 89-107, 1985.

274. Pei Y-C, Denchev PV, Hsiao SS, Craig JC, Bensmaia SJ. Convergence of submodality-specific input onto neurons in primary somatosensory cortex. J Neurophysiol 102: 1843-1853, 2009. [PubMed: 19535484]

275. Pei Y-C, Hsiao SS, Bensmaia SJ. The tactile integration of local motion cues is analogous to its visual counterpart. Proc Natl Acad Sci U S A 105: 8130-8135, 2008. [PubMed: 18524953]

276. Pei Y-C, Hsiao SS, Craig JC, Bensmaia SJ. Shape invariant coding of motion direction in somatosensory cortex. PLoS Biol 8: e1000305, 2010. [PubMed: 20126380]

277. Pei Y-C, Hsiao SS, Craig JC, Bensmaia SJ. Neural mechanisms of tactile motion integration in somatosensory cortex. Neuron 69: 536-547, 2011. [PubMed: 21315263]

278. Penfield W, Boldrey E. Somatic motor and sensory representation in the cerebral cortex of man as studied by electrical stimulation. Brain 60: 389-443, 1937.

279. Petrides M, Pandya DN. Projections to the frontal-cortex from the posterior parietal region in the rhesus-monkey. J Comp Neurol 228: 105-116, 1984. [PubMed: 6480903]

280. Phillips JR, Johansson RS, Johnson KO. Responses of human mechanoreceptive afferents to embossed dot arrays scanned across finger pad skin. J Neurosci 12: 827-839, 1992. [PubMed: 1545242]

281. Phillips JR, Johnson KO. Tactile spatial resolution. II. Neural representation of bars, edges, and gratings in monkey primary afferents. J Neurophysiol 46: 1192-1203, 1981. [PubMed: 6275041]

282. Phillips JR, Johnson KO, Hsiao SS. Spatial pattern representation and transformation in monkey somatosensory cortex. Proc Natl Acad Sci USA 85: 1317-1321, 1988. [PubMed: 3422492]

283. Pons TP, Garraghty PE, Cusick CG, Kaas JH. The somatotopic organization of area 2 in macaque monkeys. J Comp Neurol 241: 445-466, 1985. [PubMed: 4078042]

284. Pons TP, Garraghty PE, Friedman DP, Mishkin M. Physiological evidence for serial processing in somatosensory cortex. Science 237: 417-420, 1987. [PubMed: 3603028]

285. Pons TP, Garraghty PE, Mishkin M. Serial and parallel processing of tactual information in somatosensory cortex of rhesus-monkeys. J Neurophysiol 68: 518-527, 1992. [PubMed: 1527572]

286. Pons TP, Kaas JH. Corticocortical connections of area 2 of somatosensory cortex in macaque monkeys: A correlative anatomical and electro- physiological study. J Comp Neurol 248: 313335, 1986. [PubMed: 3722460] 
287. Poranen A, Hyvärinen J. Effects of attention on multiunit responses to vibration in the somatosensory regions of the monkey's brain. Elec- troencephalogr Clin Neurophysiol 53: 525$537,1982$.

288. Prud'homme MJ, Cohen DA, Kalaska JF. Tactile activity in primate primary somatosensory cortex during active arm movements: Cytoar- chitectonic distribution. J Neurophysiol 71: 173181, 1994. [PubMed: 8158227]

289. Prud'homme MJ, Kalaska JF. Proprioceptive activity in primate primary somatosensory cortex during active arm reaching movements. J Neurophysiol 72: 2280-2301, 1994. [PubMed: 7884459]

290. Pruett JR, Sinclair RJ, Burton H. Response patterns in second somatosensory cortex (SII) of awake monkeys to passively applied tactile gratings. J Neurophysiol 84, 2000.

291. Pruszynski JA, Flanagan JR, Johansson RS. Fast and accurate edge orientation processing during object manipulation. Elife 7: pii: e31200, 2017. doi: 10.1101/163790.

292. Pruszynski JA, Johansson RS. Edge-orientation processing in first-order tactile neurons. Nat Neurosci 17: 1404-1409, 2014. [PubMed: 25174006]

293. Qi H-X, Gharbawie OA, Wong P, Kaas JH. Cell-poor septa separate representations of digits in the ventroposterior nucleus of the thalamus in monkeys and prosimian galagos. J Comp Neurol 519: 738-758, 2011. [PubMed: 21246552]

294. Qi H-X, Kaas JH. Myelin stains reveal an anatomical framework for the representation of the digits in somatosensory area 3b of macaque monkeys. J Comp Neurol 477: 172-187, 2004. [PubMed: 15300788]

295. Qi H-X, Lyon DC, Kaas JH. Cortical and thalamic connections of the parietal ventral somatosensory area in marmoset monkeys (Callithrix jacchus). J Comp Neurol 443: 168-182, 2002. [PubMed: 11793354]

296. Randolph M, Semmes J. Behavioral consequences of selective subtotal ablations in the postcentral gyrus of Macaca mulatta. Brain Res 70: 55-70, 1974. [PubMed: 4207050]

297. Rasmussen AT, Peyton WT. The course and termination of the medial lemniscus in man. J Comp Neurol 88: 411-424, 1948. [PubMed: 18866776]

298. Rathelot J-A, Dum RP, Strick PL. Posterior parietal cortex contains a command apparatus for hand movements. Proc Natl Acad Sci U S A 114(16): 4255-4260, 2017. doi: 10.1073/pnas. 1608132114. [PubMed: 28373554]

299. Rathelot J-A, Strick PL. Muscle representation in the macaque motor cortex: An anatomical perspective. Proc Natl Acad Sci U S A 103: 8257-8262, 2006. [PubMed: 16702556]

300. Reed JL, Pouget P, Qi H-X, Zhou Z, Bernard MR, Burish MJ, Haitas J, Bonds a B, Kaas JH. Widespread spatial integration in primary somatosensory cortex. Proc Natl Acad Sci U S A 105: 10233-10237, 2008. [PubMed: 18632579]

301. Reed JL, Qi H-X, Kaas JH. Spatiotemporal properties of neuron response suppression in owl monkey primary somatosensory cortex when stimuli are presented to both hands. J Neurosci 31: 3589-3601, 2011. [PubMed: 21389215]

302. Reed JL, Qi H-X, Pouget P, Burish MJ, Bonds a B, Kaas JH. Modular processing in the hand representation of primate primary somatosensory cortex coexists with widespread activation. $\mathrm{J}$ Neurophysiol 104: 3136-3145, 2010. [PubMed: 20926605]

303. Reed JL, Qi H, Zhou Z, Bernard MR, Burish MJ, Bonds AB, Kaas JH. Response properties of neurons in primary somatosensory cortex of owl monkeys reflect widespread spatiotemporal integration. J Neurophysiol 103(4): 2139-2157, 2010. doi: 10.1152/jn.00709.2009. [PubMed: 20164400]

304. Richardson AG, Weigand PK, Sritharan SY, Lucas TH. A chronic neural interface to the macaque dorsal column nuclei. J Neurophysiol 115(5): 2255-2264, 2016. doi: 10.1152/jn.01083.2015. [PubMed: 26912601]

305. Rincon-Gonzalez L, Warren JP, Meller DM, Helms Tillery S. Haptic interaction of touch and proprioception: Implications for neuroprosthetics. IEEE Trans Neural Syst Rehabil Eng 19: 490 500, 2011. [PubMed: 21984518] 
306. Rinvik E, Walberg F. Studies on the cerebellar projections from the main and external cuneate nuclei in the cat by means of retrograde axonal transport of horseradish peroxidase. Brain Res 95: 371-381, 1975. [PubMed: 50867]

307. Ro T, Ellmore TM, Beauchamp MS. A neural link between feeling and hearing. Cereb Cortex 23: 1724-1730, 2013. [PubMed: 22693344]

308. Robinson CJ, Burton H. Somatotopographic organization in the second somatosensory area of M. fascicularis. J Comp Neurol 192: 43-67, 1980. [PubMed: 7410613]

309. Robinson CJ, Burton H. Somatic submodality distribution within the second somatosensory (SII), $7 \mathrm{~b}$, retroinsular, postauditory, and granular insular cortical areas of M. fascicularis. J Comp Neurol 192: 93-108, 1980. [PubMed: 7410615]

310. Robinson CJ, Burton H. Organization of somatosensory receptive fields in cortical areas $7 \mathrm{~b}$, retroinsula, postauditory and granular insula of M. fascicularis. J Comp Neurol 192: 69-92, 1980. [PubMed: 7410614]

311. Romo R, Herna'ndez A, Zainos A, Lemus L, Brody CD. Neuronal correlates of decision-making in secondary somatosensory cortex. Nat Neurosci 5: 1217-1225, 2002. [PubMed: 12368806]

312. Romo R, Herna'ndez A, Zainos A, Salinas E. Somatosensory discrimination based on cortical microstimulation. Nature 392: 387-390, 1998. [PubMed: 9537321]

313. Romo R, de Lafuente V. Conversion of sensory signals into perceptual decisions. Prog Neurobiol 103: 41-75, 2013. [PubMed: 22472964]

314. Romo R, Salinas E. Cognitive neuroscience: Flutter discrimination: Neural codes, perception, memory and decision making. Nat Rev Neurosci 4: 203-218, 2003. [PubMed: 12612633]

315. Rouiller EM, Welker E. A comparative analysis of the morphology of corticothalamic projections in mammals. Brain Res Bull 53: 727-741, 2000. [PubMed: 11179837]

316. Rowe MJ, Turman a B, Murray GM, Zhang HQ. Parallel organization of somatosensory cortical areas I and II for tactile processing. Clin Exp Pharmacol Physiol 23: 931-938, 1996. [PubMed: 8911737]

317. Rowland DL. Penile sensitivity in men: A composite of recent findings. Urology 52: 1101-1105, 1998. [PubMed: 9836563]

318. Roy A, Steinmetz PN, Hsiao SS, Johnson KO, Niebur E. Synchrony: A neural correlate of somatosensory attention. J Neurophysiol 98: 1645-1661, 2007. [PubMed: 17596415]

319. Rozzi S, Calzavara R, Belmalih A, Borra E, Gregoriou GG, Matelli M, Luppino G. Cortical connections of the inferior parietal cortical convexity of the macaque monkey. Cereb Cortex 16: 1389-1417, 2006. [PubMed: 16306322]

320. Ruben J, Schwiemann J, Deuchert M, Meyer R, Krause T, Curio G, Villringer K, Kurth R, Villringer A. Somatotopic organization of human secondary somatosensory cortex. Cerbral Cortex 11: 463-473, 2001.

321. Saal HP, Bensmaia SJ. Touch is a team effort: Interplay of submodalities in cutaneous sensibility. Trends Neurosci 2: 1-9, 2014.

322. Saal HP, Harvey MA, Bensmaia SJ. Rate and timing of cortical responses driven by separate sensory channels. Elife 4: e10450, 2015. [PubMed: 26650354]

323. Saal HP, Wang X, Bensmaia SJ. Importance of spike timing in touch: An analogy with hearing? Curr Opin Neurobiol 40: 142-149, 2016. [PubMed: 27504741]

324. Sainburg RL, Ghilardi MF, Poizner H, Ghez C. Control of limb dynamics in normal subjects and patients without proprioception. J Neuro- physiol 73: 820-835, 1995.

325. Sakata H, Takaoka Y, Kawarasaki A, Shibutani H. Somatosensory properties of neurons in the superior parietal cortex (area 5) of the rhesus monkey. Brain Res 64: 85-102, 1973. [PubMed: 4360893]

326. Salimi I, Brochier T, Smith AM. Neuronal activity in somatosensory cortex of monkeys using a precision grip. III. Responses to altered friction perturbations. J Neurophysiol 81: 845-857, 1999. [PubMed: 10036285]

327. Salimi I, Brochier T, Smith AM. Neuronal activity in somatosensory cortex of monkeys using a precision grip. I. Receptive fields and dis- charge patterns. J Neurophysiol 81: 825-834, 1999. [PubMed: 10036283] 
328. Salimi I, Brochier T, Smith AM. Neuronal activity in somatosensory cortex of monkeys using a precision grip. II. Responses to object texture and weights. J Neurophysiol 81: 835-844, 1999. [PubMed: 10036284]

329. Salinas E, Hernandez A, Zainos A, Romo R, Hernández A. Periodicity and firing rate as candidate neural codes for the frequency of vibrotactile stimuli. J Neurosci 20: 5503-5515, 2000. [PubMed: 10884334]

330. Sa'nchez-Panchuelo RM,Besle J, Mougin O, Gowland P, Bowtell R, Schluppeck D, Francis S. Regional structural differences across functionally parcellated Brodmann areas of human primary somatosensory cortex. Neuroimage 93: 221-230, 2014. [PubMed: 23558101]

331. Seal J, Commenges D. A quantitative analysis of stimulus- and movement-related responses in the posterior parietal cortex of the mon- key. Exp Brain Res 58: 144-153, 1985. [PubMed: 3987845]

332. Seelke AMH, Padberg J, Disbrow E, Purnell SM, Recanzone G, Krubitzer LA. Topographic maps within Brodmann's area 5 of macaque monkeys. Cereb Cortex 22: 1834-1850, 2012. [PubMed: 21955920]

333. Semmes J, Porter L, Randolph M. Further studies of anterior postcentral lesions in monkeys. Cortex 10: 55-68, 1974. [PubMed: 4455444]

334. Semmes J, Turner B. Effects of cortical lesions on somatosensory tasks. J Invest Dermatol 69: 181-189, 1977. [PubMed: 406334]

335. Sinclair RJ, Burton H. Neuronal activity in the primary somatosensory cortex in monkeys (Macaca mulatta) during active touch of textured surface gratings: Responses to groove width, applied force, and velocity of motion. J Neurophysiol 66: 153-169, 1991. [PubMed: 1919664]

336. Sinclair RJ, Burton H. Neuronal activity in the second somatosensory cortex of monkeys (Macaca mulatta) during active touch of gratings. J Neurophysiol 70: 331-350, 1993. [PubMed: 8360718]

337. Skedung L, Arvidsson M, Chung JY, Stafford CM, Berglund B, Rutland MW. Feeling small: Exploring the tactile perception limits. Sci Rep 3: 2617, 2013. [PubMed: 24030568]

338. Smith MC, Deacon P. Topographical anatomy of the posterior columns of the spinal cord in man. The long ascending fibres. Brain 107 (Pt 3): 671-698, 1984. [PubMed: 6478175]

339. Snyder LH, Batista AP, Andersen RA. Coding of intention in the posterior parietal cortex. Nature 386: 167-170, 1997. [PubMed: 9062187]

340. Snyder LH, Grieve KL, Brotchie P, Andersen RA. Separate body- and world-referenced representations of visual space in parietal cortex. Nature 394: 887-891, 1998. [PubMed: 9732870]

341. Soso MJ, Fetz EE. Responses of identified cells in postcentral cortex of awake monkeys during comparable active and passive joint movements. J Neurophysiol 43: 1090-1110, 1980. [PubMed: 6766995]

342. Squatrito S, Raffi M, Maioli MG, Battaglia-Mayer A. Visual motion responses of neurons in the caudal area pe of macaque monkeys. J Neu- rosci 21: RC130, 2001.

343. Sripati AP, Denchev P, Szczepanski S, Yoshioka T, Johnson KO. Spatiotemporal receptive fields from white noise and complex orthogonal pattern stimulation in SI cortex of the alert monkey. $\mathrm{J}$ Neurosci 26(7): 2101-2114, 2006. [PubMed: 16481443]

344. Steinmetz PN, Roy A, Fitzgerald PJ, Hsiao SS, Johnson KO, Niebur E. Attention modulates synchronized neuronal firing in primate somatosensory cortex. Nature 404: 187-190, 2000. [PubMed: 10724171]

345. Stepniewska I, Preuss TM, Kaas JH. Architectonics, somatotopic organization, and ipsilateral cortical connections of the primary motor area (M1) of owl monkeys. J Comp Neurol 330: 238271, 1993. [PubMed: 7684050]

346. Sur M, Garraghty PE, Bruce CJ. Somatosensory cortex in macaque monkeys: Laminar differences in receptive field size in areas 3b and 1. Brain Res 342: 391-395, 1985. [PubMed: 4041845]

347. Sur M, Merzenich MM, Kaas JH. Magnification, receptive-field area, and "hypercolumn" size in areas 3b and 1 of somatosensory cortex in owl monkeys. J Neurophysiol 44: 295-311, 1980. [PubMed: 7411189]

348. Sur M, Wall JT, Kaas JH. Modular segregation of functional cell classes within the postcentral somatosensory cortex of monkeys. Science 212: 1059-1061, 1981. [PubMed: 7233199] 
349. Sur M, Wall JT, Kaas JH. Modular distribution of neurons with slowly adapting and rapidly adapting responses in area $3 \mathrm{~b}$ of somatosensory cortex in monkeys. J Neurophysiol 51: 724-744, 1984. [PubMed: 6716121]

350. Suresh AK, Winberry J, Versteeg C, Chowdhury RH, Tomlinson T, Rosenow JM, Miller LE, Bensmaia SJ. Methodological considerations for a chronic neural interface with the cuneate nucleus of macaques. J Neurophysiol 118(6): 3271-3281, 2017. [PubMed: 28904101]

351. Suzuki Y, Gyoba J, Sakamoto S. Selective effects of auditory stimuli on tactile roughness perception. Brain Res 1242: 87-94, 2008. [PubMed: 18638461]

352. Tabot GA, Dammann JF, Berg JA, Tenore FV, Boback JL, Vogelstein RJ, Bensmaia SJ. Restoring the sense of touch with a prosthetic hand through a brain interface. Proc Natl Acad Sci U S A 110: 18279-18284, 2013. [PubMed: 24127595]

353. Tabot GA, Kim SS, Winberry JE, Bensmaia SJ. Restoring tactile and proprioceptive sensation through a brain interface. Neurobiol Dis 83: 191-198, 2014. [PubMed: 25201560]

354. Talbot WH, Darian-Smith I, Kornhuber HH, Mountcastle VB. The sense of flutter-vibration: comparison of the human capacity with response patterns of mechanoreceptive afferents from the monkey hand. J Neurophysiol 31: 301-334, 1968. [PubMed: 4972033]

355. Taoka M, Toda T, Hihara S, Tanaka M, Iriki A, Iwamura Y. A systematic analysis of neurons with large somatosensory receptive fields covering multiple body regions in the secondary somatosensory area of macaque monkeys. J Neurophysiol 116: 2152-2162, 2016. [PubMed: 27559139]

356. Taoka M, Toda T, Iriki A, Tanaka M, Iwamura Y. Bilateral receptive field neurons in the hind limb region of the postcentral somatosensory cortex in awake macaque monkeys. Exp Brain Res 134: 139-146, 2000. [PubMed: 11037280]

357. Taoka M, Toda T, Iwamura Y. Representation of the midline trunk, bilateral arms, and shoulders in the monkey postcentral somatosensory cortex. Exp Brain Res 123: 315-322, 1998. [PubMed: 9860270]

358. Taylor MM, Lederman SJ. Tactile roughness of grooved surfaces: A model and the effect of friction. Percept Psychophys 17: 23-36, 1975.

359. Thakur PH, Fitzgerald PJ, Hsiao SS. Second-order receptive fields reveal multidigit interactions in area $3 b$ of the macaque monkey. J Neurophysiol 108: 243-262, 2012. [PubMed: 22457468]

360. Tomlinson T, Miller LE. Toward a proprioceptive neural interface that mimics natural cortical activity. Adv Exp Med Biol 957: 367-388, 2016. [PubMed: 28035576]

361. Tommerdahl M Ipsilateral input modifies the primary somatosensory cortex response to contralateral skin flutter. J Neurosci 26: 5970-5977, 2006. [PubMed: 16738239]

362. Tommerdahl M, Delemos KA, Favorov OV, Metz CB, Vierck CJ, Whitsel BL. Response of anterior parietal cortex to different modes of same-site skin stimulation. J Neurophysiol 80: 3272-3283, 1998. [PubMed: 9862921]

363. Tommerdahl M, Delemos KA, Vierck CJ, Favorov OV, Whitsel BL. Anterior parietal cortical response to tactile and skin-heating stimuli applied to the same skin site. J Neurophysiol 75: 2662-2670, 1996. [PubMed: 8793772]

364. Tommerdahl M, Favorov OV, Whitsel BL. Effects of high-frequency skin stimulation on SI cortex: Mechanisms and functional implications. Somatosens Mot Res 22: 151-169, 2005. [PubMed: 16338824]

365. Tommerdahl M, Favorov O, Whitsel BL, Nakhle B, Gonchar YA. Mini- columnar activation patterns in cat and monkey si cortex. Cereb Cortex 3: 399-411, 1993. [PubMed: 8260808]

366. Tommerdahl M, Whitsel BL, Favorov OV, Metz CB, O'Quinn BL. Responses of contralateral SI and SII in cat to same-site cutaneous flutter versus vibration. J Neurophysiol 82: 1982-1992, 1999. [PubMed: 10515988]

367. Tremblay N, Bushnell MC, Duncan GH. Thalamic VPM nucleus in the behaving monkey. II. Response to air-puff stimulation during discrimination and attention tasks. J Neurophysiol 69: 753-763, 1993. [PubMed: 8385193]

368. Treue S, Maunsell JHR. Attentional modulation of visual motion processing in cortical areas MT and MST. Nature 382: 539-541, 1996. [PubMed: 8700227] 
369. Vallbo AB, Johansson RS. Skin mechanoreceptors in the human hand: Neural and psychophysical thresholds. In Sensory Functions of the Skin in Primates Elsevier, 1976 (pp. 185-199). doi: 10.1016/B978-0-08-021208-1.50021-7.

370. Vallbo AB, Olausson H, Wessberg J. Unmyelinated afferents constitute a second system coding tactile stimuli of the human hairy skin. J Neurophysiol 81: 2753-2763, 1999. [PubMed: 10368395]

371. Vallbo AB, Olausson H, Wessberg J, Kakuda N. Receptive field characteristics of tactile units with myelinated afferents in hairy skin of human subjects. J Physiol 483: 783-795, 1995. [PubMed: 7776258]

372. Vazquez Y, Zainos A, Alvarez M, Salinas E, Romo R. Neural coding and perceptual detection in the primate somatosensory thalamus. Proc Natl Acad Sci 109: 15006-15011, 2012. [PubMed: 22927423]

373. Vega-Bermudez F, Johnson KO. SA1 and RA receptive fields, response variability, and population responses mapped with a probe array. J Neu- rophysiol 81: 2701-2710, 1999.

374. de Vito JL. Corticothalamic connections of suprasylvian cortex in monkey. Exp Neurol 32: 489501, 1971. [PubMed: 4106591]

375. Wang X, Zhang M, Cohen IS, Goldberg ME. The proprioceptive rep- resentation of eye position in monkey primary somatosensory cortex. Nat Neurosci 10: 640-646, 2007. [PubMed: 17396123]

376. Warren S, Hamalainen HA, Gardner EP. Objective classification of motion- and directionsensitive neurons in primary somatosensory cortex of awake monkeys. Journal of Neurophysiol 56: 598-622, 1986.

377. Warren S, Hamalainen HA, Gardner EP. Coding of the spatial period of gratings rolled across the receptive fields of somatosensory cortical neurons in awake monkeys. J Neurophysiol 56: 623639, 1986. [PubMed: 3097272]

378. Weaver ICG, Cervoni N, Champagne FA, D’Alessio AC, Sharma S, Seckl JR, Dymov S, Szyf M, Meaney MJ. Epigenetic programming by maternal behavior. Nat Neurosci 7: 847-854, 2004. [PubMed: 15220929]

379. Weber AI, Saal HP, Lieber JD, Cheng J-WWJW, Manfredi LR, Dammann JF, III, Bensmaia SJ, Dammann JF. Spatial and temporal codes mediate the tactile perception of natural textures. Proc Natl Acad Sci 110: 17107-17112, 2013. [PubMed: 24082087]

380. Weber JT, Yin TC. Subcortical projections of the inferior parietal cortex (area 7) in the stumptailed monkey. J Comp Neurol 224: 206-230, 1984. [PubMed: 19180812]

381. Wheat HE, Salo LM, Goodwin AW. Cutaneous afferents from the monkeys fingers: Responses to tangential and normal forces. J Neurophysiol 103: 950-961, 2010. [PubMed: 19955296]

382. Whitsel BL, Franzen O, Dreyer DA, Hollins M, Young M, Essick GK, Wong C. Dependence of subjective traverse length on velocity of moving tactile stimuli. Somatosens Res 3: 185-196, 1986. [PubMed: 3749661]

383. Whitsel BL, Petrucelli LM, Werner G. Symmetry and connectivity in the map of the body surface in somatosensory area II of primates. J Neurophysiol 32: 170-183, 1969. [PubMed: 4975532]

384. Witham CL, Baker SN. Modulation and transmission of peripheral inputs in monkey cuneate and external cuneate nuclei. J Neurophysiol 106: 2764-2775, 2011. [PubMed: 21865437]

385. Witney AG, Wing AM, Thonnard J-L, Smith AM. The cutaneous contribution to adaptive precision grip. Trends Neurosci 27: 637-643, 2004. [PubMed: 15374677]

386. Woolsey CN, Fairman D. Contralateral, ipsilateral, and bilateral representation of cutaneous receptors in somatic areas I and II of the cerebral cortex of pig, sheep, and other mammals. Surgery 19: 684-702, 1946. [PubMed: 21028543]

387. Xu J, Wall JT. Cutaneous representations of the hand and other body parts in the cuneate nucleus of a primate, and some relationships to previously described cortical representations. Somatosens Mot Res 13: 187-197, 1996. [PubMed: 9110422]

388. Xu J, Wall JT. Functional organization of tactile inputs: From the hand in the cuneate nucleus and its relationship to organization in the somatosensory cortex. J Comp Neurol 411: 369-389, 1999. [PubMed: 10413773] 
389. Yau JM, Connor CE, Hsiao SS. Representation of tactile curvature in macaque somatosensory area 2. J Neurophysiol 109: 2999-3012, 2013. [PubMed: 23536717]

390. Yau JM, Kim SS, Thakur PH, Bensmaia SJ. Feeling form: the neural basis of haptic shape perception. J Neurophysiol 115: 631-642, 2016. [PubMed: 26581869]

391. Yau JM, Pasupathy A, Fitzgerald PJ, Hsiao SS, Connor CE. Analogous intermediate shape coding in vision and touch. Proc Natl Acad Sci U S A 106: 16457-16462, 2009. [PubMed: 19805320]

392. Yeterian EH, Pandya DN. Corticothalamic connections of the posterior parietal cortex in the rhesus monkey. J Comp Neurol 237: 408-426, 1985. [PubMed: 4044894]

393. Yumiya H, Kubota K, Asanuma H. Activities of neurons in area 3a of the cerebral cortex during voluntary movements in the monkey. Brain Res 78: 169-177, 1974. [PubMed: 4211778]

394. Zhang HQ, Zachariah MK, Coleman GT, Rowe MJ. Hierarchical equivalence of somatosensory areas I and II for tactile processing in the cerebral cortex of the marmoset monkey. $\mathrm{J}$ Neurophysiol 85: 1823-35, 2001. [PubMed: 11352999]

395. Zimny ML. Mechanoreceptors in articular tissues. Am J Anat 182: 16-32, 1988. [PubMed: 3291597] 
(A)

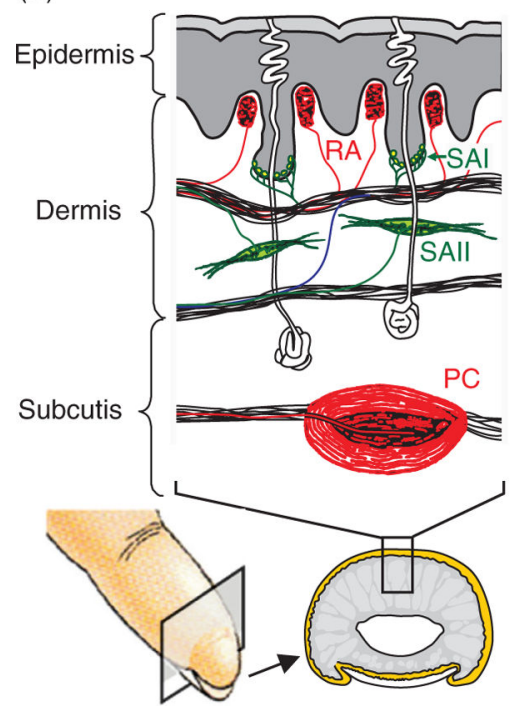

(B)

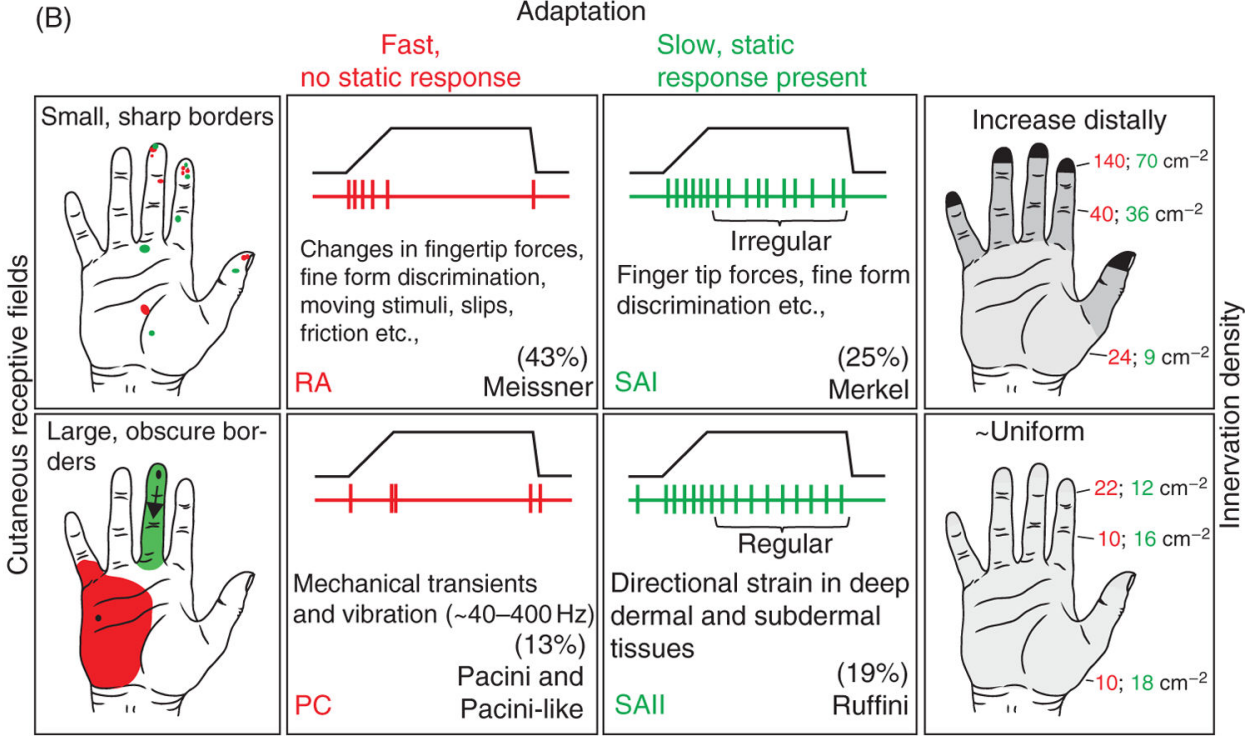

Figure 1.

The four classes of cutanueous afferents of the glabrous skin. (A) Morphology of the different mechanoreceptors and their respective locations in the skin. (B) Adaptation properties and receptive field (RF) size of the four classes of cutaneous afferents. Rapidly adapting (sometimes referred to as fast adapting, particularly for humans) versus slowly adapting refers to responses to indentations (transient vs. sustained, respectively). Type I versus type II refers to the size of the RFs, determined in part by the depth of the mechanoreceptors in the skin: Type I fibers have small RFs whereas type II fibers have large ones. The density of innervation depends on the fiber type: Type I fibers innervate the skin more densely than do type II fibers. For example, rapidly adapting afferent type II (PC) afferents show rapidly adapting responses with large RFs and relatively low innervation density (type II). Adapted, with permission, from (183). 
(A)

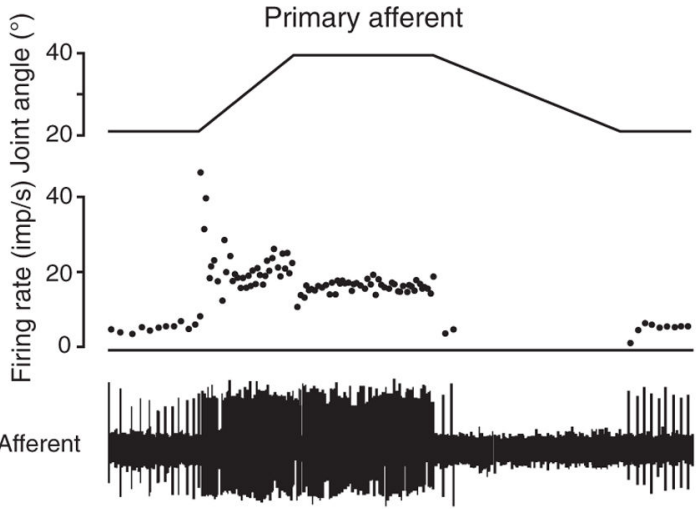

(B)
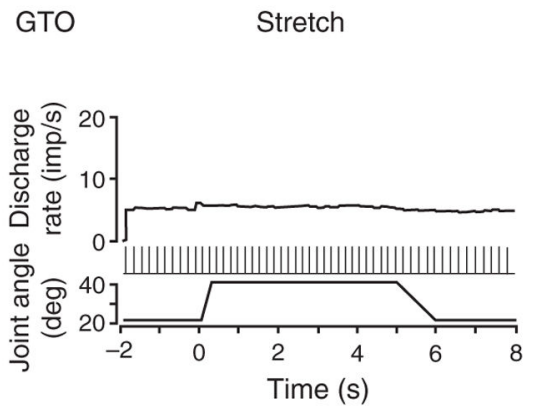

(C)

Joint afferent

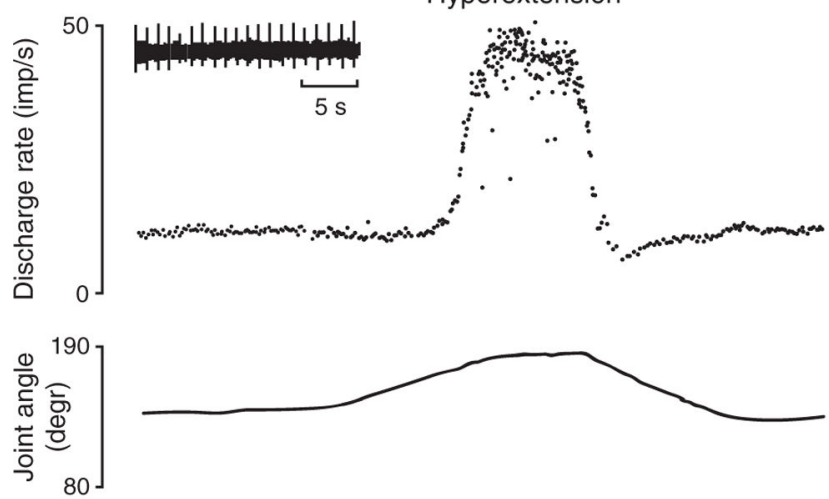

Secondary afferent
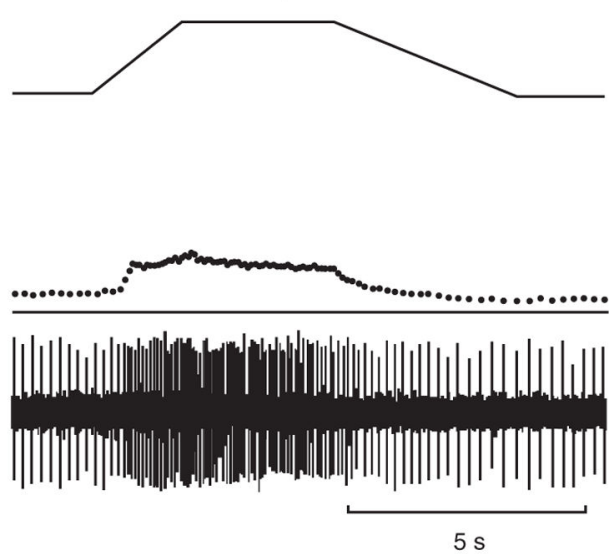

Isometric contraction

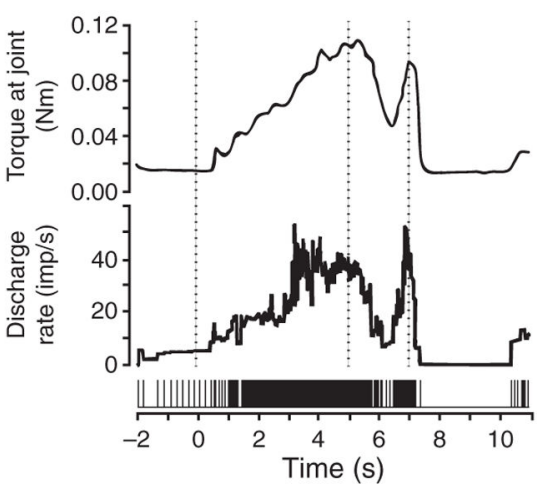

Hyperflexion

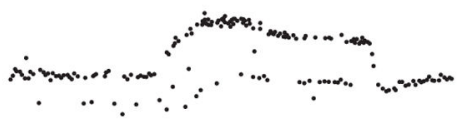

Figure 2.

Typical responses of proprioceptive afferents. (A) Responses of a primary (left) and secondary (right) spindle afferent from the finger extensors muscles to passive ramp and hold stretches applied to the metacarpophalangeal (MCP) joint. Primary afferents tend to be more sensitive to changes in length than secondary ones. Adapted, with permission, from (95). (B) Golgi tendon organ (GTO) do not respond to passive ramp and hold stretches (left) but respond robustly to isometric contraction (right). Adapted, with permission, from (96). (C) Responses of a joint afferent associated with the proximal interphalangeal joint of the 
index finger during passive manipulations. Joint receptors tend to only respond at the extrema of joint movements, perhaps to signal the threat of injury. Adapted, with permission, from (30). 


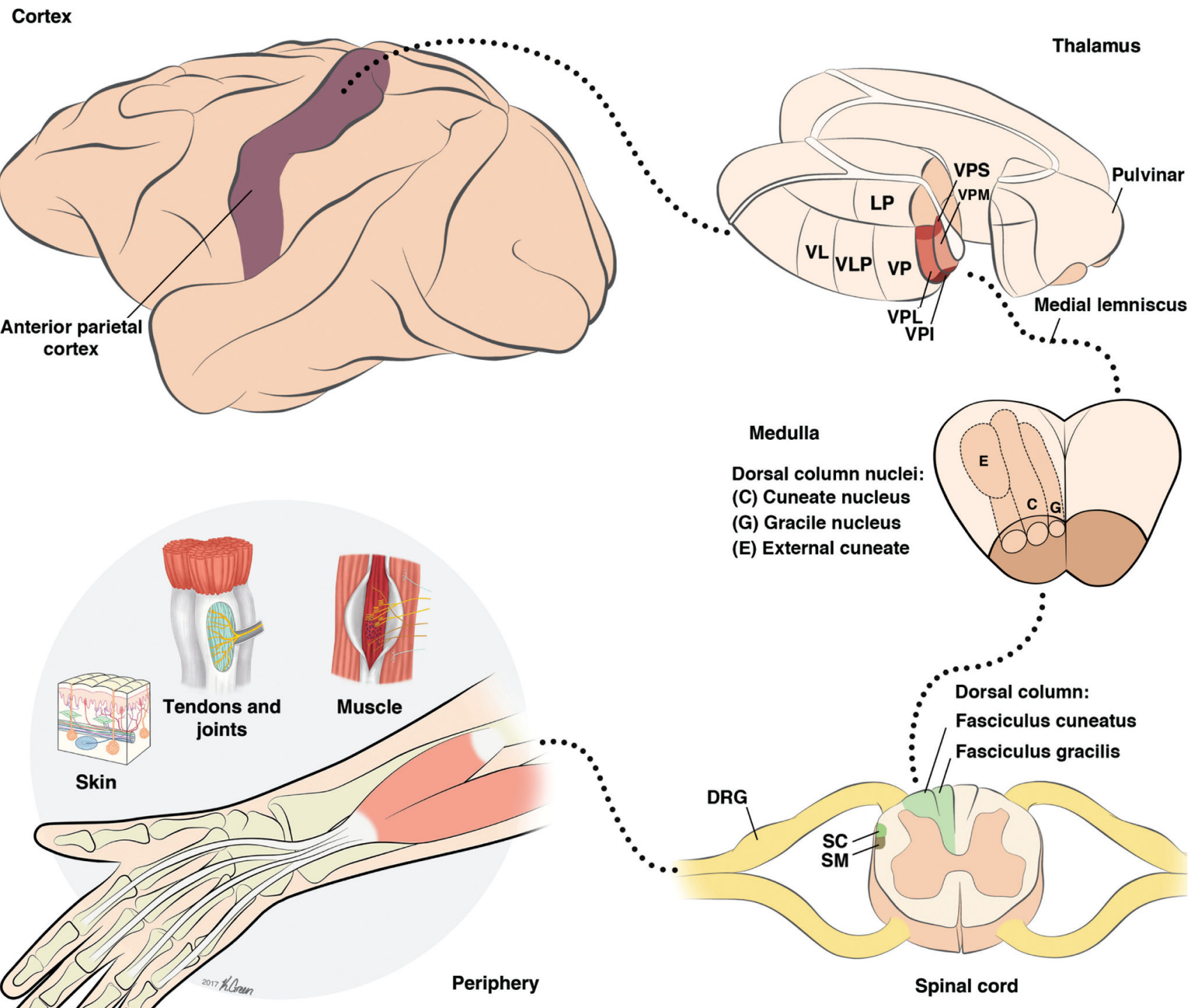

Figure 3.

Pathways from somatosensory periphery to cortex. Afferent fibers at the periphery bundle in fascicles that join to form the nerves. Afferent cell bodies are gathered in the dorsal root ganglia (DRG). When entering the spinal cord through the dorsal root, afferent axons branch, sending one projection to the dorsal horn and one projection to the dorsal column nuclei (DCN) through the dorsal column. The DCN projects contralaterally through the medial lemniscus to the ventroposterior complex of the thalamus, which in turns relays the information to cortex. Abbreviations: Dorsal root ganglion (DRG); spinomedullothalamic (SM), and spinocervicothalamic (SC) tracts. Thalamus: ventral posterior (VP), posterolateral (VPL), posteromedial (VPM), posterior inferior (VPI) and posterior superior (VPS) nuclei, posterior division (VLp) of the ventral lateral nucleus (VL), lateral posterior nucleus (LP). 


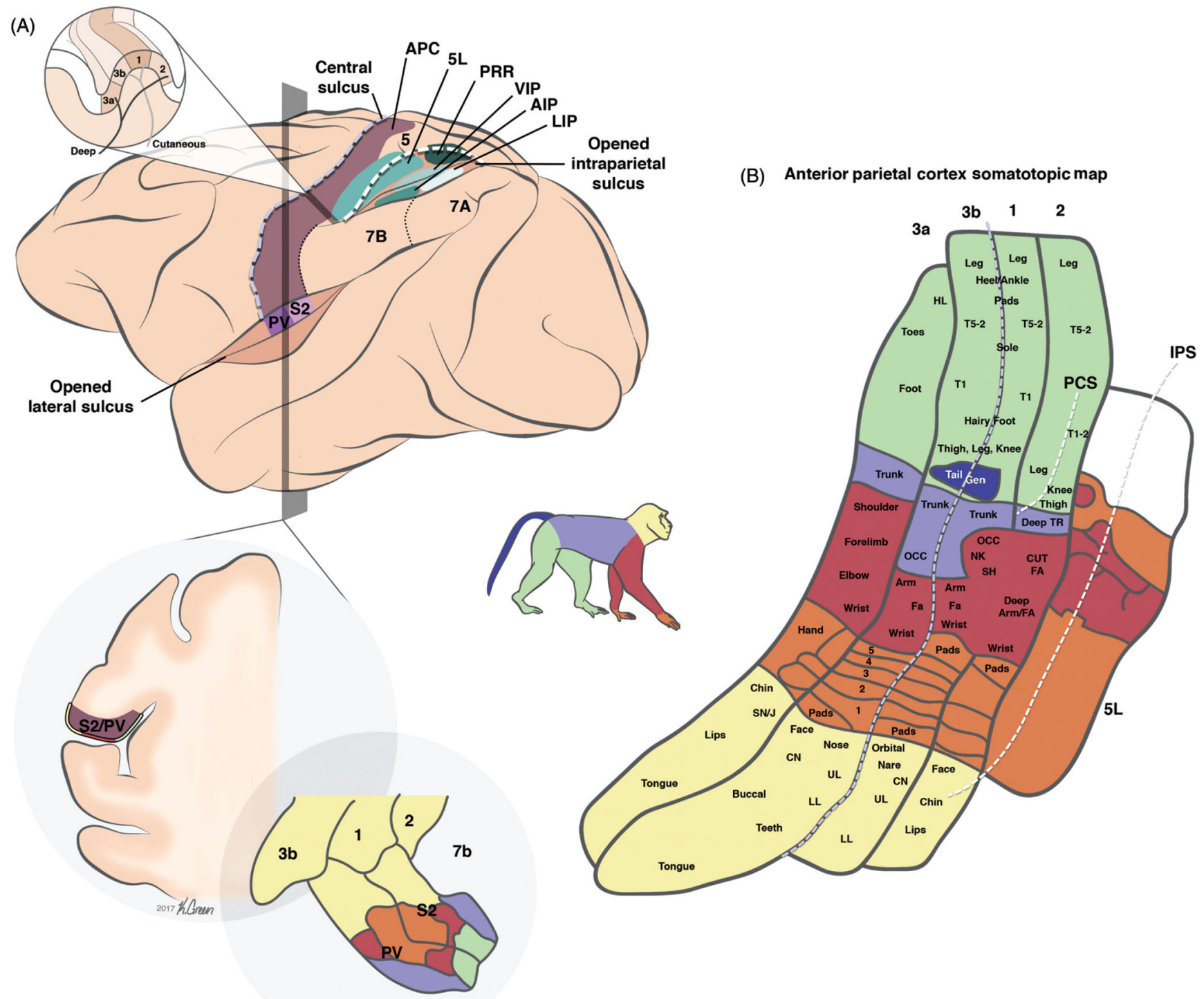

(c) Lateral parietal cortex

Figure 4.

Organization of somatosensory cortical areas. (A) A lateral view of the brain showing the different somatosensory areas in macaque monkey cortex. Adapted, with permission, from (198). Inset: Horizontal section of the postcentral gyrus at the level of the hand representation, showing the position of the different APC modules relative to the central and the intraparietal sulci. (B) Detailed view of the somatotopic representation of the body in the four fields of APC (areas 3a, 3b, 1, and 2) and in area 5L. Adapted, with permission, from (261, 332). (C) Coronal section showing the location of LPC in the lateral sulcus. Adapted, with permission, from (214). Abbreviations: Anterior parietal cortex (APC); second somatosensory area (S2); parietal ventral area (PV); parietal reaching region (PRR); anterior (AIP), ventral (VIP) and lateral (LIP) intraparietal areas; post central sulcus (PCS); intraparietal sulcus (IPS). Somatotopic map: Upper lip (UL); lower lip (LL); chin (CN); 
snout/jaw (SN/J); digits of the hand (1-5); (cutaneous) forearm ((CUT) FA); occiput (OCC); trunk (TR); toes (T1-5); hindlimb (HL). 


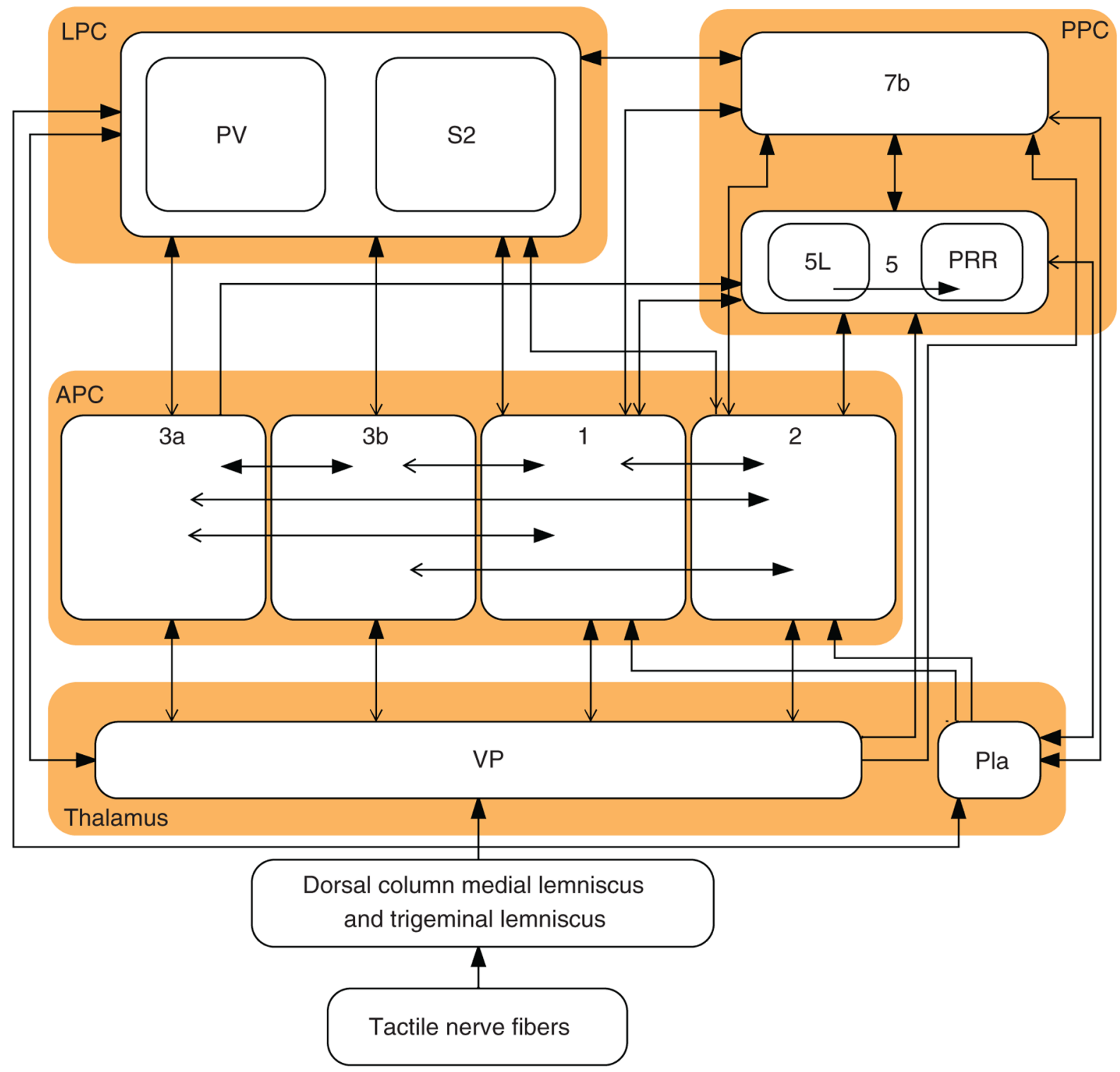

Figure 5.

Major connections between somatosensory areas. Schematic representation of the major connections between somatosensory areas in the central nervous system, split into four major regions: the thalamus, the anterior parietal cortex (APC), the lateral parietal cortex (LPC), and the posterior parietal cortex (PPC). Abbreviations: Ventral posterior nucleus (VP), anterior pulvinar nucleus (Pla), secondary somatoensory cortex (S2), parietal ventral area (PV), parietal reach region (PRR). Area 5 also receive input from the lateral posterior nucleus in thalamus (LP, not shown in the chart). 
(A)

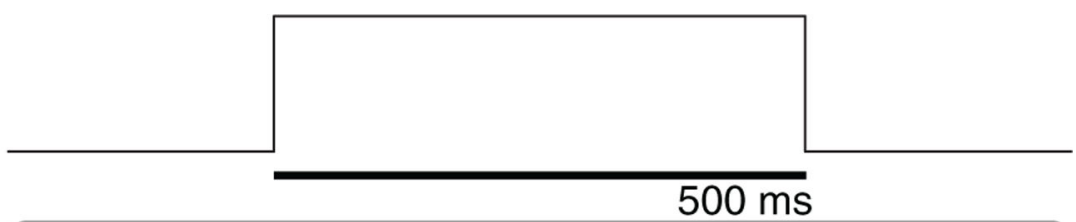

(B)

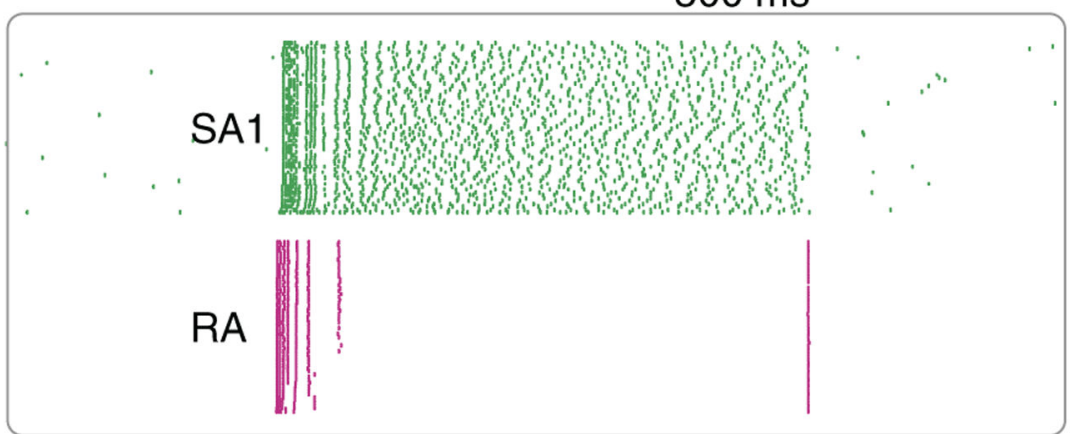

(C)
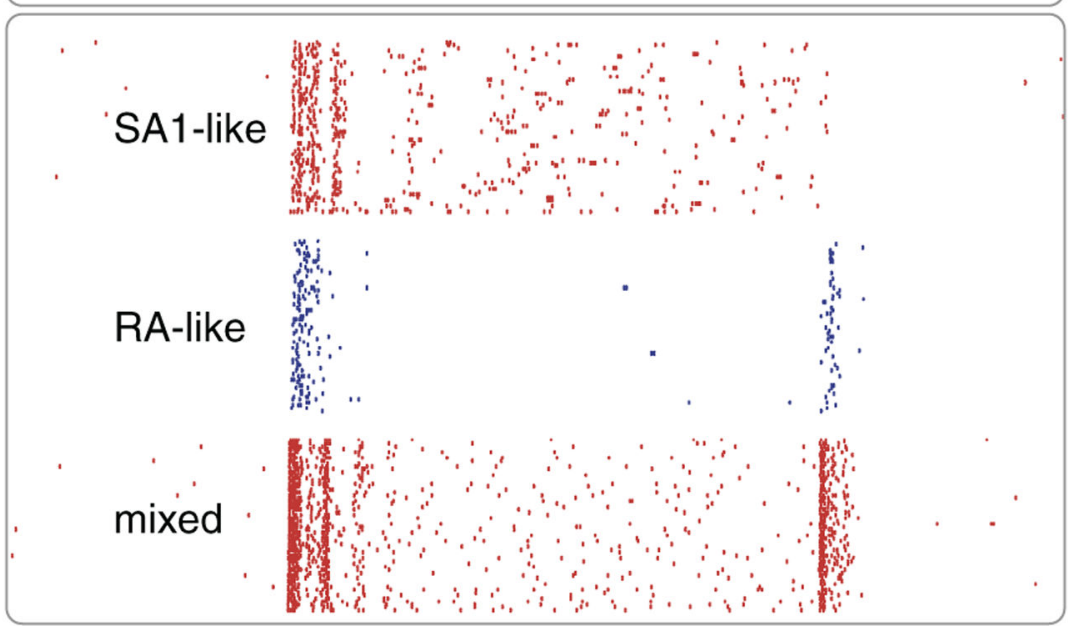

Figure 6.

Submodality convergence in APC. (A) Trajectory of a punctate stimulus indented $2 \mathrm{~mm}$ into the center of a neuron's receptive field. (B) Typical response of a slowly adapting type 1 (SA1) and rapidly adapting (RA) afferent to 60 repeated presentations of the stimulus. (C) Response of typical neurons in area $3 \mathrm{~b}$. Some neurons respond throughout the stimulation interval and do not show phasic off responses, similar to SA1 fibers; others respond with phasic on-off responses, similar to RA1 fibers, but the majority respond with a mixture of sustained and phasic responses, implying input from both fiber types. Adapted, with permission, from (274). 


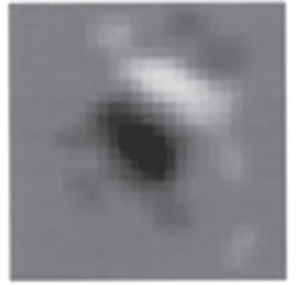

RF

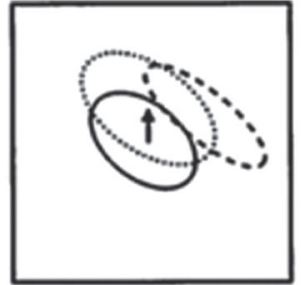

Predicted RF

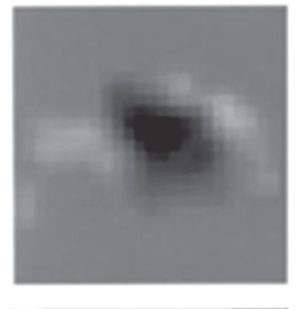

$10 \mathrm{~mm}$
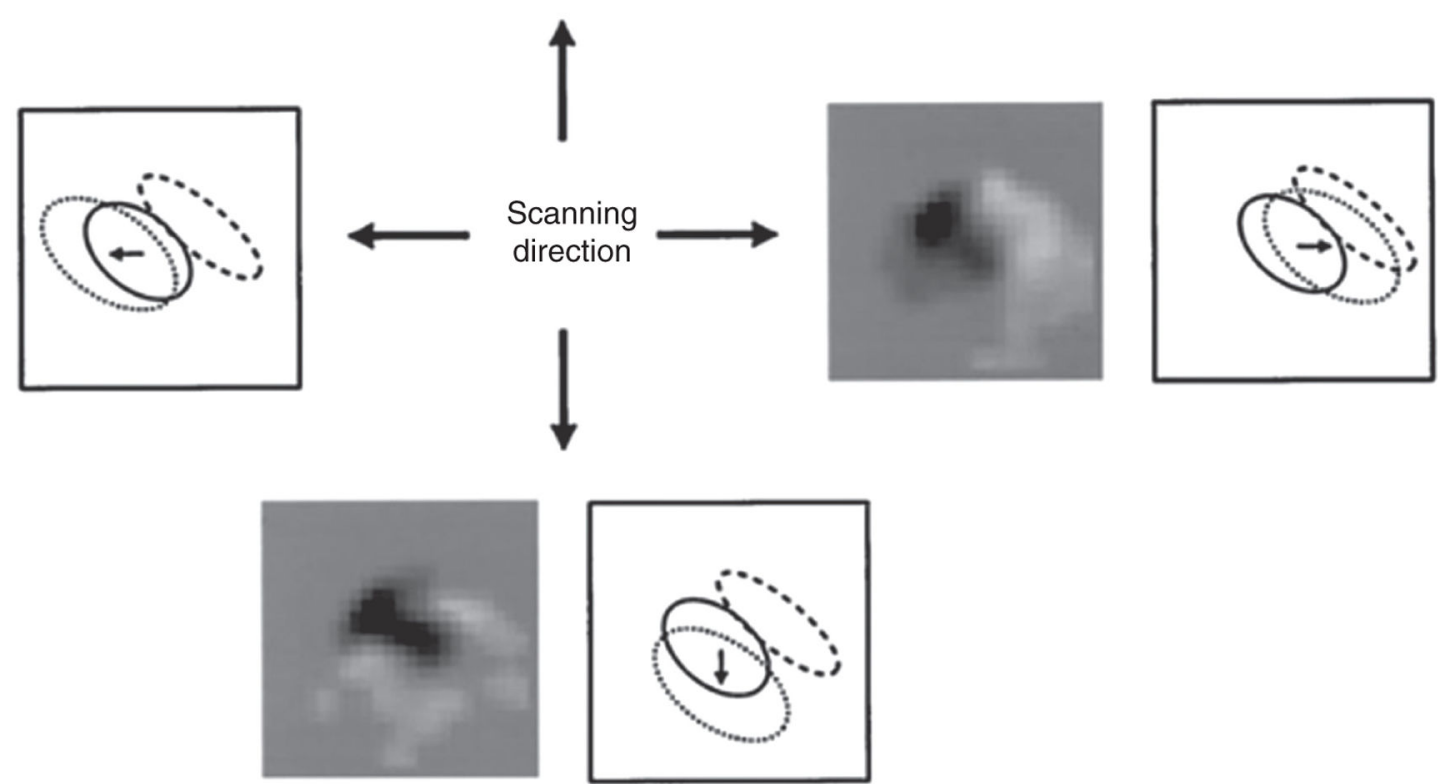

Figure 7.

Spatial structure of receptive fields of a neuron in area $3 \mathrm{~b}$. The two squares in each group display the RF estimated from the raw data (left) and the positions of the modeled Gaussian representations (right). Left: The experimental RF was obtained by continuously scanning the finger with a random pattern of raised dots, and then computing an RF map using reverse correlation (see (82)). Dark regions are excitatory, white regions are inhibitory. Right: The locations of the excitatory (solid ellipse) and fixed inhibitory components are unaffected by scanning direction and the lagged inhibitory component (dotted ellipse) trails the center by a fixed distance in each direction. Reproduced, with permission, from (81). 
(A)
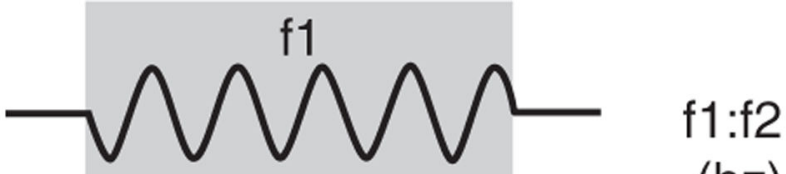

(hz)

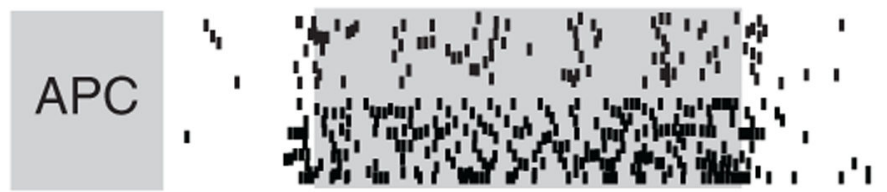

10:18

$26: 18$

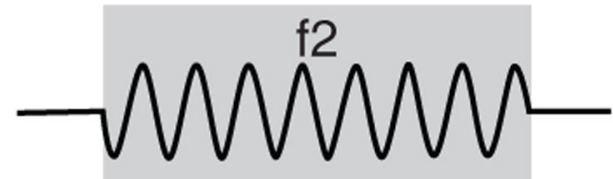

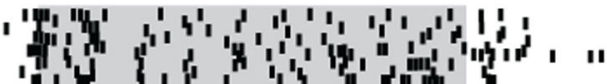

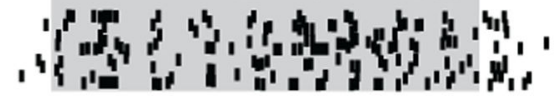

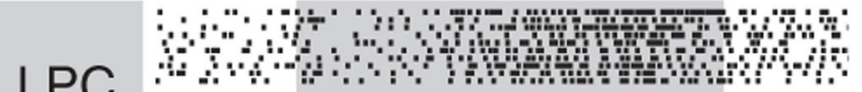

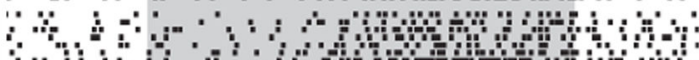

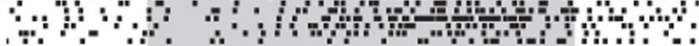

$10: 18$

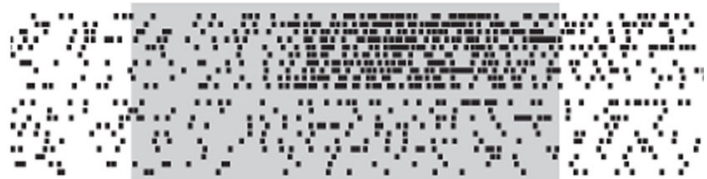

(B)
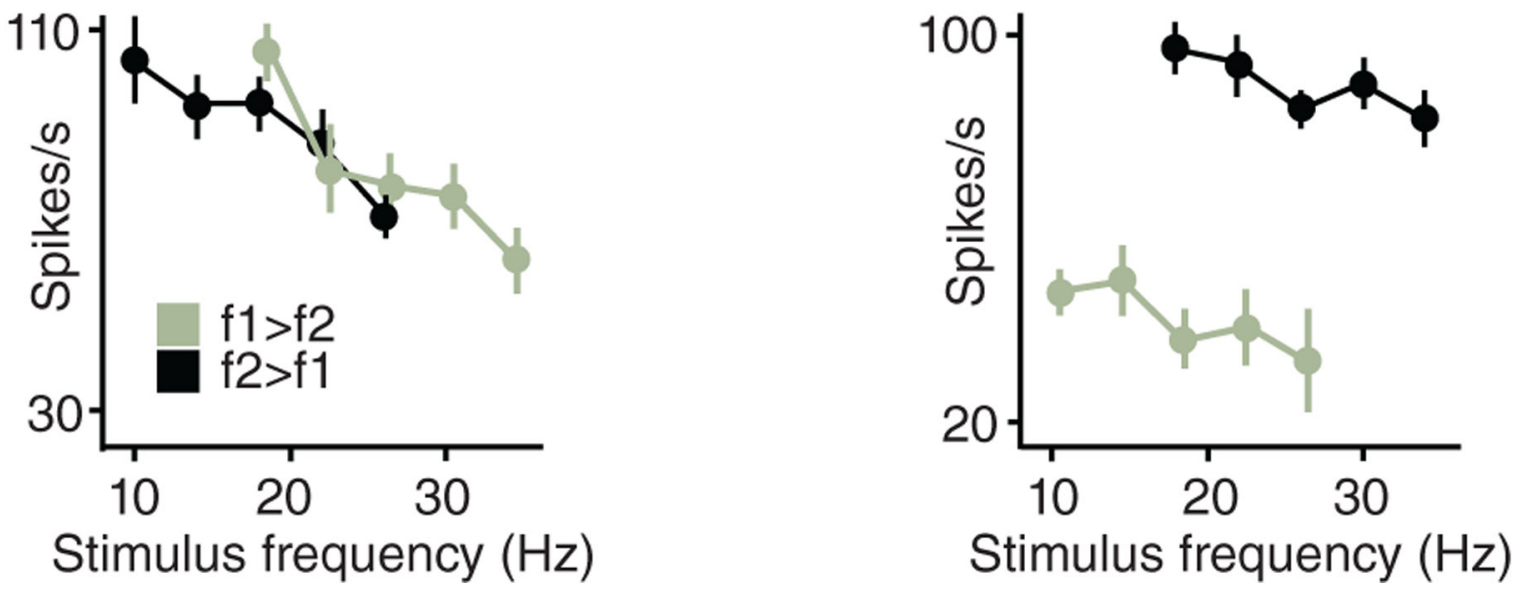

Figure 8.

In contrast to their counterparts in primary somatosensory cortex, neurons in secondary somatosensory cortex exhibit task- dependent modulation in their responses to identical vibratory stimuli. (A) Spiking responses recorded from one neuron in APC and one in LPC (adapted, with permission, from (152) and from (311), respectively). Each row shows the response to a pair of stimuli: 10 or $26 \mathrm{~Hz}$ in the first stimulus period $(f 1)$ and $18 \mathrm{~Hz}$ in the second ( $f 2)$. In APC, the response to $f 2$ is independent of $f 1$, while in LPC, the response to $f 2$ is greater when $f 2>f 1$. (B) LPC firing rates as a function of the frequency of vibration in the tactile stimulus. During the first stimulation period $(f 1)$, rates decrease monotonically as stimulus frequency increases. During the comparison period $(f 2)$, neurons respond preferentially when $f 2>f 1$ (shown here) or vice versa (black points show trials on which $f 2$ $>f 1$; green traces denote trials on which $f 2<f 1$ ). 


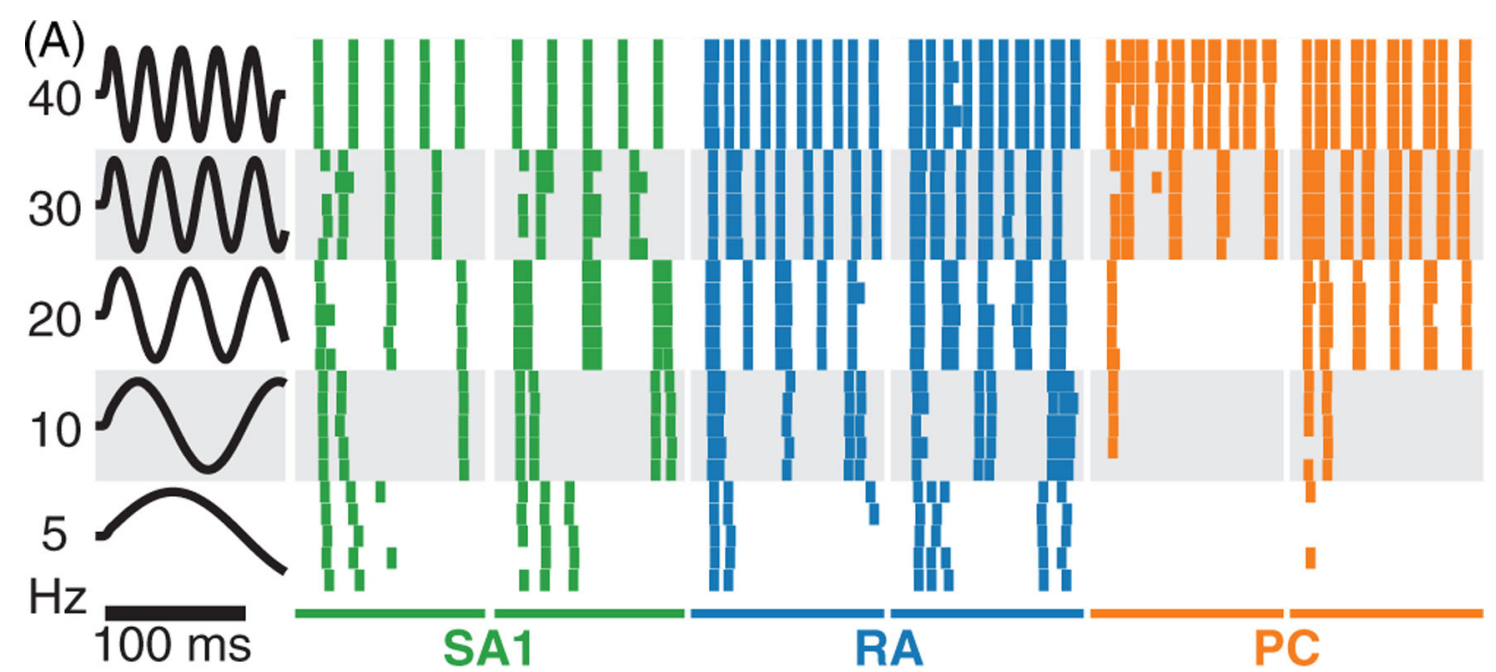

(B)

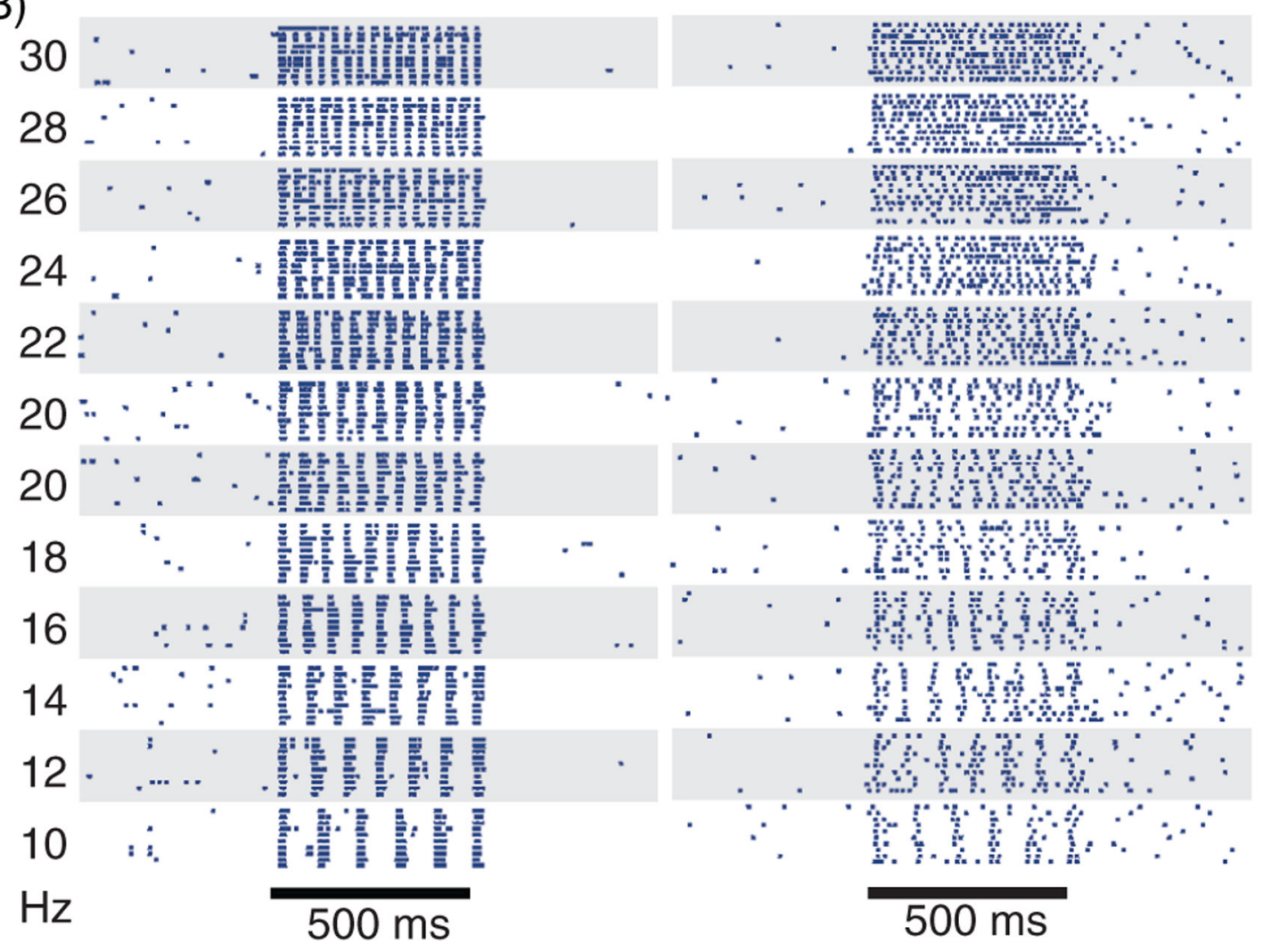

Figure 9.

Temporal patterning in peripheral and cortical responses to sinusoidal vibrations applied to the skin. (A) Typical response of peripheral afferents (two SAI in green, two RA in blue, and two PC in orange) to sinusoidal vibrations (amplitude $=250$ microns) of different frequencies applied in the center of their RF. The responses of tactile fibers are strongly phase-locked to the stimulus and highly repeatable. Data adapted, with permission, from (252). (B) Responses of two typical APC neurons to sinusoidal vibrations. APC neurons show various degrees of phase-locking and greater trial-to-trial variability. Within this low- 
frequency range, the frequency of the stimulus can be extracted from both the temporal patterning of the response and the mean firing rate. Reproduced, with permission, from (152, $314)$. 
(A)
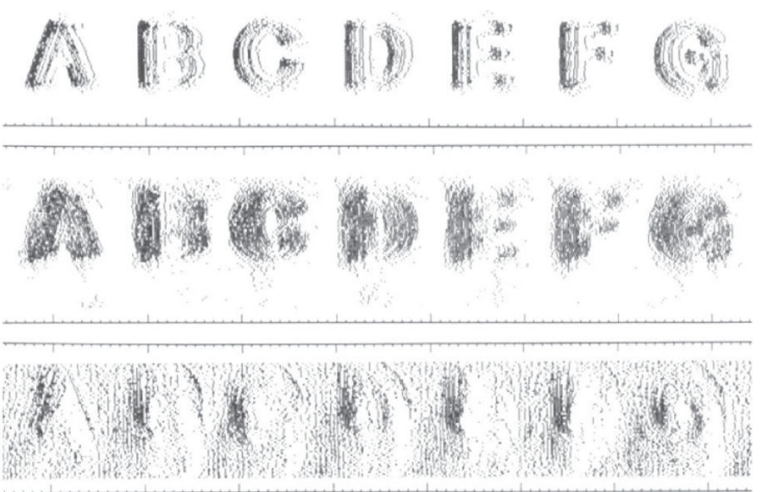

(C)

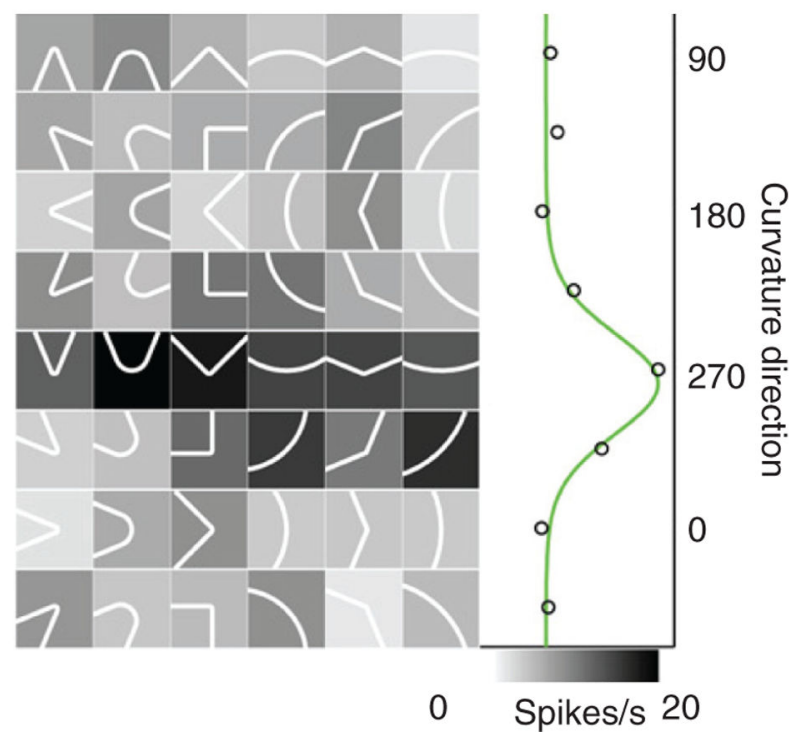

(B)

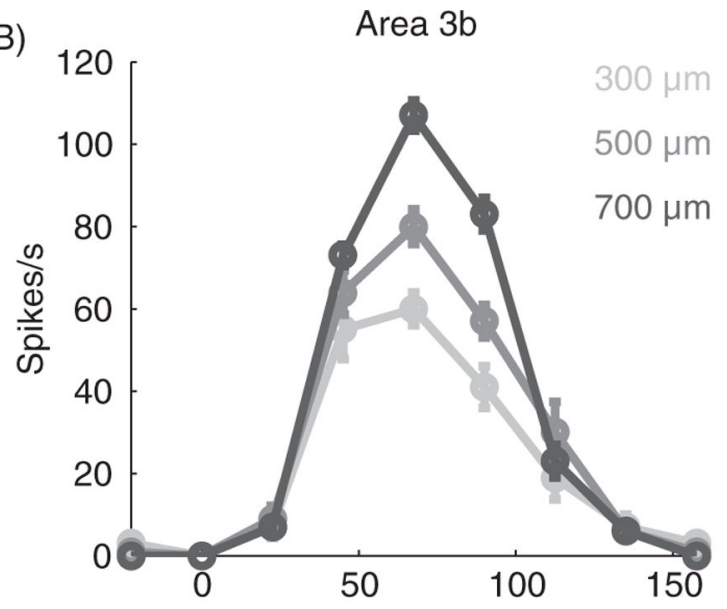

(D)

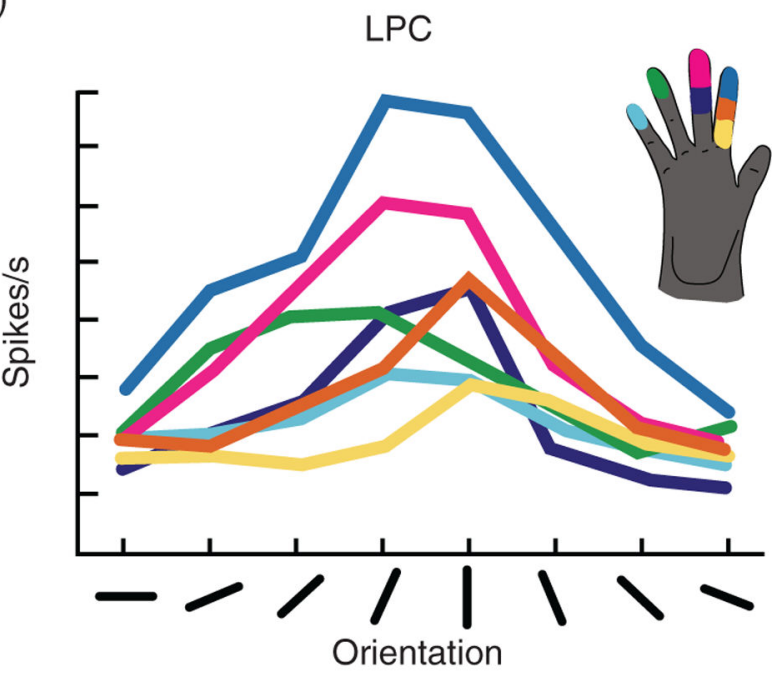

Figure 10.

Spatial processing in the somatosensory system. (A) Reconstructed response of tactile nerve fibers to embossed letters scanned across the skin. As in the retina, the spatial configuration of the stimulus is reflected in the spatial pattern of activation it evokes in SA1 and RA populations. Reproduced, with permission, from (282). (A) Responses of a neuron in area $3 \mathrm{~b}$ to oriented edges indented into the skin (eight orientations, three indentation depths). This neuron is strongly tuned for edge orientation, as are neurons in primary visual cortex.

Reproduced, with permission, from (11). (C) Responses of an LPC neuron to curvatures indented into the skin. This neuron prefers intermediate curvatures with the convex end pointing proximally. This type of feature selectivity is not observed in early stages of cortical processing (e.g., in area 3b). Reproduced, with permission, from (391). (D) Responses of an LPC neuron to bars indented into the skin. This neuron exhibits the similar preferred orientation over large swaths of skin (position-invariant orientation tuning). Reproduced, with permission, from (107). 

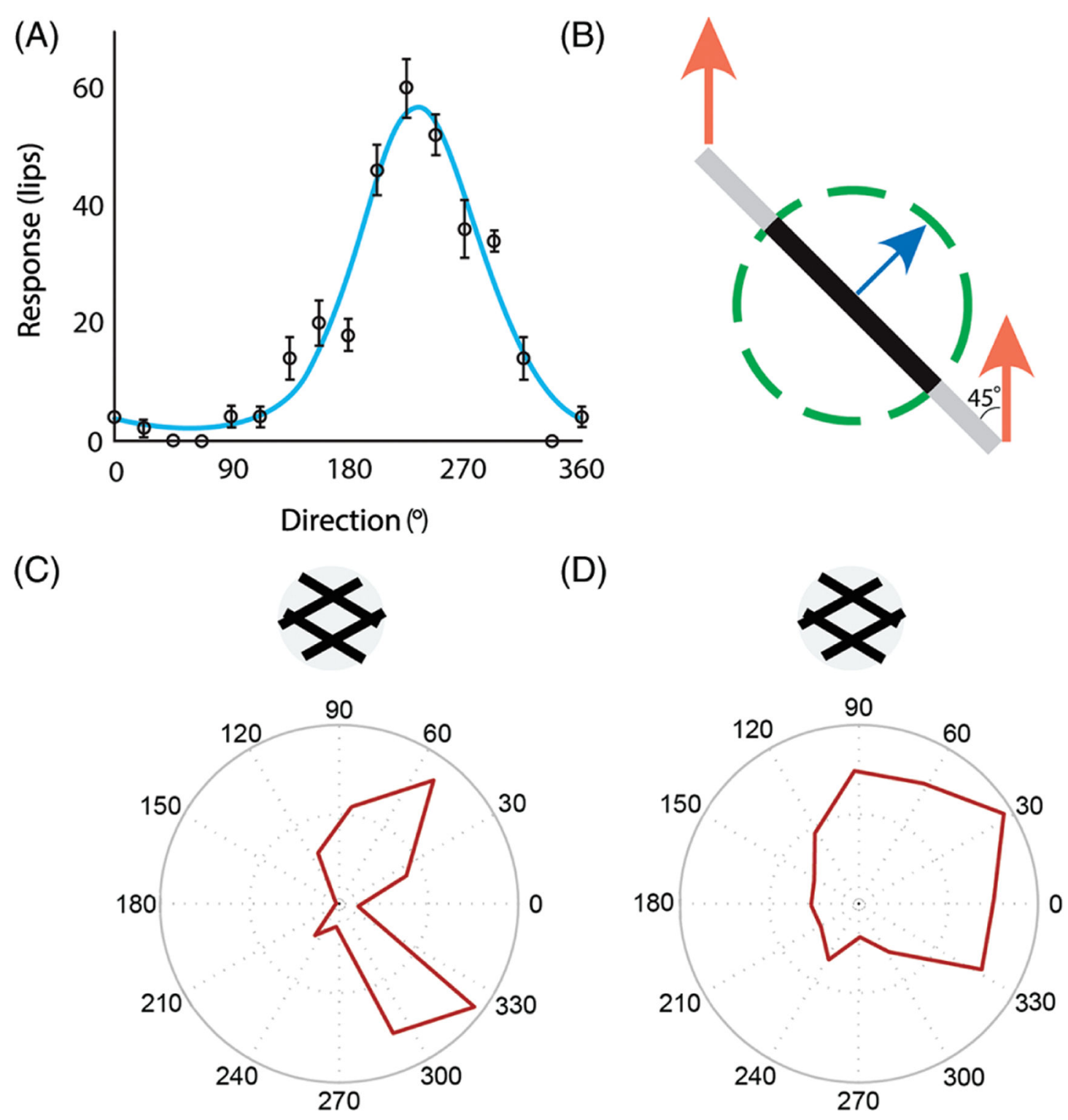

Figure 11.

Motion coding in APC. (A) Direction tuning of a neuron in area $3 \mathrm{~b}$ to bars scanned across its receptive field. Adapted, with permission, from (276). (B) The geometry of the aperture problem. The orange arrows show the actual motion of the bar; the blue arrow shows the motion of the bar as observed through the circular aperture (dashed circle). When an edge is observed through a circular aperture, the only available information about its direction of motion is along the axis perpendicular to its orientation. In other words, no time-varying information is conveyed along the parallel axis. In the example, a bar oriented at 450 and moving upward at speed s seems to be moving up and to the right with speed $s=\sin (45 \circ)$. Neurons in early stages of processing (APC or V1) experience the portion of a stimulus that impinges upon their small RFs, so through the equivalent of an aperture. (A) Response of a neuron in area 1 that responds to the motion of the component gratings but not to the global motion of the plaid. This neuron will respond if either of the component gratings is moving 
in its preferred direction. (D) Response of a neuron in area 1 that responds to the global motion of the plaid. This neuron's response reflects the integration of local motion cues, each subject to the aperture problem, except those emanating from intersections, which convey unambiguous information about motion direction. Reproduced, with permission, from (277). 
Without cutaneous input

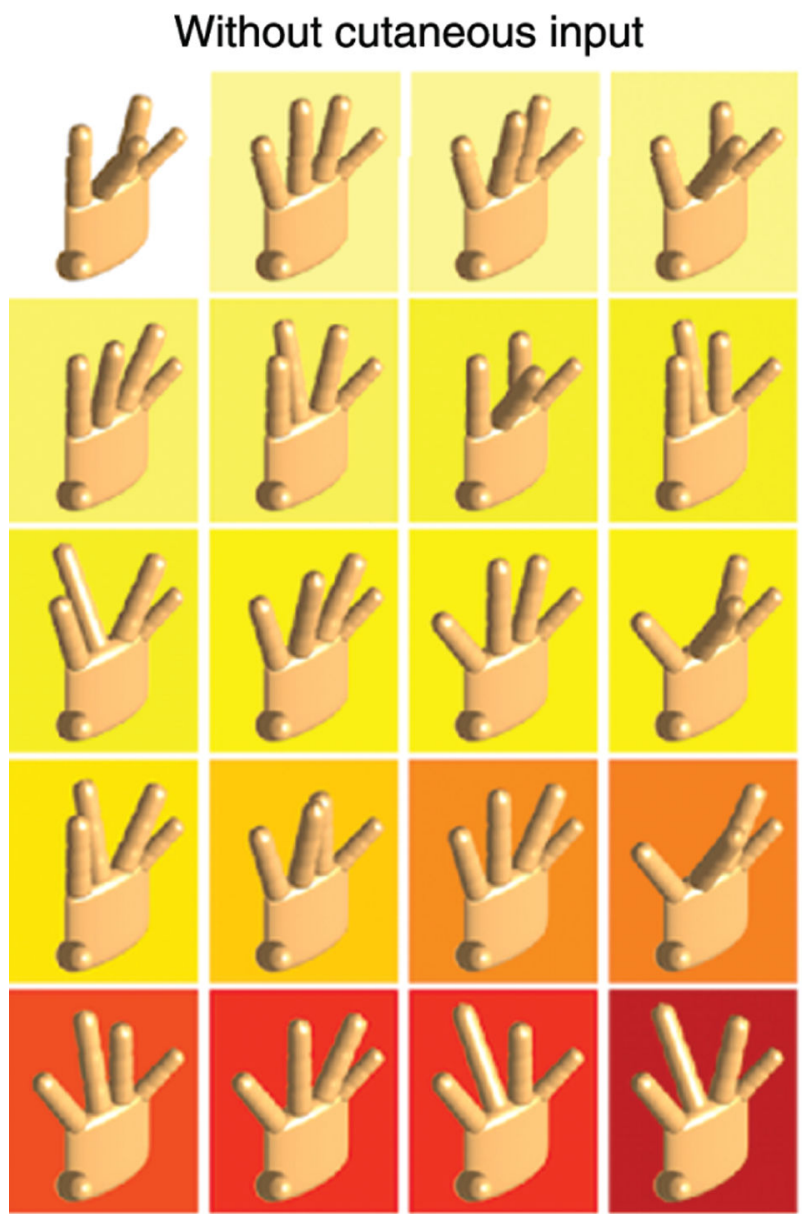

Figure 12. input.

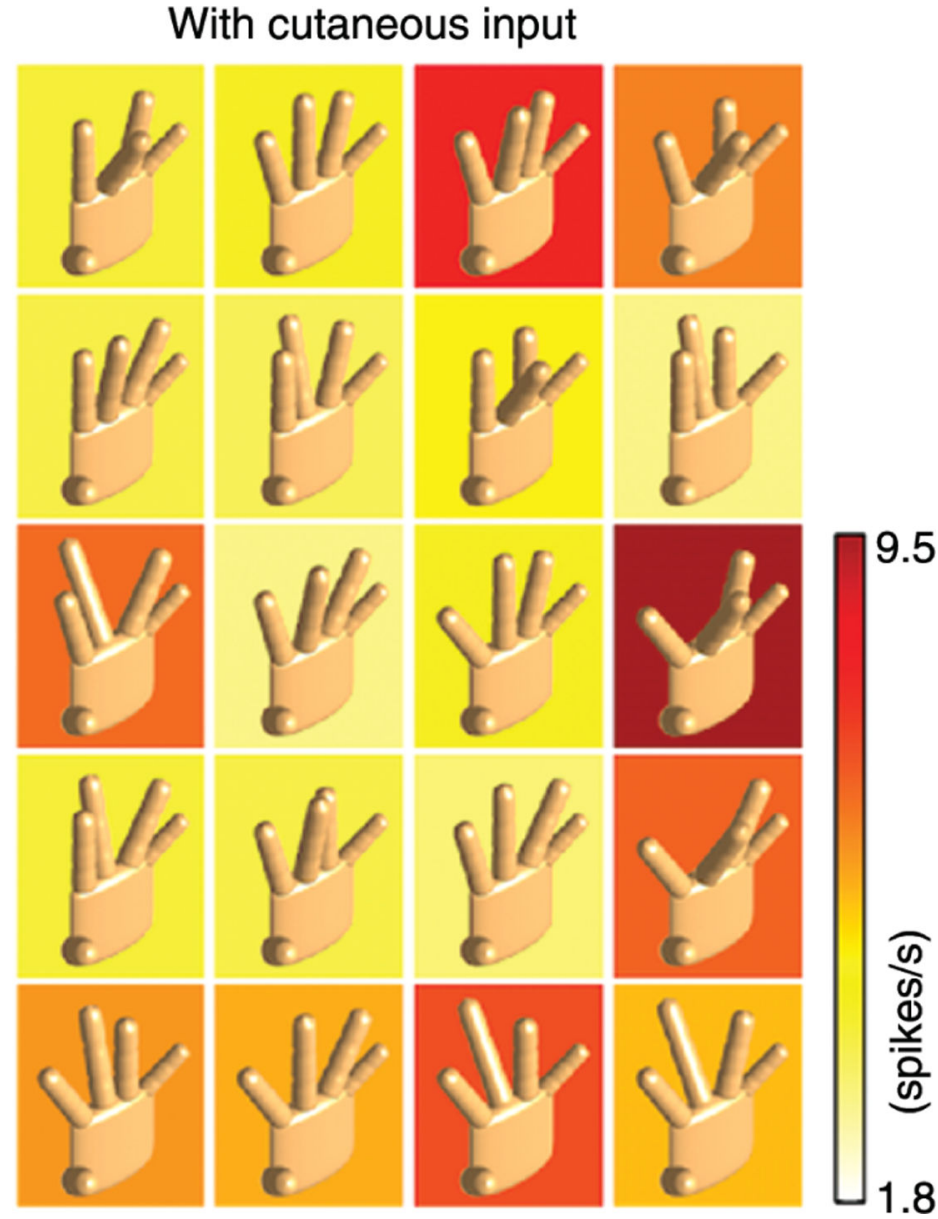

Neuron in area 2 that exhibits both tactile and proprioceptive responses (courtesy of Sung Soo Kim, see (206)). This neuron's activity is modulated when the hand is placed in different configurations using a motorized apparatus (left panel). However, responses are further modulated by cutaneous stimulation, consisting of edges indented into the skin (right panel). The neuron's response is a complex function of hand conformation and cutaneous 